\title{
Pacific Northwest
}

\section{Fuel Fabrication Capability Research and Development Plan}

\section{Global Threat Reduction Initiative - Convert Program}

\section{June 2013}
DJ Senor
D Burkes 


\title{
DISCLAIMER
}

This report was prepared as an account of work sponsored by an agency of the United States Government. Neither the United States Government nor any agency thereof, nor Battelle Memorial Institute, nor any of their employees, makes any warranty, express or implied, or assumes any legal liability or responsibility for the accuracy, completeness, or usefulness of any information, apparatus, product, or process disclosed, or represents that its use would not inf ringe privately owned rights. Reference herein to any specific commercial product, process, or service by trade name, trademark, manufacturer, or otherwise does not necessarily constitute or imply its endorsement, recommendation, or favoring by the United States Government or any agency thereof, or Battelle Memorial Institute. The views and opinions of authors expressed herein do not necessarily state or reflect those of the United States Government or any agency thereof.

\author{
PACIFIC NORTHWEST NATIONAL LABORATORY \\ operated by \\ BATTELLE \\ for the \\ UNITED STATES DEPARTMENT OF ENERGY \\ under Contract DE-AC05-76RL01830
}

Printed in the United States of America
Available to DOE and DOE contractors from the
Office of Scientific and Technical Information
P.O. Box 62, Oak Ridge, TN 37831-0062;
ph: (865) 576-8401
fax: $(865) 576-5728$
email: reports@adonis.osti.gov

Available to the public from the National Technical Information Service

5301 Shawnee Rd., Alexandria, VA 22312

ph: (800) 553-NTIS (6847)

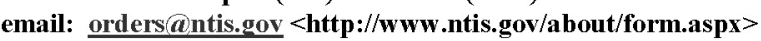

Online ordering: http://www.ntis.gov

This document was printed on recycled paper. 


\section{Fuel Fabrication Capability Research and Development Plan}
DJ Senor
D Burkes

June 2013

Prepared for

the U.S. Department of Energy

under Contract DE-AC05-76RL01830

Pacific Northwest National Laboratory

Richland, Washington 99352 



\section{Summary}

The purpose of this document is to provide a comprehensive review of the mission of the Fuel Fabrication Capability (FFC) within the Global Threat Reduction Initiative Convert Program, along with research and development $(\mathrm{R} \& \mathrm{D})$ needs that have been identified as necessary to ensuring mission success. The design and fabrication of successful nuclear fuels must be closely linked endeavors. Therefore, the overriding motivation behind the FFC R\&D program described in this plan is to foster closer integration between fuel design and fabrication to reduce programmatic risk by ensuring the following:

- The manufacturing process consistently produces fuel with acceptable quality (i.e., meets or exceeds design requirements)

- The sensitivity of material properties and characteristics to manufacturing process parameters is clearly understood so adequate process specifications can be defined

- Fuel product specifications are realistic and achievable using the selected manufacturing methods

- A better linkage between the effect of process parameters on fuel performance, to ensure that changes or variability in manufacturing does not have an adverse effect on irradiation behavior

These motivating factors are all interrelated, and progress addressing one will aid understanding of the others. The FFC R\&D needs fall into two principle categories, 1) baseline process optimization, to refine the existing fabrication technologies, and 2) manufacturing process alternatives, to evaluate new fabrication technologies that could provide improvements in quality, repeatability, or cost. The FFC R\&D Plan examines efforts currently under way in regard to coupon, foil, plate, and fuel element manufacturing, and provides recommendations for a number of R\&D topics that are of high priority but not currently funded (i.e., knowledge gaps). The plan ties all FFC R\&D efforts into a unified vision that supports the overall Convert Program schedule in general, and the fabrication schedule leading up to the MP-1, MP-2, and FSP-1 irradiation experiments specifically.

The FFC R\&D Plan describes the downselection methodology for optimizing the baseline fabrication process as well as considering alternative manufacturing technologies. The criteria for downselection include the following considerations:

- Technical Merit - Does the process produce parts that meet product specification requirements?

- Reproducibility - Does the process consistently produce high-quality parts?

- Economics - Does the process offer life-cycle (not just capital) cost savings over the baseline process, including considerations of efficient use of uranium feedstock and scrap recycle??

- Scaling - Does the process scale to full prototypic part dimensions?

- Throughput - Does the process lend itself to high-volume throughput without sacrificing its advantages?

- Quality Assurance - Does the process lend itself to implementation in an NQA-1 manufacturing environment? 
- Environment, Safety, and Health - Can the process be implemented effectively in a uranium production facility regulated by the U.S. Department of Energy and/or the Nuclear Regulatory Commission?

- Schedule - Can the process be developed and implemented in time to meet the Convert Program schedule for fuel down-selection?

The fabrication technology decision gates and downselection logic and schedules are tied to the schedule for fabricating the MP-1 fuel plates, which will provide the necessary data to make a final fuel fabrication process downselection. Because of the short turnaround between MP-1 and the follow-on MP-2 and FSP-1 experiments, the suite of specimen types that will be available for MP-1 will be the same as those available for MP-2 and FSP-1. Therefore, the only opportunity to explore parameter space and alternative processing is between now and 2016 when the candidate processes are down-selected in preparation for the MP-1, MP-2, and FSP-1 plate manufacturing campaigns. A number of key risks identified by the FFC are discussed in this plan, with recommended mitigating actions for those activities within FFC, and identification of risks that are impacted by activities in other areas of the Convert Program.

The intent is for this R\&D Plan to be a living document that will be reviewed and updated on a regular basis (e.g., annually) to ensure that FFC R\&D activities remain properly aligned to the needs of the Convert Program. The R\&D Plan does not include discussion of FFC initiatives related to production-scale manufacturing of fuel (e.g., establishment of the Pilot Line Production Facility), rather, the goal of this plan is to document the research and development activities needed ultimately to enable high-quality and cost-effective production of the fuel by the commercial fuel fabricator. 


\section{Acronyms and Abbreviations}

\begin{tabular}{|c|c|}
\hline ATR & Advanced Test Reactor \\
\hline ATR-C & ATR critical assembly \\
\hline $\mathrm{B} \& \mathrm{~W}$ & Babcock \& Wilcox \\
\hline DOE & U.S. Department of Energy \\
\hline DU & depleted uranium \\
\hline DU-Mo & depleted uranium-molybdenum \\
\hline EBSD & electron backscatter diffraction \\
\hline EDS & energy dispersive spectroscopy \\
\hline EPJ & electromagnetic pulse joining \\
\hline ESD & electro-spark deposition \\
\hline EU & enriched uranium \\
\hline FD & fuel development \\
\hline FFC & fuel fabrication capability \\
\hline FLA-ICP-MS & femtosecond laser ablation inductively-coupled plasma mass spectrometry \\
\hline FY & fiscal year \\
\hline GTRI & Global Threat Reduction Initiative \\
\hline HEU & highly enriched uranium \\
\hline HFIR & High Flux Isotope Reactor \\
\hline HIP & hot isostatic press \\
\hline HPRR & high performance research reactor \\
\hline ICP-MS & inductively-coupled plasma mass spectrometry \\
\hline ICP-OES & inductively-coupled plasma optical emission spectrometry \\
\hline INL & Idaho National Laboratory \\
\hline LEU & low enriched uranium \\
\hline LEU-Mo & low enriched uranium-molybdenum \\
\hline MAQP & Manufacturing and Quality Plan \\
\hline MITR & Massachusetts Institute of Technology Reactor \\
\hline Mo & molybdenum \\
\hline MURR & Missouri University Research Reactor \\
\hline NNSA & National Nuclear Security Administration \\
\hline PM & powder metallurgy \\
\hline PNNL & Pacific Northwest National Laboratory \\
\hline PVD & physical vapor deposition \\
\hline QA & quality assurance \\
\hline QRL & quality rigor level \\
\hline$R \& D$ & research and development \\
\hline
\end{tabular}


$\mathrm{RC}$

RERTR

SEM

U-Mo

$\mathrm{UMoF}$

UPF

UT

VAR

VIM

WBS

XRF reactor conversion

Reduced Enrichment Research and Test Reactor

scanning electron microscopy

uranium-molybdenum

uranium-molybdenum feedstock

Uranium Processing Facility

ultrasonic testing

vacuum arc remelting

vacuum induction melting

work breakdown structure

$\mathrm{x}$-ray fluorescence 


\section{Contents}

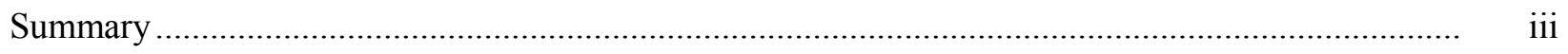

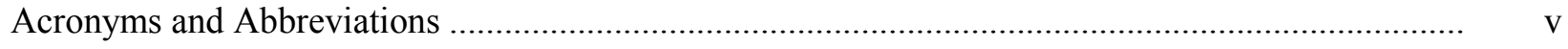

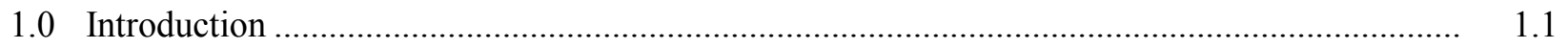

1.1 Mission of the GTRI Convert Program ........................................................................ 1.1

1.2 Role of the Fuel Fabrication Capability ........................................................................ 1.2

1.3 Fuel Fabrication Process Development to Date ............................................................. 1.3

2.0 Motivation and Objectives of FFC Research and Development .......................................... 2.1

2.1 Lack of a Well-defined, Repeatable Process ................................................................ 2.1

2.2 Uncertain Relationship Between Process Parameters and Material Characteristics ........... 2.1

2.3 Need for Clearly-Defined and Value-added Product Specifications.................................. 2.2

2.4 Relationship between FFC and FD Research and Development Plans ............................ 2.2

3.0 Coupon Manufacturing Research and Development .......................................................... 3.1

3.1 Coupon Baseline Process Optimization .................................................................... 3.2

3.1.1 Molybdenum Feedstock Form..................................................................... 3.2

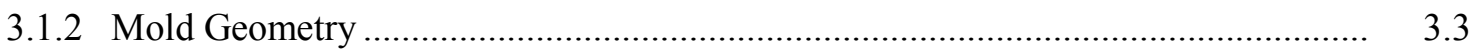

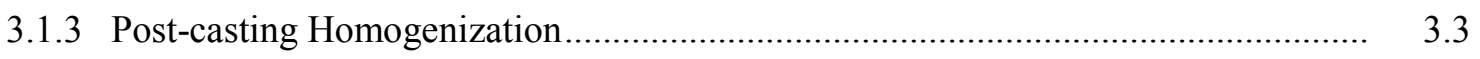

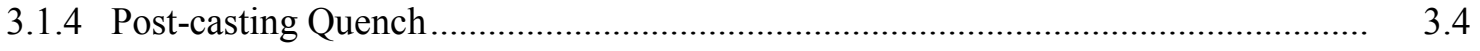

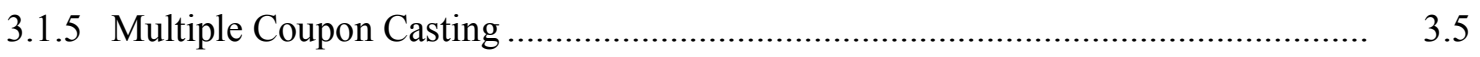

3.1.6 Separate Alloying and Downblending .......................................................... 3.6

3.1.7 Master DU-Mo Alloy Casting Parameters …....................................................... 3.7

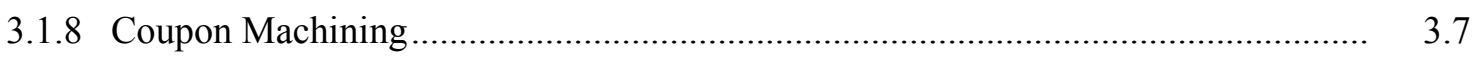

3.1.9 Rolling Process Modeling ........................................................................... 3.9

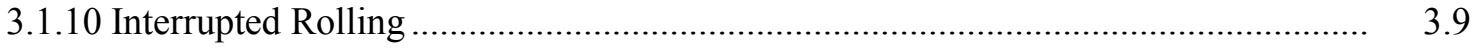

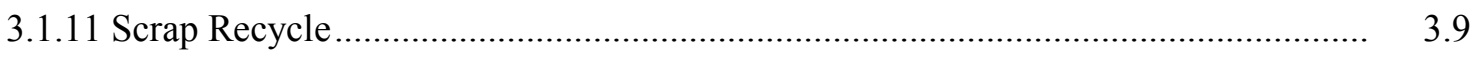

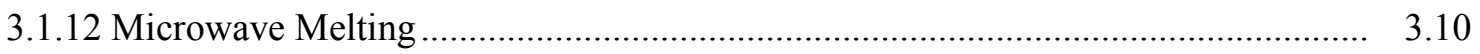

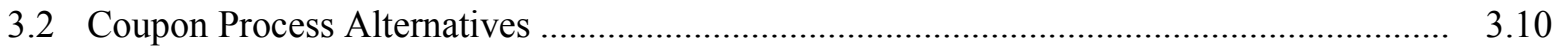

3.2.1 Billet Casting ........................................................................................ 3.11

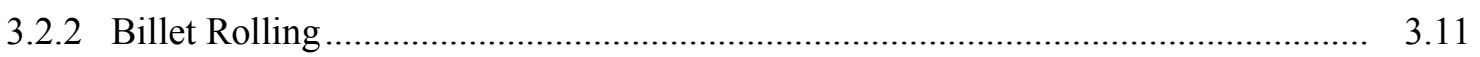

3.2.3 Powder Metallurgy Coupon Fabrication ............................................................ 3.12

$4.0 \quad$ Foil Manufacturing Research and Development ................................................................. 4.1

4.1 Foil Baseline Process Optimization .......................................................................... 4.2

4.1.1 Hot Rolling Reduction ............................................................................. 4.2

4.1.2 Cold Rolling Reduction................................................................................... 4.4

4.1.3 Rolling of Separately-alloyed and Downblended Foils.......................................... 4.5

4.1.4 Effect of Annealing Parameters on Foil Flatness ..................................................... 4.5

4.1.5 Effect of Warm Rolling on Foil Flatness ............................................................ 4.6

4.1.6 Optimized Co-rolling Parameters.................................................................. 4.6 


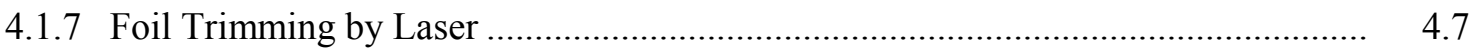

4.1.8 Foil Trimming by Water Jet ........................................................................ 4.7

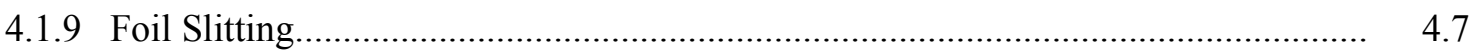

4.1.10 X-Ray Fluorescence Measurements of Zr Thickness........................................... 4.8

4.1.11 U-Mo/Zr Scrap Recycle Process Development..................................................... 4.8

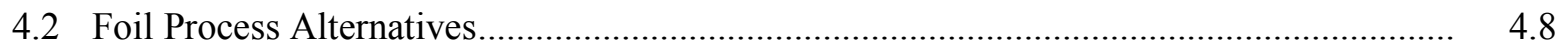

4.2.1 Alternative Zr Application Methods .............................................................. 4.9

4.2.2 Chemical Analysis Method Improvement........................................................ 4.12

5.0 Plate Manufacturing Research and Development.............................................................. 5.1

5.1 Plate Baseline Process Optimization......................................................................... 5.3

5.1.1 Clad-to-Foil Thickness Ratio Effect on HIP .................................................... 5.3

5.1.2 Clad-to-Foil Thickness Ratio and Bend Radius Effects on Forming ....................... 5.4

5.1.3 HIP Can Optimization................................................................................. 5.5

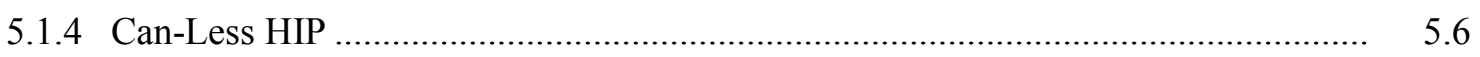

5.1.5 Plate Trimming by Laser............................................................................... 5.6

5.1.6 Inspection Methods to Improve Plate Machining Efficiency ................................ 5.7

5.1.7 Machining with Time-saver ......................................................................... 5.8

5.1.8 Manufacturing Plates with Fins.......................................................................... 5.8

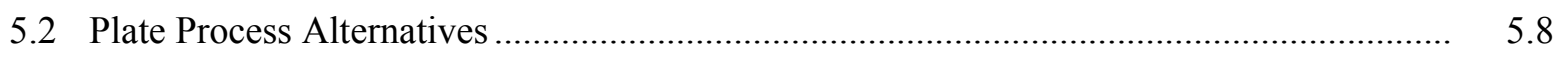

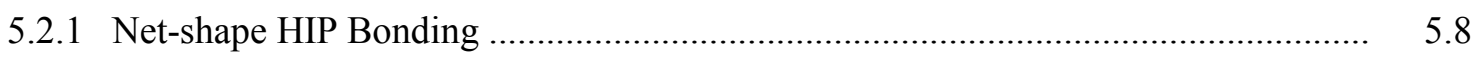

5.2.2 Hot Pressing ................................................................................................. 5.9

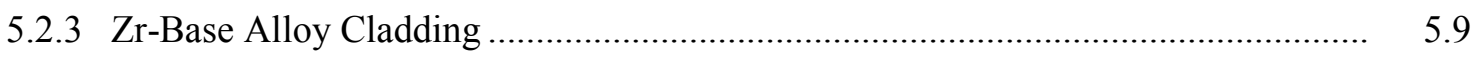

6.0 Element Manufacturing Research and Development .................................................. 6.1

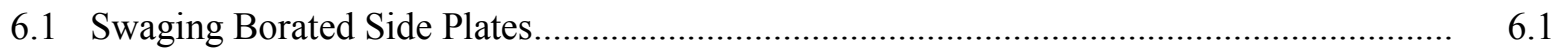

6.2 Welding Borated Side Plates ................................................................................. 6.1

6.3 Fuel Element Assembly with Zr-Base Alloy Cladding ................................................. 6.2

6.4 Machining Element End Adapters .......................................................................... 6.2

7.0 Cross-Cutting Research and Development Efforts.......................................................

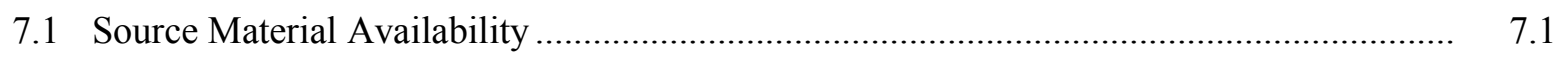

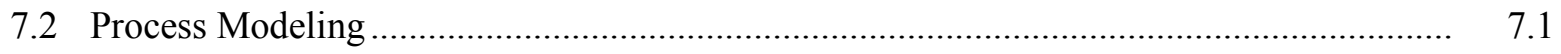

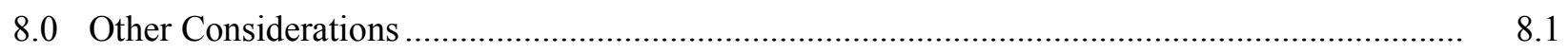

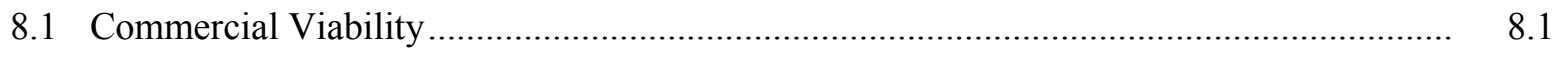

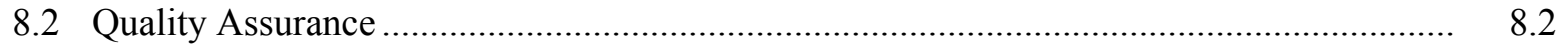

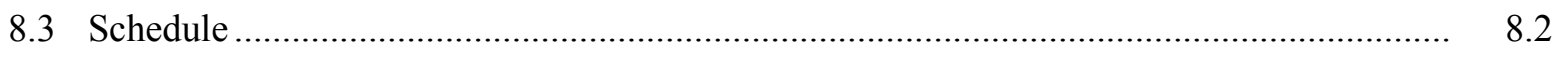

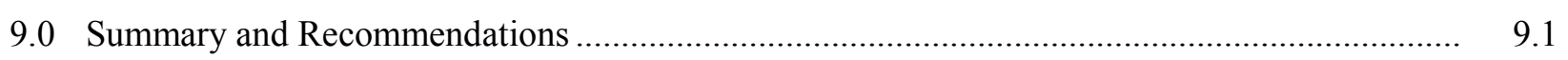

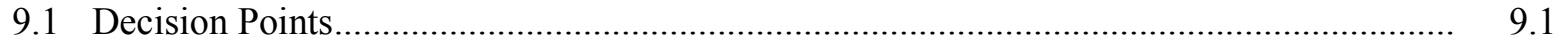

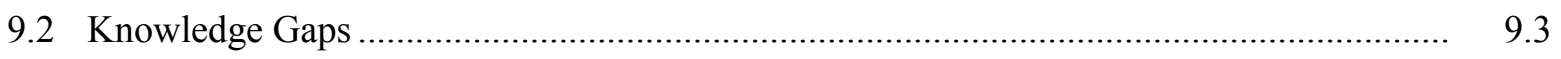

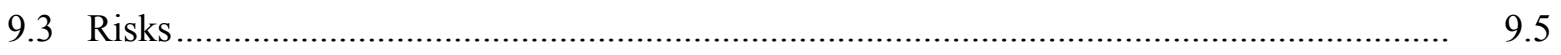

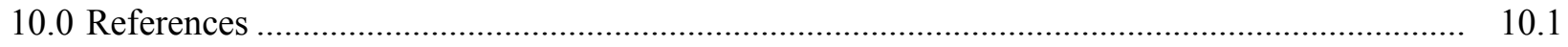




\section{Figures}

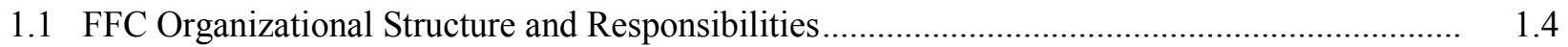

2.1 Schematic Representation of the Ideal Relationships in the Understanding of Processing,

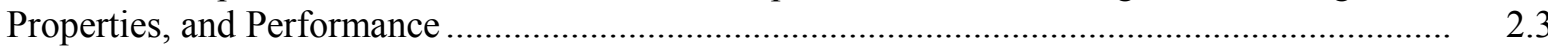

2.2 Schematic Representation of Current Relationships in the Understanding of Processing,

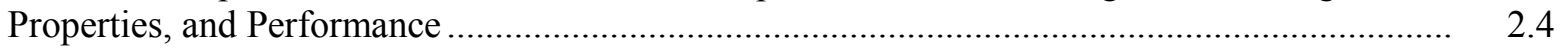

3.1 Simplified Flow Sheet for Baseline Coupon Manufacturing Process...................................... 3.1

3.2 FFC Coupon Manufacturing R\&D Activities Described in Section 3.0 .................................. 3.2

4.1 Simplified Flow Sheet for Baseline Foil Manufacturing Process ...............................................

4.2 FFC Foil Manufacturing R\&D Activities Described in Section 4.0 ....................................... 4.2

5.1 Simplified Flow Sheet for Baseline HIP Can Assembly Process ........................................... 5.1

5.2 Simplified Flow Sheet for Baseline Plate Manufacturing Process ............................................. 5.2

5.3 FFC Plate Manufacturing R\&D Activities Described in Section 5.0 ....................................... 5.2

6.1 FFC Element Manufacturing R\&D Activities Described in Section 6.0 .................................. 6.1

7.1 Cross-cutting FFC R\&D Activities Described in Section 7.0 ….........................................

8.1 Convert Program Schedule Showing Key Fuel Down-selection Decision Points That Drive Manufacturing Process Research and Development Needs ......................................................

9.1 FFC Research and Development Down-selection Milestones Supporting the Overall Convert Program Schedule 


\section{Tables}

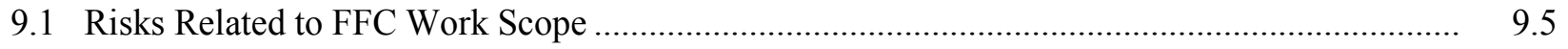




\subsection{Introduction}

The purpose of this document is to provide a comprehensive review of the mission of the Fuel Fabrication Capability (FFC) within the Global Threat Reduction Initiative (GTRI) Convert Program, along with research and development $(\mathrm{R} \& \mathrm{D})$ needs that have been identified as necessary to ensuring mission success. In Section 1.0, the role of the FFC within the Convert Program is outlined, as are relevant linkages to other aspects of the Program including Fuel Development (FD) and Reactor Conversion (RC). The motivation behind each of the identified R\&D needs and the objectives of the R\&D program is described in Section 2.0. Primary drivers include the need to 1) define a repeatable manufacturing process, 2) relate process parameters to material properties and characteristics, 3) contribute to definition of the product and process specifications, and 4) integrate FFC and FD research and development activities to focus on relevant characteristics and avoid duplication of effort. Descriptions of the individual R\&D activities planned to satisfy the objectives are included in Sections 3.0, 4.0, 5.0 and 6.0 for coupon (uranium-molybdenum (U-Mo) fuel meat), foil (U-Mo fuel with diffusion barrier), plate (clad fuel), and element (multiple plate assemblies) manufacturing process development, respectively. Each of these four sections considers two principal categories of R\&D, 1) baseline process optimization, to refine the existing fabrication technology, and 2) process alternatives, to evaluate new fabrication technology that could provide improvements in quality, repeatability, or cost. Section 7.0 describes a number of cross-cutting activities necessary for FFC to advance the state of the art in fuel fabrication. Section 8.0 discusses other considerations associated with FFC R\&D efforts, including criteria for assessing commercial viability of manufacturing process, quality assurance, and schedule. Section 9.0 describes the logic and schedule for critical decision points and their relationship to manufacturing and process development needs, a listing of knowledge gaps that are not currently being addressed within approved FFC scope, and a summary of risks that could impact FFC execution of the R\&D Plan. The intent is for this plan to be a living document that will be reviewed and updated on a regular basis (e.g., annually) to ensure that FFC R\&D activities remain properly aligned to the needs of the Convert Program. The R\&D Plan does not include FFC initiatives related to production-scale manufacturing of fuel, rather, the goal of this plan is to document the research and development activities needed to enable high-quality and cost-effective production of the fuel by the commercial fuel fabricator.

\subsection{Mission of the GTRI Convert Program}

Operating within the U.S. Department of Energy (DOE)/National Nuclear Security Administration (NNSA), the GTRI mission is to reduce and protect vulnerable nuclear and radiological material located at civilian sites worldwide. In order to achieve this mission, GTRI has three pillars that provide a comprehensive approach to achieving this mission.

1. Convert research reactors and radioisotope production facilities from the use of highly enriched uranium (HEU) to low enriched uranium (LEU) fuel

2. Remove and facilitate disposition of excess nuclear and radiological materials

3. Protect high priority nuclear and radiological materials from theft and sabotage

In support of the first pillar, the GTRI Reactor Conversion program (referred to in this document as

the Convert Program) works with civilian research and test reactors operating with HEU fuel around the world. While NNSA provides enhanced physical protection systems at research and test reactors, 
converting the fuel used in these reactors to LEU permanently secures the site by removing the threat posed by continued HEU operations. As the manufacture, shipment and storage of the HEU fuel for these reactors can present an opportunity for terrorists to acquire the HEU they seek, eliminating the use of HEU in civilian research and tests reactors by verifying the shutdown or conversion of these reactors to an LEU-based fuel provides permanent threat reduction (NNSA 2013b).

A key component of the GTRI Convert Program is conversion from HEU to LEU of six U.S. high performance research reactors (HPRRs) including the Advanced Test Reactor (ATR), the ATR critical assembly (ATR-C), the High Flux Isotope Reactor (HFIR), the National Bureau of Standards Reactor, the Missouri University Research Reactor (MURR), and the Massachusetts Institute of Technology Reactor (MITR). The driver for conversion of these six reactors within the U.S. is to lead by example and influence international reactor operators to convert to a fuel that is less attractive for proliferators from a safeguards point of view, but effectively maintains the core mission and needs of the reactor. The scope described in this document is associated with fabrication of the LEU fuel for the six U.S. HPRRs.

\subsection{Role of the Fuel Fabrication Capability}

The U.S. HPRR portion of the Convert Program consists of three principal activities, referred to as pillars. These include FD, FFC, and RC. The overall objective of the FFC is to establish a cost-effective and efficient manufacturing process that can be implemented by a commercial entity to provide LEU fuel to the U.S. HPRRs after conversion from their existing HEU fuel. The baseline LEU fuel and fuel fabrication process was developed by the FD pillar. It consists of a plate-type fuel with a monolithic U$10 \mathrm{Mo}$ alloy foil bonded on two sides with a $\mathrm{Zr}$ diffusion barrier, and clad within an Al-base alloy. Ultimately, the RC pillar will employ the commercial product developed by FFC in conversion of the six U.S. HPRRs from their existing HEU fuel to the new LEU fuel.

Specifically, the FFC will:

- Transfer fabrication knowledge and processes to a commercial fuel fabricator

- Establish LEU manufacturing capability to support the conversion of the six U.S. HPRRs

- Demonstrate cost-effective and efficient production of developmental and production LEU fuel

- Procure initial reactor loadings to support conversion

- Fabricate demonstration and experiment fuel products as requested by the program

The scope described in this R\&D Plan is necessary to ensure that FFC can meet these objectives on a schedule and with product quality consistent with overall programmatic guidance. Technical challenges, budget limitations, and schedule disruptions will increase the risk that the FFC objectives cannot be met on the programmatic timeline described in Section 9.0. Further, it is important to note that this R\&D Plan does not address potential changes in the fuel manufacturing process to address irradiation performance issues. Irradiation testing and fuel performance analysis are the responsibility of the FD pillar. If irradiation testing or fuel performance modeling suggests that changes are needed to the fuel manufacturing process, changes to the R\&D program outlined in this plan will be required. Such changes also have the potential to increase the risk that the FFC objectives cannot be met on the programmatic timeline. 
The R\&D activities described in this document are executed by a variety of organizations including national laboratories, universities and commercial entities, as shown in Figure 1.1. Specifically, work is currently being conducted at Los Alamos National Laboratory, Idaho National Laboratory (INL), Pacific Northwest National Laboratory (PNNL), Y-12 National Security Complex, Georgia Institute of Technology, Babcock \& Wilcox (B\&W) Nuclear Operations Group, Manufacturing Sciences Corporation, Aerojet, and selected universities. While FFC management resides at PNNL, the FFC is not a PNNL program. It is a national effort within the overall Convert Program. Accordingly, work is apportioned based on considerations of technical capabilities, available capacity, and overall cost and schedule. Thus, the division of work described in this document is an optimization of the available resources to achieve the FFC objectives described above. If events warrant, scope may be moved from one organization to another, and if new scope is warranted, particularly if it is outside the envelope of current technologies, new organizations not currently involved may be approached to contribute.

\subsection{Fuel Fabrication Process Development to Date}

The five U.S. HPRRs and one critical assembly addressed by the Convert Program currently utilize dispersion fuel consisting of HEU-containing particulate distributed throughout an Al-base alloy matrix. The material form of the dispersion particulate varies, including UAl $\mathrm{x}_{\mathrm{x}}$ for ATR and ATR-C (Gerstner et al. 2010), MITR (Newton 2011), and MURR (Foyto et al. 2012), and $\mathrm{U}_{3} \mathrm{O}_{8}$ for HFIR (Primm et al. 2006) and National Bureau of Standards Reactor (Hanson and Diamond 2011). While dispersion fuel forms, including $\mathrm{U}_{3} \mathrm{Si}_{2}$ and $\mathrm{U}-\mathrm{Mo}$ alloy dispersions in an Al-base alloy matrix, have been demonstrated for low power research reactors $\left(<5 \mathrm{MW}_{\mathrm{t}}\right)$, the $\mathrm{U}$ density of dispersion fuels may not be adequate to preserve acceptable performance of HPRRs. Typical $U$ density of dispersion fuels is $2.3 \mathrm{~g} / \mathrm{cm}^{3}$ for $U A l_{x}$, $3.2 \mathrm{~g} / \mathrm{cm}^{3}$ for $\mathrm{U}_{3} \mathrm{O}_{8}, 6.0 \mathrm{~g} / \mathrm{cm}^{3}$ for $\mathrm{U}_{3} \mathrm{Si}_{2}$ (note that $\mathrm{U}_{3} \mathrm{Si}_{2}$ was only qualified for a density up to $4.8 \mathrm{~g} / \mathrm{cm}^{3}$ ) and $8.5 \mathrm{~g} / \mathrm{cm}^{3}$ for U-10Mo (Wachs et al. 2008). Therefore, development of monolithic U-Mo alloy fuels was undertaken starting in 2004, drawing on experience with metallic fuels in general and U-Mo alloy fuels in particular dating back to the 1950s (e.g., Fox et al. 1958, Shoudy et al. 1963). The U density of U-10Mo monolithic fuel is $15.3 \mathrm{~g} / \mathrm{cm}^{3}$ (Wachs et al. 2008), which has the potential to provide sufficient fissile material at less than $20 \%$ enrichment in ${ }^{235} \mathrm{U}$ to preserve the performance exhibited by the U.S. HPRRs using highly-enriched dispersion fuel. 


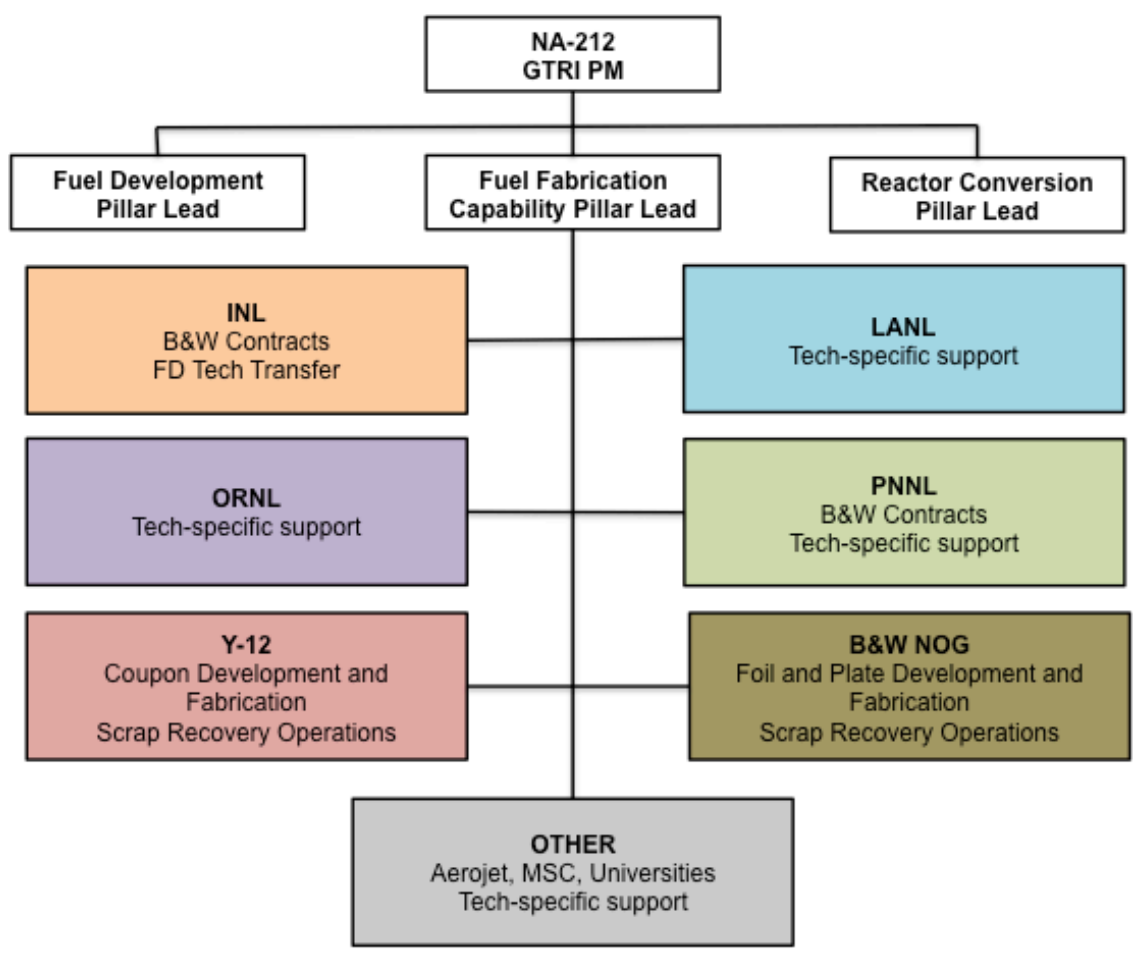

Figure 1.1. FFC Organizational Structure and Responsibilities

The first irradiation experiments of U-10Mo monolithic fuel in a "mini-plate" configuration ( 1 in. $\mathrm{x}$ 4 in. $x 0.055$ in.) were conducted at ATR in 2005 under the Reduced Enrichment Research and Test Reactor (RERTR) program. Seven insertions were conducted over the next few years as part of the RERTR -6, -7A, -8, -9A, -9B, -10A, and -10B experiments at ATR. These were followed by irradiation experiments starting in 2008 that included larger fuel plates (2.21 in. x 22.5 in. x 0.05 in.) and were designated AFIP-2 and -3. These tests were conducted over a range of peak fuel temperatures, average fission density, average fission rate, and average heat flux to evaluate the irradiation behavior of the fuel over a variety of HPRR-relevant operating conditions. The tests evaluated irradiation performance of alloy compositions ranging from $7 \mathrm{wt} \%$ to $12 \mathrm{wt} \%$ molybdenum (Mo), a range of fuel meat to cladding thickness ratios, different foil configurations with and without diffusion barriers, Zr-base alloy cladding, and a variety of fabrication methods. The fabrication methods were developed in a laboratory setting to produce the RERTR- and AFIP-size plates and included variations in coupon reduction schedules, different diffusion barrier materials and application methods, variations in foil reduction schedules, and different fuel/cladding bonding methods. Based on the in-reactor and post-irradiation examination results from these experiments, the baseline fuel form and associated baseline fuel fabrication processes were identified (Robinson et al. 2009). The irradiation experiments conducted before the down-selection of the final fuel form and fabrication processes did not include various HPRR-specific features such as cladding fins, contoured fuel meat, or integral burnable absorbers. Subsequent irradiation experiments, including RERTR-12 and AFIP-4, -6, -6 MKII, and -7 were conducted after the down-selection. Several of these experiments experienced failures during irradiation; some were related to fuel performance while others were not. In addition, certain irradiation performance issues such as low post-irradiation blister threshold temperature were identified after the RERTR-12 and AFIP-4 experiments (PIE has not been conducted on the AFIP-6, -6 MKII, or -7 experiments to date). Despite these issues, the baseline fuel form and associated fabrication processes identified in Robinson et al. (2009) were provided to FFC for commercial technology transfer and scale-up to prototypic dimensions and throughput. 
The FFC was initially created in 2007 to identify appropriate commercial entities for manufacturing of U-10Mo monolithic fuel with prototypic dimensions and throughput (assuming conversion of all six U.S. HPRRs using the same fuel form). This assessment was completed in 2009, and FFC then started working toward transferring the fuel fabrication technology developed by FD at the laboratory scale to a commercial manufacturer. Scoping studies were conducted to determine the feasibility of scaling the FD fabrication process to appropriate size and throughput to produce the four key stages of the fuel: 1) U10Mo fuel meat (coupons), 2) $\mathrm{Zr}$ diffusion barrier application to the fuel meat (foils), 3) bonding of the foils to the cladding (plates), and 4) assembly of plates into fuel elements. By 2011, the baseline processes for producing the base fuel form was fully defined (Moore and Marshall 2010; Park et al. 2010) and subsequent work focused on establishing a limited production facility to demonstrate prototypic-scale manufacturing of the fuel. More recently, the need has become apparent for optimization of the baseline processes as well as consideration of alternative processes where they offer potentially significant product quality, cost, or throughput advantages. Consequently, FFC has embarked on an applied research and development program to evaluate fabrication parameters and their effect on manufacturing efficiency and product quality. In addition, FFC has started considering the work that will be necessary to fully define acceptable manufacturing processes for "complex" fuel to include U.S. HPRR-specific features such as fins, contoured fuel meat, and integral burnable absorbers. The current FFC R\&D effort described by this plan addresses optimization and alternatives for base fuel manufacturing, but includes only limited scope focused on complex fuel manufacturing. 



\subsection{Motivation and Objectives of FFC Research and Development}

The overriding motivation for conducting the research and development activities described in this plan is the need to ensure the following:

- The manufacturing process consistently produces fuel with acceptable quality (i.e., meets or exceeds design requirements)

- The sensitivity of material properties and characteristics to manufacturing process parameters is clearly understood so adequate process specifications can be defined

- Fuel product specifications are realistic and achievable using the selected manufacturing methods

- A better linkage between the effect of process parameters on fuel performance, to ensure that changes or variability in manufacturing does not have an adverse effect on irradiation behavior

These motivating factors are all interrelated, and progress addressing one will aid understanding of the others. The following sections expand on these motivating factors, define the specific objectives of the FFC R\&D program, and explain how the FFC R\&D program will reduce overall programmatic risk in these areas.

\subsection{Lack of a Well-defined, Repeatable Process}

Currently, the fuel fabrication process is poorly defined. While manufacturing methods have been identified for each step in fuel fabrication, details associated with those processes have not been defined. For example, cold rolling has been identified as the method of choice for reducing the coupons to the desired thickness, primarily because of the ability to achieve specified dimensional tolerances (Meyer et al. 2012). However, acceptable degrees of cold work have not been specifically defined, and a range will likely be required due to differences in fuel-to-clad thickness ratios in plates for different reactors (and between plates in the same fuel element for some of the reactors). In addition, there is evidence that different microstructures can result for the same overall reduction depending on the specific reduction schedule. Aggressive early reduction steps followed by more moderate reduction steps can produce a different microstructure than a greater number of moderate reduction steps (Meyer et al. 2012). To ensure a truly repeatable fabrication process that meets all applicable design requirements, it is necessary to fully define each aspect of the process. In this way, unintended consequences resulting from operator-specific actions are avoided and yield is maximized. The ultimate goal in defining the fabrication process is the development of a Manufacturing and Quality Plan (MAQP) that provides a basis for process definition, review, and acceptance. Many of the FFC R\&D activities described in this plan will inform the development of a MAQP that will meet the needs of the designer, the fabricator, the quality assurance organization, and ultimately, the regulator.

\subsection{Uncertain Relationship Between Process Parameters and Material Characteristics}

Currently, there is incomplete understanding of the relationship between manufacturing process parameters and resulting material properties and characteristics. By defining the process as described in 
Section 2.1, the parameter space for each manufacturing method is bounded and the range of process parameter variability is identified. Developing a thorough understanding impact of process parameter variation within this operational envelope is required to avoid locking the manufacturer into a very narrow range of acceptable process parameters that could impact product quality and yield. By understanding the sensitivity of material properties and characteristics (e.g., grain size and orientation, or carbide precipitate size and distribution) to changes in process parameters, the opportunity exists to relax specifications where appropriate and optimize the manufacturing process to achieve improved product quality and yield. In addition, understanding the relationship between processing and properties, even outside the range of process specifications, allows the designer to more easily disposition nonconformances resulting from unexpected process variations. Without this knowledge, the designer is forced to reject any product resulting from out-of-tolerance process parameters because of the uncertainty on product acceptability for its intended purpose. The goal of the FFC R\&D activities addressing this issue is to generate models that can be used to define process specifications.

\subsection{Need for Clearly-Defined and Value-added Product Specifications}

Currently, FD is preparing a draft fuel product specification. The product specification is intended to provide guidance for FFC development of process specifications. The focus for the designer should be on properties and characteristics that can be measured in the fuel product in either intermediate or final condition. The fuel designer should have a clear understanding of the relationship between these properties and characteristics on irradiation performance. By developing appropriate product specifications, the designer can then ensure that fresh fuel exhibits the properties and characteristics that are known to demonstrate acceptable irradiation performance. By developing the understanding described in Section 2.2, the fabricator can ensure that appropriate process parameters are used during fabrication to provide the properties and characteristics in the product desired by the designer. In addition, the designer will have confidence that the product specification is realistic and can be achieved using the manufacturing methods defined and specified by the fabricator. Thus, the ultimate goal for many of the FFC R\&D activities described in this plan is to provide feedback to FD regarding the feasibility of achieving the fuel product specification requirements.

\subsection{Relationship between FFC and FD Research and Development Plans}

Design and manufacturing of any product are very closely linked, and the development of product specifications, process specifications, MAQPs, and other related documents is an iterative process based on the observed performance of the product in question. Therefore, the final motivation behind the FFC $\mathrm{R} \& \mathrm{D}$ program described in this plan is to foster closer integration between FFC and FD efforts to reduce programmatic risk by ensuring common goals and shared vision.

An ideal representation of the iterative nature of understanding the relationship among processing, properties and performance is shown in Figure 2.1, specifically for reactor fuel. Fabrication process development studies should provide the understanding to connect the relationship between manufacturing processes and properties. An irradiation testing campaign should provide the understanding to connect the relationship between properties and performance in the reactor. Finally, there should be a feedback loop provided by fuel performance modeling that relates in-reactor performance back to manufacturing processes so that the right parameters are being controlled during fabrication to ensure satisfactory performance. 


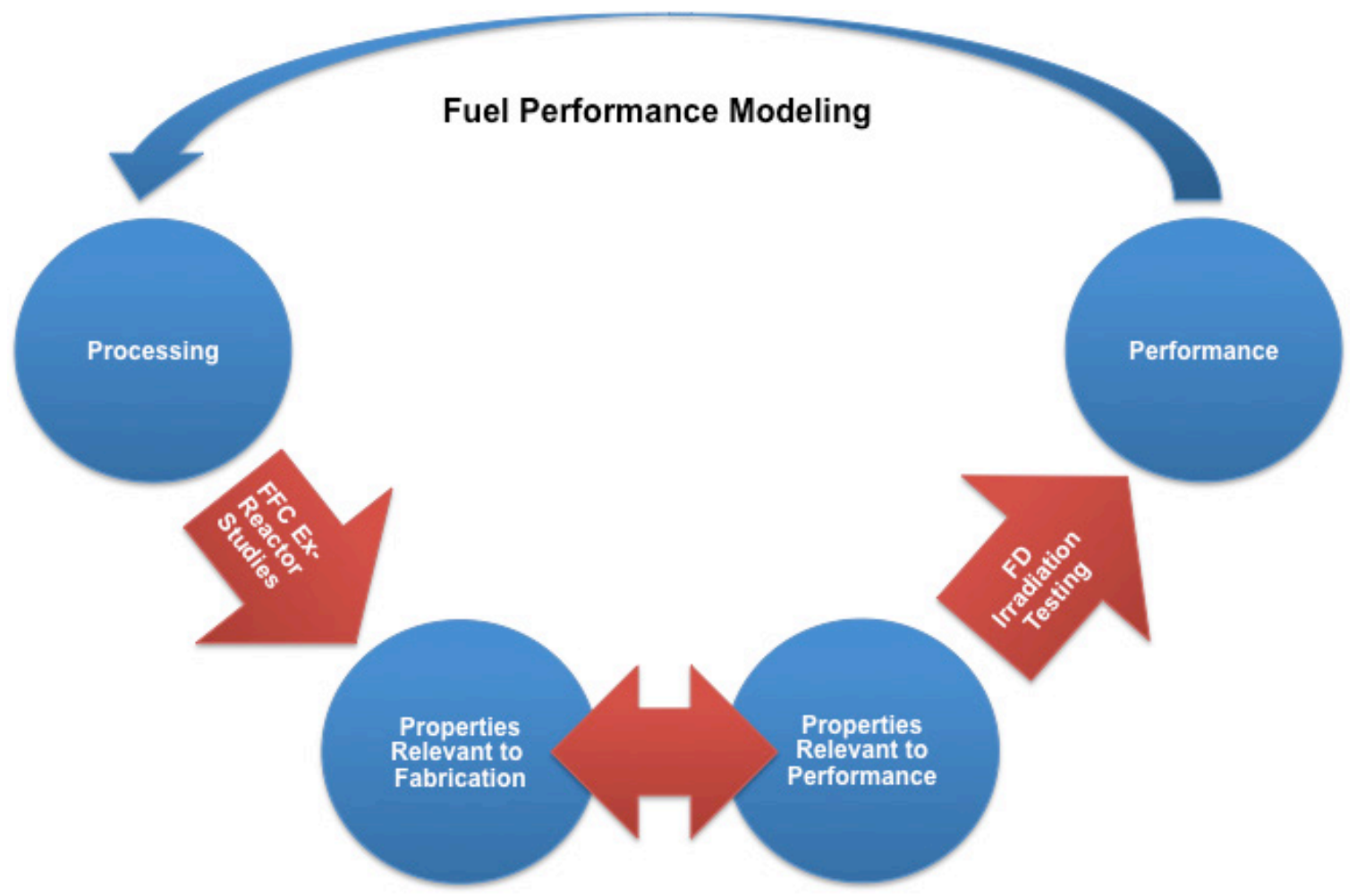

Figure 2.1. Schematic Representation of the Ideal Relationships in the Understanding of Processing, Properties, and Performance

Figure 2.2 is a representation of the current situation in the Convert Program, showing disconnects in the understanding of the relationships among processing, properties, and performance. First, there is currently a disconnect with respect to material properties and characteristics. The FFC R\&D program described in this plan will address the understanding of the relationship between processing and properties. However, without tighter integration to the FD irradiation testing program, there is no guarantee that the properties relevant for manufacturing are the same as the properties relevant for irradiation performance. Therefore, it is possible that FFC and FD are not addressing a common set of material properties and characteristics that will aid in definition of manufacturing methods, product specifications, and process specifications. Second, there is currently no feedback mechanism to relate irradiation performance back to processing to ensure that limited resources are directed at the highestpriority issues. This is particularly true with regard to parameters that could be significantly altered by process or parameter choices (e.g., grain size, carbide size, etc.). While there are disparate models to describe fuel swelling and other aspects of irradiation performance, there currently is no comprehensive effort to create a code that attempts to predict performance of plate-type research reactor fuel. Such a code would be beneficial to fuel designers to help guide development of irradiation test matrices and product specifications, but also to fabricators to guide R\&D efforts relating processing to properties and development of process specifications and MAQPs defining production fuel manufacturing. 

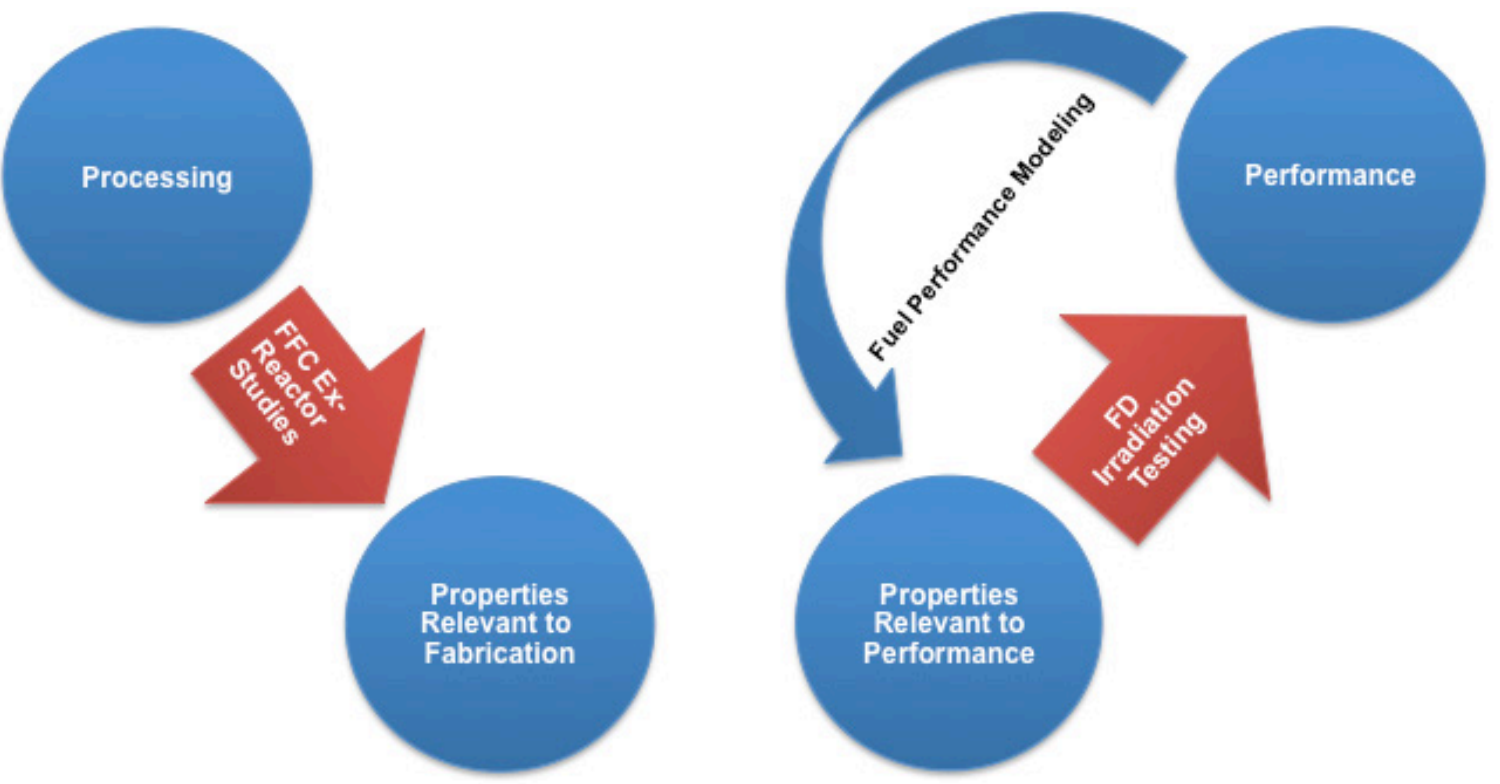

Figure 2.2. Schematic Representation of Current Relationships in the Understanding of Processing, Properties, and Performance

By embarking on a closely-linked and integrated series of well-planned, disciplined research and development activities, FFC and FD can ensure that the disconnects in the current program are addressed and that progress toward the common goal of producing effective LEU research reactor fuel at an affordable cost and in a sustainable fashion can be achieved. The R\&D program described by this plan represents the FFC contribution to establishing an integrated Convert Program R\&D effort ultimately leading to development and deployment of LEU research reactor fuel. 


\subsection{Coupon Manufacturing Research and Development}

For the purposes of this document, coupon manufacturing encompasses all activities from uranium and molybdenum feedstock preparation through final surface finishing of the U-10Mo coupon (fuel meat). This portion of the baseline manufacturing process is shown in Figure 3.1 and the R\&D activities described in this section are shown in Figure 3.2. The following sections describe R\&D efforts that are needed to optimize the baseline process as well as process alternatives that may offer improvements in quality, repeatability or cost. The numbers in parentheses following some of the subsection headings indicate the Convert Program Work Breakdown Structure (WBS) under which the work is planned. If a subsection does not have a WBS associated with it, it is because this work is not currently included in the Convert Program planning basis. In these cases, inclusion in this document forms the basis for a recommendation to include the work in future FFC scope planning for the reasons described in the subsections below.

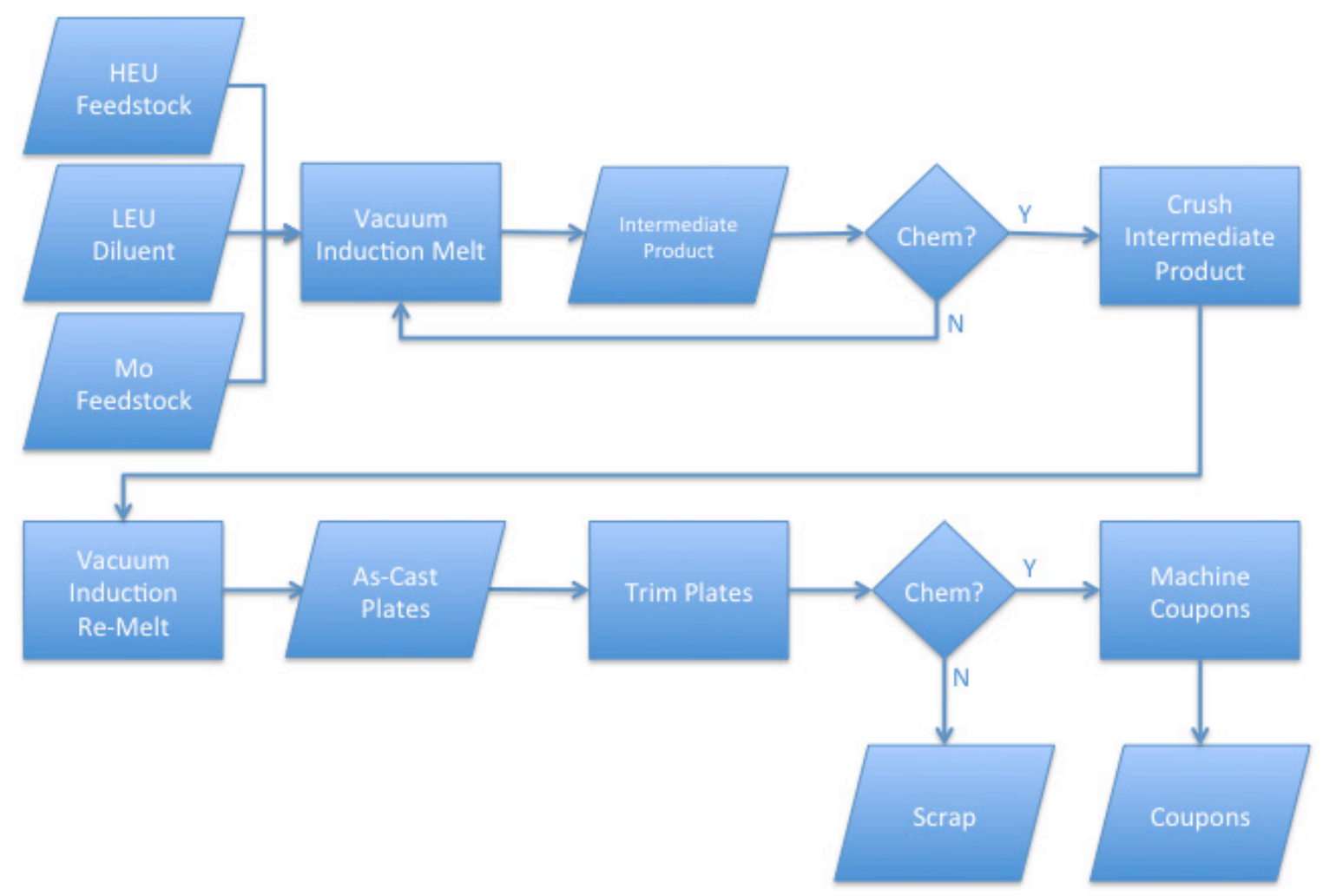

Figure 3.1. Simplified Flow Sheet for Baseline Coupon Manufacturing Process 


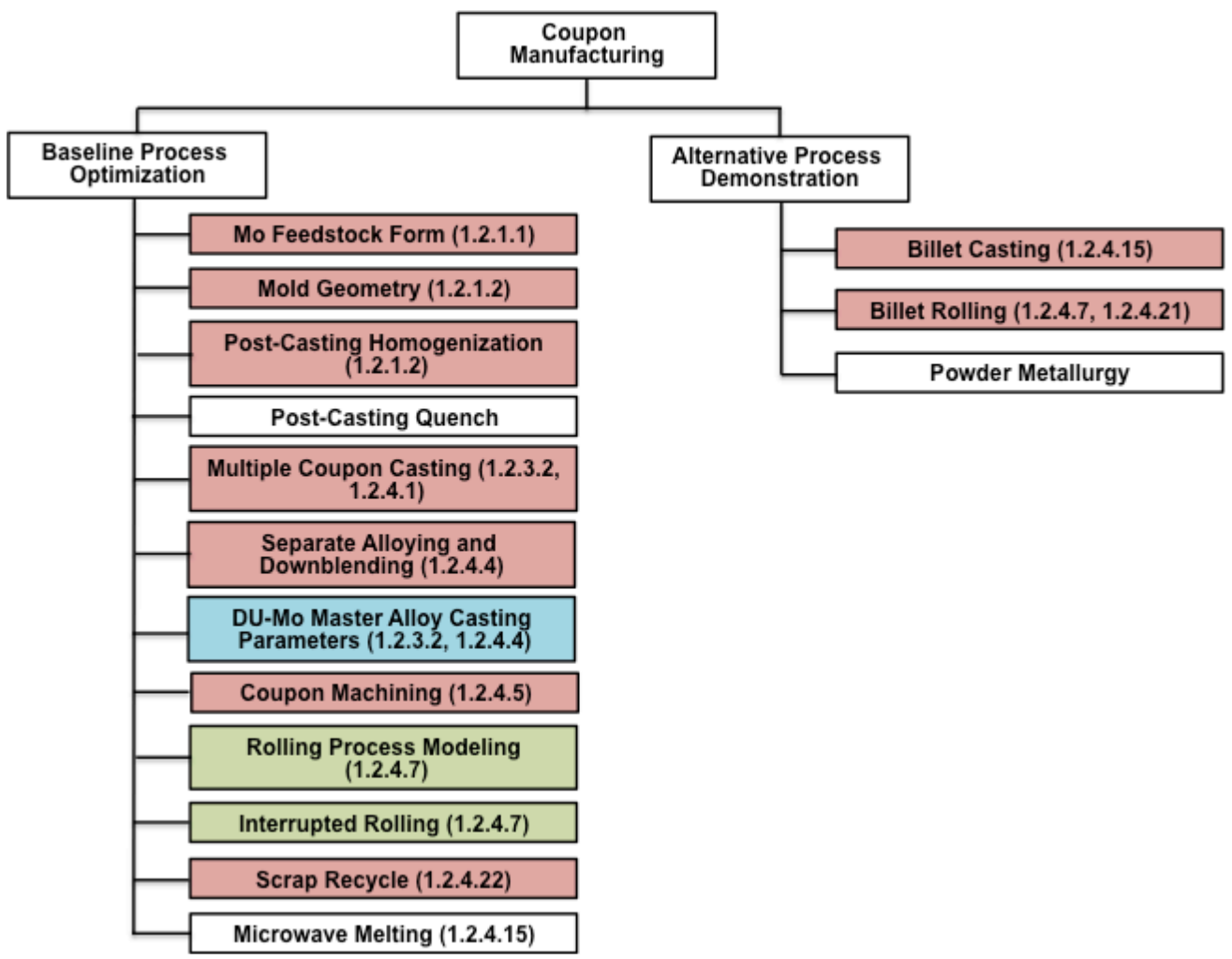

Figure 3.2. FFC Coupon Manufacturing R\&D Activities Described in Section 3.0. The colors denote the responsible organization(s) for each activity and correspond to the colors in Figure 1.1. The white boxes denote activities that are recommended but not currently funded.

\subsection{Coupon Baseline Process Optimization}

The principal process development needs for coupon manufacturing are related to improving cast product consistency, maximizing casting efficiency, improving casting yield, and producing consistently acceptable microstructures and dimensions in the final coupon product. Results from this portion of the R\&D program will provide insight into material tendencies from which sampling plans can be better defined. Further, results from these investigations will define a process baseline so that time and cost saving measures can effectively be analyzed.

\subsubsection{Molybdenum Feedstock Form (1.2.1.1)}

This activity investigates the influence of Mo feedstock form on Mo uniformity in the material used to cast plates. The objective of these experiments is to down-select the Mo feedstock for subsequent casting experiments with minimal impact on alloy purity. Three Mo feedstock forms will be used to cast two logs each to be used as U-10Mo feedstock for subsequent casting operations. The Mo feedstock forms will be powder, rod, and corrugated foil. Impurity concentrations of the depleted uranium (DU) feed material will be determined by utilizing inductively-coupled plasma mass spectrometry (ICP-MS) or ICP-optical emission spectrometry (ICP-OES) and a LECO test (for Carbon). Impurities of particular importance are $\mathrm{C}, \mathrm{Si}, \mathrm{Fe}, \mathrm{Cu}$, and $\mathrm{Zr}$. The mass of $\mathrm{DU}$ and $\mathrm{Mo}$ for each alloy and casting run will be reported and in each case the nominal Mo content will be 10 weight percent. Three thermocouples will be used for each casting run to estimate rheological characteristics. The location of the three 
thermocouples will be the crucible, the mold top, and the mold bottom. Any anomalies during the casting processes will be documented and reported. The resultant logs will be characterized by ICP-MS or ICPOES for analytical chemistry, specifically Mo content, on samples from the top, middle, and bottom of each log. This work scope must be completed in order to provide feedstock for additional casting and homogenization experiments described in Sections 3.1.2 and 3.1.3.

\subsubsection{Mold Geometry (1.2.1.2)}

This work scope requires successful completion of the Mo feedstock investigation described in Section 3.1.1 to provide the necessary feed material. The objective of this study is to investigate the influence of mold geometry on impurity level and homogeneity of cast plates. Two casting mold geometries will be used to produce plate thicknesses of $0.200 \mathrm{in}$. and $0.375 \mathrm{in}$. A total of nine plates will be cast from the $0.200 \mathrm{in}$. mold and six plates from the $0.375 \mathrm{in}$. mold. The resultant plates will be subjected to radiography to determine if and to what extent any inhomogeneities in the cast product exist. Furthermore, the presence of inclusions or other casting defects as a result of the different Mo feedstock and mold geometries will be identified. Results of the radiography, along with the analytical chemistry described in Section 3.1.1, will be utilized to down-select the Mo feedstock form (i.e., powder, rod, or corrugated foil). The down-selection will be made based upon the sample set that has the highest statistical degree of Mo uniformity and lowest impurity concentration while also taking casting efficiency and processing time into account. This is a hold point in the study, meaning that no additional processing will occur until the decision on Mo feedstock form has been made.

Sacrificial samples will be taken from each plate for chemical analysis and metallography with the remaining material from each plate. ICP-MS or ICP-OES and a LECO test (for Carbon) will be utilized to determine nominal composition of $\mathrm{U}$ and Mo, and the concentration of impurities including $\mathrm{C}, \mathrm{Si}, \mathrm{Fe}$, and $\mathrm{Zr}$. Variations in composition should be determined via optical microscopy, scanning electron microscopy (SEM), and energy dispersive spectroscopy (EDS)/ wavelength dispersive spectroscopy. Average grain size and microhardness should be measured to determine if (and to what extent) transformation/decomposition has occurred, as well as assist in drawing conclusions from any of the metallographic observations. Some of the plates will be used for the post-casting homogenization and quenching studies described in Sections 3.1.3 and 3.1.4, respectively.

\subsubsection{Post-casting Homogenization (1.2.1.2)}

Using the nine plates from the $0.200 \mathrm{in}$. mold and six plates from the $0.375 \mathrm{in}$. mold cast as part of the study described in Section 3.1.2, a four-hour homogenization treatment at $1000^{\circ} \mathrm{C}$ will be performed inmold after each casting. Six of the 0.200 in. plates and three of the 0.375 in. plates will be subjected to the homogenization treatment, with the remaining plates undergoing no homogenization treatment (serving as controls). Time and temperature will be recorded using the thermocouples located in the mold (described in Section 3.1.2) for those plates undergoing an in-mold homogenization step. After completion of the four hour homogenization treatment, the furnace will be allowed to cool to ambient temperature under vacuum.

The plates will be subjected to the same radiographic examination described in Section 3.1.2 for the mold geometry study. Furthermore, the presence of inclusions or other casting defects as a result of the different Mo feedstock and homogenization treatment will be identified. Results of the radiography, 
including the radiography described in Section 3.1.2, along with the analytical chemistry results described in Section 3.1.1, will be utilized to down-select the Mo feedstock form (i.e., powder, rod, or corrugated foil). The down-selection will be made based upon the sample set that has the highest statistical degree of Mo uniformity and lowest impurity concentration while also taking casting efficiency and processing time into account. This is a hold point in the study, meaning that no additional processing will occur until the decision on Mo feedstock form has been made.

An additional $48 \mathrm{~kg}$ of feed material will be required to produce plates for subsequent processing after the Mo feedstock form is downselected. The casting process defined by the study in Section 3.1.1 will be utilized to prepare another three log castings. The resultant DU-10Mo alloy feed material will be used to prepare two additional 0.200 in. plates with no homogenization treatment, one additional 0.200 in. plate with the in-mold homogenization treatment, two additional 0.375 in. plates with no homogenization treatment, and two additional 0.375 in. plates with the in-mold homogenization treatment. Thus, a total of six plates with each thickness will be prepared using the downselected Mo feedstock form. Of the six plates with each thickness, half will have been subjected to the in-mold homogenization treatment. The remaining plates (i.e., those produced from the Mo feedstock not selected) will be labeled accordingly and placed in storage. Plates using the downselected Mo feedstock selected by the study in Section 3.1.1 and Section 3.1.3 will be machined to produce coupons that will progress to the hot rolling experiments (Section 4.1.1). Two different coupon sizes will be machined from each plate thickness. Two of the $0.200 \mathrm{in}$. thick plates receiving no homogenization treatment will be machined to produce four 7.54 in. $x 3.3$ in. $x 0.138$ in. coupons (two coupons per plate). The process will be repeated for two plates that received the in-mold homogenization treatment. The remaining 0.200 in. thick plates (one each subjected to a homogenization treatment and no homogenization treatment) will be machined to produce four 2.64 in. $x 3.3$ in. x 0.138 in. coupons (four coupons per plate). Thickness tolerance on the coupons is defined as $0.138 \pm 0.013$ in. thick. Two of the 0.375 in. thick plates receiving no homogenization treatment will be machined to produce four 3.2 in. $x 3.3$ in. $x 0.325$ in. coupons (two coupons per plate). The process will be repeated for two plates that received the in-mold homogenization treatment. The remaining 0.375 in. thick plates (one each subjected to a homogenization treatment and no homogenization treatment) will be machined to produce four 1.13 in. $\mathrm{x} 3.3 \mathrm{in} . \mathrm{x}$ 0.325 in. coupons (four coupons per plate). Thickness tolerance on these coupons is defined as $0.325 \pm$ 0.015 in. An in-process visual inspection will be performed during the machining operations to ensure there are no visible surface defects having a dimension of 0.050 in. in any direction. If such a defect is found, attempts to rework the coupon will be made, so long as the thickness is within the allowable tolerance band. If rework is not possible or unsuccessful, dimensional measurements of the defect will be made and the coupon will be retained for further study.

\subsubsection{Post-casting Quench}

To evaluate the effects of post-homogenization heat treatment cooling rate on Mo uniformity and other microstructural features, it would be useful to compare the baseline process (natural cooling under vacuum) to a forced cooling (quench) process. For example, the mold could be allowed to cool to some temperature after which air or inert gas could be introduced to the furnace to more rapidly cool to ambient conditions. Using an inert gas might allow the process to begin at higher temperature, thereby significantly reducing the cooling time. Even if rapid cooling does not offer Mo uniformity or microstructural benefits, it could potentially improve throughput that could reduce costs in a manufacturing setting. 
Coupons produced under the study described in Sections 3.1.1 and 3.1.3 could potentially be used for this study if not dedicated to one of the other activities already identified in this plan. Failing that, new coupons would need to be cast, preferably using the down-selected Mo feedstock form and casting process identified during the study described in Section 3.1.1. To evaluate the impact of cooling rate on coupon microstructure, non-destructive analysis including radiography, and destructive analysis including optical metallography, SEM, EDS, XRD, and chemical analysis (ICP-MS, ICP-OES, and/or LECO) to analyze for $\mathrm{Mo}, \mathrm{Si}, \mathrm{Fe}, \mathrm{Zr}$, and $\mathrm{C}$ would be performed. Additional microstructural features of interest would include grain size, microhardness, phase composition, and the presence, size, and distribution of second-phase precipitates.

\subsubsection{Multiple Coupon Casting (1.2.4.1, 1.2.3.2, 1.2.3.3)}

To improve coupon casting efficiency, it is desirable to better match the mass of the as-cast coupons to the mass of the logs that are melted. One way to do this is to cast as many as three to five coupons simultaneously instead of one. This also potentially reduces the need to mix multiple logs to produce coupons, which could improve material traceability. To support initial development of the commercial fabrication facility, a total of 96 depleted uranium-molybdenum (DU-Mo) and 96 low enriched uraniummolybdenum (LEU-Mo) coupons are needed. Each batch of 96 coupons will be divided into subsets that will allow for investigation of different process variables.

The 96 DU-Mo coupons will be divided into two batches. The first batch will consist of 66 coupons fabricated by blending Mo rod feedstock and DU in a log casting. The log casting will be crushed to produce broken metal pieces that will be re-melted and cast into a three-plate mold. A total of 11 castings will be performed resulting in 33 plates from which 66 coupons can be machined. The second batch consists of 30 coupons fabricated by arc-melting DU-Mo (termed uranium-molybdenum feedstock (UMoF)) and then blending with DU and casting directly into the final plate mold, thus omitting the intermediate log casting step. A total of 15 castings will be performed resulting in 15 plates from which 30 coupons can be machined.

Similarly, the 96 LEU-Mo coupons will be divided into two batches of 48 coupons each. One batch of 48 coupons will be cast using the baseline DU-Mo feedstock (a second batch of 48 will be produced using a different DU-Mo master alloy as described in Section 3.1.7). To produce the 48 coupons, five logs will be required (assuming 2.5 as-cast coupons per log). From these five logs, 12 coupons will be cast using the baseline single-plate book mold (i.e., 12 casting runs) and 12 coupons will be cast using a three-plate book mold (i.e., four casting runs).

All as-cast coupons will be machined to 6.25 in. $x 4.00$ in. x 0.125 in. However, if shallow surface defects are present in the as-cast coupons, they can be removed by machining to a minimum thickness of $0.090 \mathrm{in}$. Other relevant requirements on the finished coupons include a surface finish of R63M, $45^{\circ}$ chamfered edges, and meeting the chemical and isotopic specifications defined by SPC-1167 (INL 2011). Data will be collected to correlate the appearance, area, character, and distribution of surface defects with the depth of machining required to eliminate them. These data will help optimize the casting and postcasting machining processes in the future, and they will provide input and benchmark comparisons to computational modeling work being conducted in parallel with the experimental work described above. 


\subsubsection{Separate Alloying and Downblending (1.2.4.4)}

This activity will demonstrate the feasibility of producing a homogeneous DU-14.5 Mo (nominal $\mathrm{wt} \%$ ) master alloy through a two-step melting process. In a subsequent casting process described in Section 3.1.7, the master alloy produced will be down-blended with enriched uranium (EU) to produce LEU-10Mo alloy plates. It is hypothesized that such a master alloy/down-blend approach will avoid some of the problems that currently plague simultaneous alloying and down-blending. There may also be cost benefits realized by performing the initial alloying step in a DU facility. Thus, the outcome of this study may help reduce overall program risk and the challenges encountered with alloying during the EU down-blending step.

The two-step melting process consists of first casting a composite U-Mo electrode by vacuum induction melting (VIM) or fabricating a box electrode from VIM-cast and wrought DU and Mo plate. This is followed by vacuum arc remelting (VAR) of the electrode to produce a final 6 in. diameter $(200 \mathrm{~kg})$ ingot. These ingots will be size reduced to a convenient size for subsequent casting operations. This approach draws on previous experience producing homogeneous U-Nb alloys by a similar process (Cadden et al. 1974).

The two melting activities of this task will examine the following variables to assess the impact on Mo uniformity in the as-cast ingots:

- VAR using two different electrode production methods:

- VIM-cast composite electrode (DU cast around Mo plate)

- Box electrodes (fabricated from VIM melted DU and Mo plate);

- Two variations on VAR process parameters:

- Melting parameters to yield a small melt pool

- Melting parameters to yield a large melt pool

- Single and double VAR

The resulting ingots will be characterized for homogeneity of Mo and for impurity content. Molybdenum distribution will be assessed by performing ICP-MS or ICP-OES as a function of position within the VAR ingot. ICP samples will be taken from the ingot after it is sliced vertically in half, and will be analyzed at center and edge locations at the bottom, center, and top of the ingot (for a total of 9 locations per ingot). Molybdenum distribution will also be assessed as a function of position on the vertical ingot slice using x-ray fluorescence (XRF). Results will be compared with the results taken from log castings as part of the study described in Section 3.1.1.

This activity will also demonstrate that the LEU-Mo master-alloy produced by VIM-VAR can be "down-blended" and rolled (co- and cold-rolled) to produce a U-10Mo foil. U-14.5Mo master alloy taken from one of the VAR ingots will be combined with DU (acting as a surrogate for EU) and VIM cast into three identical 4.331 in. $x 5.906$ in. $x 0.551$ in. coupons. One coupon will be sectioned and chemical analysis (ICP-MS/ICP-OES and XRF) will be performed as a function of position. X-ray fluorescence will be performed in lieu of radiography during this developmental phase. 


\subsubsection{Master DU-Mo Alloy Casting Parameters (1.2.3.2, 1.2.3.3, 1.2.4.4)}

Three separate technologies are being investigated to produce a DU-Mo master alloy that can then be downblended with HEU. The current process involves VIM the DU/NU diluent with HEU. This process currently occurs in a high security facility that is not necessary for work with DU materials. The idea behind utilizing a master DU-Mo alloy is to outsource the production at a current DU vendor or lower security area for the alloying of material with DU/NU and Molybdenum. These types of facilities typically carry a lower overhead and therefore can deliver a better price point for production. Development of master DU-Mo alloy casting parameters and options occurs simultaneously with a number of other WBS elements, including those described in Sections 3.1.5 and 3.1.6.

A VIM/VAR processing route is one technology being investigated to produce a master DU-Mo alloy. This effort was explained in detail in Section 3.1.6.

The second technology consists of alloying DU with Mo only using traditional VIM and casting into 0.5 in. diameter rods. This technology is currently being tested by Aerojet where all necessary process parameters, procedures, etc. to establish the capability to produce UMoF will be developed. The smallest heat for Aerojet is around 500kg, but with current tooling it is expected that $480 \mathrm{lbs}(217 \mathrm{~kg})$ of product in $1 / 2 \mathrm{lb}$. pieces at the conclusion of the development program will be delivered to Y-12 for use as part of WBS element 1.2.3.3 (described in Section 3.1.5). The homogeneity of the delivered product is crucial to the downstream success of foil rolling. Therefore to demonstrate the validity of the Aerojet method it will be necessary to statistically sample the development product at the Aerojet facilities and analyze them analytically at Y-12 for the standard U (10) Mo suite of analysis. It is anticipated a sample size of $n<60$ should adequately represent the population. Once the analytical results are obtained they will be evaluated statistically. Based upon the analytical results obtained by Aerojet as well as the over check performed by $\mathrm{Y}-12$, the validity of the manufacturing process will be demonstrated.

The final technology consists of alloying DU with Mo using traditional arc-melting, resulting in approximately $500 \mathrm{~g}$ UMoF buttons. This technology is currently being tested at Y-12 to develop the necessary parameters, procedures, etc. to supply UMoF for WBS elements 1.2.3.2 and 1.2.3.3 (described in Section 3.1.5).

The parameters and process constraints of each master alloy technology will be evaluated in addition to determining the ease with which the master alloy can be introduced to the downblending process step to cast alloy plates. Any improvements to the Mo homogeneity of the final product and/or reductions in process cost are highly desirable.

\subsubsection{Coupon Machining (1.2.4.5)}

The baseline coupon manufacturing process casts U-Mo plates at $\sim 0.2$ in. thick. The resulting casting is then machined to $0.125 \pm 0.013$ in. thick with a surface finish of $63 \mu \mathrm{in}$ or better. Approximately $35 \%$ of the as-cast material is machined and discarded as scrap in this process step. The basis for the baseline coupon thickness and surface finish requirements is not well defined. However, the current cost to machine a coupon and the amount of scrap generated is incompatible with the long-term goals of the Convert Program. This study will investigate two potential alternatives to the machining process. While some degree of machining will still be required to size the coupon length and width, a majority of the cost 
and scrap is associated with thickness and surface finish requirements. The two alternative processes investigated in this study are:

- Pickling of the cast plate to remove the oxide surface and then bare rolling the plate to the specified coupon thickness and surface finish

- Utilizing a belt sander (also referred to as a "time-saver") to remove thin layers from the surface of the cast plate and then bare rolling the plate to the specified coupon thickness and surface finish

The study will also investigate the feasibility of introducing these two alternative processing options into the baseline LEU-Mo production processes. This initial feasibility study will consider the material requirements, including but not limited to, surface conditions, production capabilities, and throughput analysis, for each alternative process and the baseline process. Each alternative process yields different challenges that must be dealt with. For the pickling process, current production safety basis requirements and equipment availability must be evaluated as well as processes for dealing with the disposition of the pickling solution since it cannot be treated in existing HEU processing streams. For the time-saver process, the feasibility study will include assessments of available equipment, installation of identified equipment into the uranium production facility (i.e., criticality concerns, facility safety concerns, etc.), disposition of the powder generated and potential production impacts. Because the use of a time-saver on radioactive material is not currently an existing capability within the program, the evaluation of this method will be limited to the feasibility study only.

Demonstration of the pickling process will proceed after feasibility has been determined. A total of six plates will be made available from the study, three plates of 0.200 in. thickness and three plates of 0.375 in. thickness. The six plates will be obtained from the unused, non-homogenized plates from the study described in Section 3.1.2 (additional plates taken from the separately-alloyed and down-blended material described in Section 3.1.7 would be of interest as well). One sample from each as-cast plate will be obtained for surface analysis. The sample will be taken from either edge (length-wise) from the plates and will be approximately $1 \mathrm{in}$. wide. With the remaining material, one of the plates will be subjected to pickling. After pickling, a similar 1 in. wide section along the length of the plate will be taken for surface analysis. The plate will be further examined visually noting any discoloration, surface pitting, or other surface defects. Based on dimensional measurements, the plate may require bare hot rolling to the intermediate thickness of 0.130 in. If bare hot rolling is performed, the resultant plates will be examined for thickness variation and surface conditions. A final 1 in. wide section along the length of the as-hotrolled plate will be taken for surface analysis. The remaining castings will be used to evaluate the influence of process parameters on product quality, as necessary.

Dimensional measurements will be obtained after each process step (plate casting, pickling, rolling). Beginning at a reference corner, thickness measurements will be taken at a minimum of $0.25 \mathrm{in}$. intervals along the length in rows spaced $0.5 \mathrm{in}$. apart along the width of the plate. Variability of the plate thickness will be determined from the thickness measurements taken after each process step. Surface analysis of the products will be performed utilizing Secondary Ion Mass Spectrometry, Auger electron spectroscopy, or similar surface science techniques. Specifically, the degree of oxygen (and other notable impurity) contamination as a function of depth into the plate will be noted. These results shall be compared with a baseline machined coupon. Surface finish measurements will also be taken on the plates after each process step. Measurements from this study will be compared to the nominal surface finish for coupons of $63 \mu$ in or better. 


\subsubsection{Rolling Process Modeling (1.2.4.7)}

This study will develop a rolling process model to predict the results of, and evaluate process options for, coupon and foil rolling. This effort will provide guidance to experimental studies on both hot and cold rolling described in Sections 3.2.2 and 4.1.6. The study will evaluate process parameter variations to optimize the baseline reduction process (both hot and cold rolling) from as-cast/as-machined plates to finished U-Mo coupons ready for $\mathrm{Zr}$ co-rolling. In addition, the study will consider the $\mathrm{Zr}$ co-roll bonding process and evaluate parameters for optimizing the reduction of coupons to foils.

\subsubsection{Interrupted Rolling (1.2.4.7)}

A series of interrupted rolling studies will be conducted to evaluate the evolution of coupon geometry and microstructure during hot and cold rolling. Specimens will be evaluated after selected rolling reductions between as-cast/as-machined plates to finished U-Mo coupons ready for $\mathrm{Zr}$ co-rolling. Characterization will include ultrasonic inspections to identify macroscopic defects, optical and scanning electron microscopy (with electron backscatter diffraction, EBSD) to observe grain size and orientation and distribution/composition of second-phase inclusions, and evaluation of surface finish. The study will consider the impact of the various coupon characteristics on downstream processing such as $\mathrm{Zr}$ barrier application and co-rolling to final foil dimensions, and make recommendations for optimized process parameters to improve product quality, increase yield, and/or decrease cost.

\subsubsection{Scrap Recycle (1.2.4.22)}

The baseline U-Mo casting process produces as-cast plates at about 0.2 in. thick. This is a two-step casting process, resulting in $\sim 10 \%$ of the feed material going to skull oxide scrap. The current baseline process uses a band saw to cut the starting coupons, resulting in saw fine scrap, due to the blade, and scrap from excess material around the coupon. The large excess pieces are currently consolidated and recycled. After cutting the starting coupons, the baseline process machines the plate to $0.125 \pm 0.013$ in. with a surface finish of $63 \mu \mathrm{in}$ or better, resulting in a large volume of scrap (approximately $35 \%$ of the cast material is currently discarded as scrap in this process step). The machine turnings and saw fines are currently stored under a coolant due to their pyrophoricity. The amount of scrap generated (that is currently not recycled) and the storage of material under coolant is unacceptable to the long-term sustainability of the program. This study will investigate potential methods to recycle the fine U-Mo scrap material and also to process scrap/waste to a form that is easier to store and subsequently recycle.

Four possibilities for dealing with the skulls, turnings and fines will be studied:

- Briquette and recast the U-Mo alloy as-is

- Briquette and purify through electrorefining to U metal or U-Mo alloy

- Convert to oxide and purify $\mathrm{U}$ by sublimation of $\mathrm{MoO}_{3}$

- Dissolve U and purify by precipitation

The first two methods are the best candidates for the machine turnings, since oxidation rates are lower than $\mathrm{U}$ metal because of the Mo content. The machine turnings will be washed to remove the coolant and other organic contaminants, which would lead to unacceptable carbon contamination or exceed other 
contaminants listed in the specification. The washed chips will be briquetted and the alloy recast from the briquettes. The alloy chemistry will then be sampled. With direct casting, the initial contaminants, carbon and oxide are expected to be high, but the experiment will determine if these exceed specification requirements.

The second method will process the briquettes through the electrorefining and consolidation processes. Electrorefining has been shown to be particularly capable of removing silica and carbon impurities. This experiment will determine the degree of separation of the $U$ and Mo with regard to the proximity of the eletropotentials. The product chemistry will be sampled and compared to specification requirements.

The third method is a good candidate for saw fines and skull oxides. Since the skulls are partially oxidized in processing, the easiest path is to complete the oxidation of the $\mathrm{U}$ and $\mathrm{Mo}$ to $\mathrm{U}_{3} \mathrm{O}_{8}$ and $\mathrm{MoO}_{3}$, respectively. The $\mathrm{MoO}_{3}$ can be sublimed from the uranium at $1150^{\circ} \mathrm{C}$ in an air atmosphere leaving behind purified $\mathrm{U}_{3} \mathrm{O}_{8}$. The oxide chemistry will be sampled and the impurities will be compared to specification requirements. The $\mathrm{MoO}_{3}$ will be disposed of as waste.

The fourth method is also a good candidate for the saw fines and skull oxides. The saw fines and oxides will be dissolved in $\mathrm{HNO}_{3}$. Part of the Mo will precipitate as $\mathrm{MoO}_{3}$ and be removed by centrifugation. The supernatant will be treated with $\mathrm{H}_{2} \mathrm{O}_{2}$ to precipitate the uranium as $\mathrm{UO}_{4}-\mathrm{H}_{2} \mathrm{O}$ that will be converted to $\mathrm{U}_{3} \mathrm{O}_{8}$ in a furnace at $600^{\circ} \mathrm{C}$. The oxide chemistry will be sampled and compared to specification requirements. The $\mathrm{MoO}_{3}$ will be disposed of as waste.

\subsubsection{Microwave Melting (1.2.4.15)}

Historically, microwave melting methods have not been used for uranium alloys because the melting and casting operation is not as turbulent as in VIM casting. The melt pool in microwave casting is relatively quiescent when compared to the electromagnetic stirring achieved in VIM casting. However, it is possible that, if properly mixed, microwave melting might offer some advantages over induction melt casting in Mo uniformity. A study is presently underway to evaluate microwave casting process parameters including filters, inert gas stirring, sequential melting of $U$ and $\mathrm{Mo}$, and alternative crucible materials and coatings (Cook et al. 2012).

\subsection{Coupon Process Alternatives}

There are two principal alternatives under consideration for coupon manufacturing. The first is associated with a streamlined casting process that yields a billet that can be directly reduced by rolling to coupon dimensions. The second has to do with reducing the coupon all the way from an as-cast (in the case of billet casting) or as-cast/as-machined (in the case of the baseline process) dimension to the final U-Mo fuel meat dimension (0.006-0.020 in.). This approach will be necessary if an alternative method to apply the $\mathrm{Zr}$ barrier is identified by the studies described in Section 4.2 (or if future FD irradiation experiments reveal that a $\mathrm{Zr}$ barrier is not required for particular HPRRs). 


\subsubsection{Billet Casting (1.2.4.15)}

The baseline U-Mo casting process produces plates that are about $0.2 \mathrm{in}$. thick. These plates are subsequently machined to $0.125 \pm 0.013$ in. with a surface finish of $63 \mu$ in or better, resulting in high costs and large volume of scrap. One option to improve the process is to cast large slabs, called billets, that subsequently could be rolled to 0.125 in., thereby eliminating much of the costly machining process and significantly improving material yield (see Section 3.2.2).

This study will evaluate billet casting via VIM with following parameters:

- Direct cast with DU and Mo foil (Ar stir after molten)

- Direct cast with DU and Mo pellets (Mo added after DU molten)

- Cast billet with separately-alloyed feedstock as described in Section 3.1.6 (for comparison)

In each case, three castings will be made and sampled to evaluate chemical homogeneity, defects, and second-phase inclusions. An additional six castings will be made using the VIM casting process that yields the best homogeneity of the three approaches. The six castings will be sampled for chemistry and evaluated for homogeneity, inclusions, and defects.

\subsubsection{Billet Rolling (1.2.4.7, 1.2.4.21)}

If direct billet casting proves feasible (see Section 3.2.1), the resulting billets will need to be rolled at least to final coupon dimensions. If one of the alternate $\mathrm{Zr}$ deposition methods proves feasible (see Section 4.1), then the billets will need to be rolled to intermediate or even final foil dimensions. This study will investigate the influence of billet mold thickness on the impurity level and homogeneity of cast billets. In addition, the study will also investigate the influence of billet rolling technique on the final coupon. Unidirectional rolling and cross-rolling will be investigated. Finally, the experiment will examine three different methods of sectioning coupons after rolling. First, six logs will be made to precast the U-Mo material. Three billets will be cast in a 7 in. $x 9$ in. $x 1$ in. mold and rolled in a unidirectional fashion. Three billets will be cast in a 5 in. $x 5$ in. $x 1$ in. mold and rolled in a crossdirectional fashion. Each billet will be examined by radiography and ultrasonic testing (UT) to understand and identify any voids in the castings. It is assumed that each billet will yield a minimum of four coupons. Three different methods of sectioning will be studied including sawing, shearing and EDM. This process time, edge condition and surface condition of the coupons will be evaluated and compared.

To support development of this alternative coupon fabrication process, a computational model will be developed as described in Section 3.1.9 to evaluate rolling process parameters. This model will be applied to the billet casting and bare rolling alternative process in much the same manner as described in Section 3.1.9 for optimization of the baseline coupon reduction process. In addition, the model will be used to evaluate further thickness reduction of the coupons to final U-Mo foil thickness in the event that one or more of the alternative $\mathrm{Zr}$ application processes described in Section 4.2 proves promising. With these processes, it is envisioned that the U-Mo coupon would be reduced from the as-cast plate or billet dimensions to the final fuel meat thickness at which point the $\mathrm{Zr}$ would be applied. 
The experimental interrupted rolling methodology described in Section 3.1.10 will also be applied to evaluating thickness reductions all the way to final U-Mo fuel meat dimensions. Evaluation of the surface finish and microstructure will aid process optimization in conjunction with the understanding gained from the computational rolling model. In this way, process alternatives can be optimized in the event an alternative $\mathrm{Zr}$ application process proves promising.

\subsubsection{Powder Metallurgy Coupon Fabrication}

If an efficient powder metallurgy (PM) processing route could be identified for production of coupons, it could provide benefits that carry all the way through foil and plate fabrication. For example, if coupons could be formed to near-net shape directly, there would be obvious benefits in reducing coupon casting and machining effort. In addition, PM coupon fabrication might offer some advantages to ensuring uniform distribution of Mo and ${ }^{235} \mathrm{U}$, depending on the form of the starting powders. Further, there are some parallels with current dispersion fuel fabrication methods that might streamline process development and fuel qualification efforts. Finally, PM coupon fabrication (i.e., to net shape) would offer obvious benefits for contoured fuel fabrication for HFIR. In addition to these possible advantages, however, such a process might also lend itself to simultaneous, or at least simplified sequential, $\mathrm{Zr}$ coating application. With proper dimensional control, a Zr-coated PM coupon could be directly used in several proposed alternative plate assembly processes such as net-shape hot isostatic press (HIP) bonding (Section 5.2.1) or hot pressing (Section 5.2.2). 


\subsection{Foil Manufacturing Research and Development}

Foil manufacturing encompasses all activities from the finished U-10Mo coupon described in Section 3.0 through the final fuel foil that consists of the U-10Mo fuel meat in its final prototypic dimensions and bonded to a $\mathrm{Zr}$ diffusion barrier. This portion of the baseline manufacturing process is shown in Figure 4.1 and the R\&D activities described in this section are shown in Figure 4.2. The following sections describe $R \& D$ efforts that are needed to optimize the baseline process as well as process alternatives that may offer improvements in quality, repeatability or cost. As described in Section 3.0, numbers in parentheses following some of the subsection headings indicate the Convert Program WBS under which the work is planned. If a subsection does not have a WBS associated with it, it is because this work is not currently included in the Convert Program planning basis. In these cases, inclusion in this document forms the basis for a recommendation to include the work in future FFC scope planning for the reasons described in the subsections below.

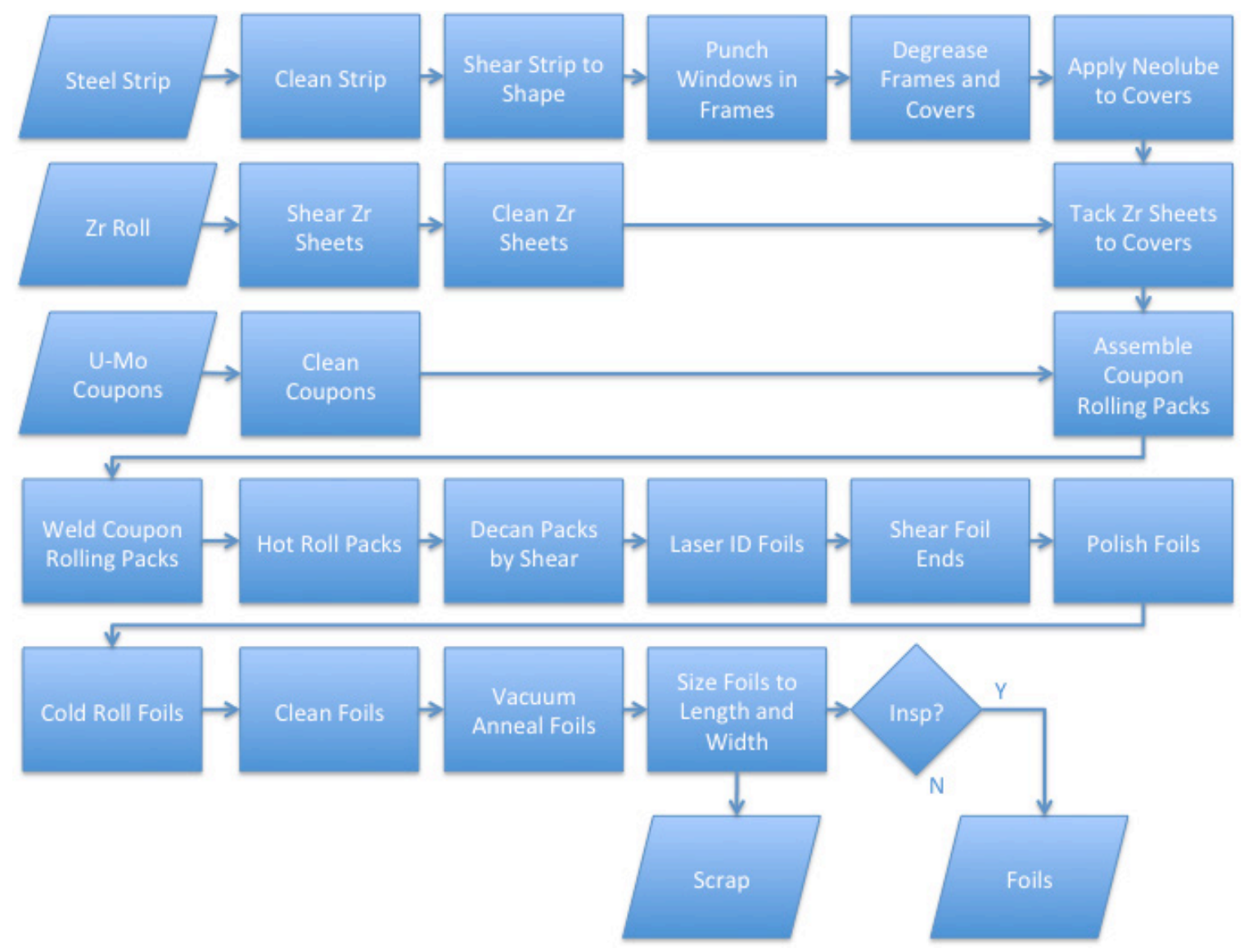

Figure 4.1. Simplified Flow Sheet for Baseline Foil Manufacturing Process 


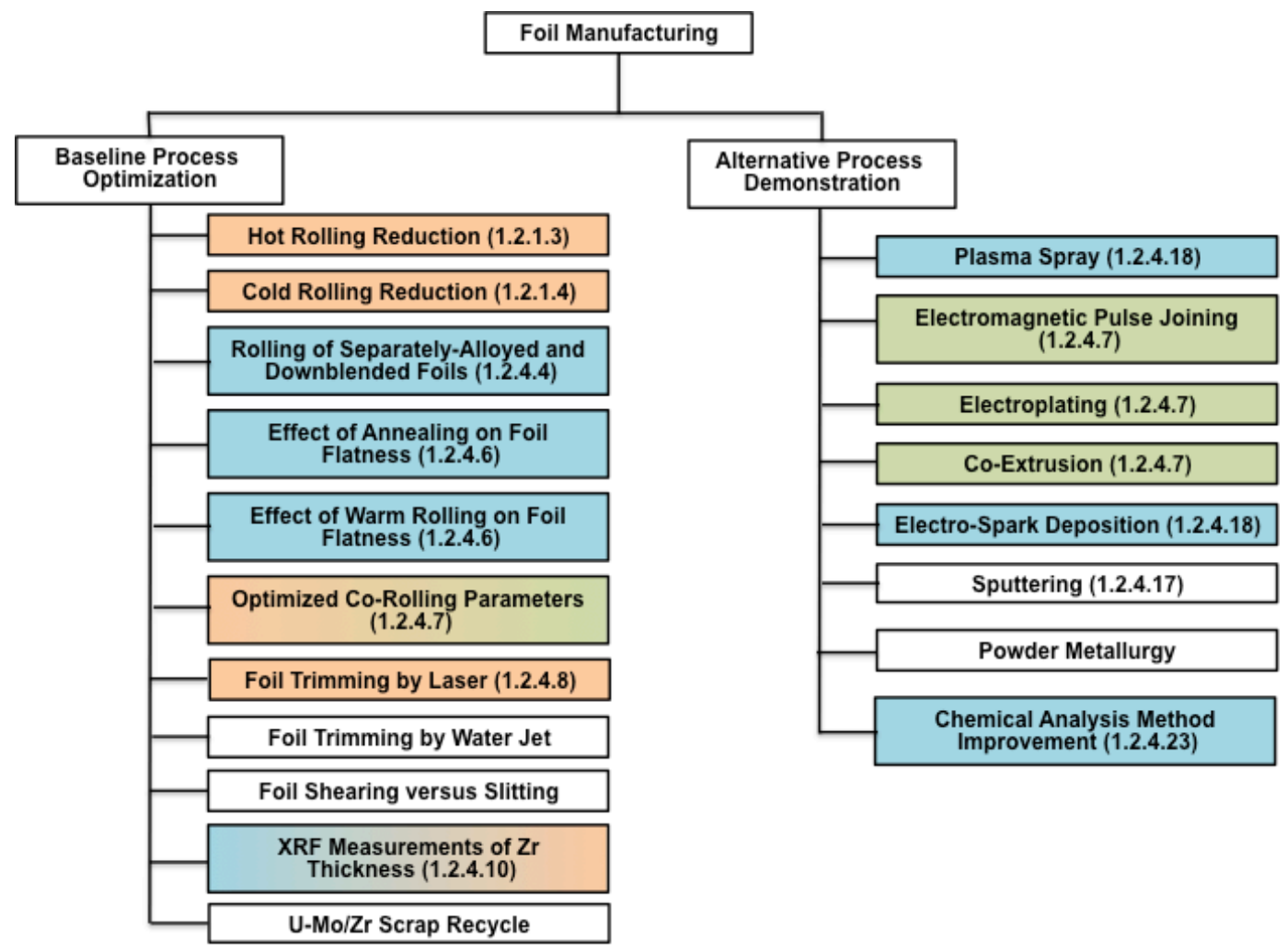

Figure 4.2. FFC Foil Manufacturing R\&D Activities Described in Section 4.0. The colors denote the responsible organization(s) for each activity and correspond to the colors in Figure 1.1. The white boxes denote activities that are recommended but not currently funded.

\subsection{Foil Baseline Process Optimization}

The principal process development needs for foil manufacturing are related to improving as-rolled product consistency, uniform diffusion barrier thickness, acceptable U-Mo and Zr microstructure, foil flatness, and material utilization. Based on the assumption that there is a desirable set of material properties and characteristics (defined by the product specification) that provides the opportunity for good fuel performance as shown in Figure 2.1, the objective of the baseline process optimization studies in the following sections is to identify methods to produce foils in a high yield, low waste, and cost-effective fashion. To this end, consideration will be given both to processing and performance characteristics.

\subsubsection{Hot Rolling Reduction (1.2.1.3)}

This work scope investigates the hot rolling process utilized to bond the $\mathrm{Zr}$ to the U-10Mo alloy and to reduce the machined coupons prepared in the study described in Section 3.1.3 to a standard sheet thickness of $0.040 \mathrm{in.} \mathrm{(} 0.045 \mathrm{in}$. including $\mathrm{Zr}$ ). The series of experiments conducted here involves canning all 32 DU-10Mo coupons prepared in the study described in Section 3.1.3 sandwiched between two layers of $\mathrm{Zr}$ sheet in a mild steel (SAE 1020) can. Since two different plate thicknesses are produced (as a result of the casting experiments in Section 3.1.3 and two different foil thicknesses are needed for the cold rolling studies described in Section 4.1.2, three different $\mathrm{Zr}$ sheet thicknesses are needed to ensure that the final $\mathrm{Zr}$ thickness is nominally the same for each rolled plate (i.e., 0.001 in. thick on either side of the finished foil). 
Before welding the can, the coupons will be cleaned with nitric acid, demineralized water, and ethanol and $\mathrm{Zr}$ foils cleaned using diamond polish and washed with $\mathrm{H}_{2} \mathrm{O}$ and alcohol. The hot rolling schedule will vary depending on the starting plate thickness (i.e., thicker plates will undergo greater reduction with more passes than thinner plates). Hot rolling trials, using (for example) SS coupons, will be performed in order to validate rolling assembly design and develop an effective rolling schedule for 0.325 in. thick coupons. As standard practice, all hot rolling should be done at $650 \pm 10^{\circ} \mathrm{C}$ utilizing a box furnace. No more than six roll passes should be made before a subsequent re-heat of the roll can, unless dictated by the rolling schedule. Each plate within a series of same thickness and with and without homogenization should receive the same amount of hot work, such that statistical information on foil thickness reproducibility can be obtained.

The roll separating force and temperature (entry and exit) for each pass should be measured and recorded using infrared thermometry. At the end of each pass (or at a minimum at the end of each series of passes), the spread (i.e., increase in pack width) of the roll pack should be measured and recorded. Upon completion of the prescribed rolling schedule, the roll pack will be annealed at $650 \pm 10^{\circ} \mathrm{C}$ for 45 minutes, after which the pack is removed from the box furnace and allowed to cool naturally to ambient temperature. The Zr-coated DU-10Mo sheets will be sheared from the roll can and inspected visually for any defects or anomalies. Sheets will be cleaned using ethanol to remove the non-stick Neolube layer applied before hot rolling.

The sheet length and width will be measured. Thickness measurements over the length and width of the sheet will be made. Starting at a reference corner, thickness measurements will be taken at 1 in. spacing along the length, with a minimum of three thickness measurements taken across the width, thus establishing a nominal 1 in. square grid. Variability of the sheet thickness will be determined by comparing the actual thickness measurements to the nominal sheet thickness ( $\sim 0.045$ in. including $\mathrm{Zr})$. A surface roughness gauge may also be used characterize the hot rolled surface.

A visual inspection of the sheet will be conducted and each foil will be weighed after hot rolling. If there is edge cracking, the sheet may be trimmed to remove the cracks (there is no specified trimming dimension). However, if there are no significant edge cracks, the foil will be suitable for the cold rolling study described in Section 4.1.2. One foil per coupon will be produced and within each sample set, three of the resultant foils will progress to cold rolling, while one of the foils will be sacrificed for characterization. Uniformity of the Zr thickness will be performed non-destructively using an XRF technique before cutting samples for destructive analysis. Samples for metallography and microhardness will be sectioned from the sacrificial foil at a minimum of three locations (i.e., both ends of the foil and the center) in both the transverse and longitudinal direction. Optical microscopy will be utilized for performing a "feature survey" of each foil sample. Namely, identification of atypical foil features such as voids, inclusions, etc. Optical microscopy will also be used for evaluating the thickness uniformity of the $\mathrm{Zr}$ layer and for performing an average grain size analysis of the DU-10Mo alloy (note any rollinginduced banded microstructure may make measurements of grain size challenging). Optical metallography Zr thickness measurements will be compared to XRF measurements performed in the same region as the met sample to validate the non-destructive technique. Variations in composition and/or decomposition should be determined via optical microscopy, SEM, and EDS. A minimum of three tensile test specimens both in the transverse and longitudinal direction will be prepared from the sacrificial foil in the same locations as the metallographic samples. The scrap generated from the shearing process will be weighed and labeled accordingly (for each sample) and will be retained 
throughout the duration of the study. The scrap may be needed for additional characterization later in the R\&D program, depending on the results of subsequent studies.

\subsubsection{Cold Rolling Reduction (1.2.1.4)}

This work scope investigates the cold rolling process utilized to uniformly reduce the Zr-coated DU10Mo monolithic foils prepared in the hot rolling study (Section 4.1.1) to a final specified thickness. The series of experiments conducted here will involve cold rolling the 24 foils produced from hot rolling in the study described in Section 4.1.1 to two nominal final thicknesses, $0.009 \mathrm{in}$. and $0.022 \mathrm{in}$. The starting foil thickness that will be cold rolled is nominally $0.045 \mathrm{in}$. Longer starting foils will be cold-rolled to the 0.022 in. thickness, while shorter starting foils will be cold-rolled to the 0.009 in. thickness. As a result of utilizing different initial $\mathrm{Zr}$ layer thicknesses, the final $\mathrm{Zr}$ thickness on either side of the foil should nominally be $0.001 \mathrm{in}$. after cold rolling.

For each cold rolling campaign, the number of cold roll passes given to each foil with each nominal target thickness will be similar. However, it is noted that the foils with a thinner nominal target thickness will receive more cold work than those foils with a thicker nominal target thickness; observations of processing behavior differences will be documented. The length and width of each foil will be measured after completing cold rolling. Starting at a reference corner, thickness measurements will be taken at 1 in. spacing along the length, with a minimum of three thickness measurements taken across the width, thus establishing a nominal $1 \mathrm{in}$. square grid. Variability in the foil thickness will be determined by comparing the actual thickness and the prescribed nominal foil thickness (either $0.022 \mathrm{in}$. or $0.009 \mathrm{in}$ ). The foils will be sheared to $25 \mathrm{in}$. long; thus, $2-25 \mathrm{in}$. finished foils will be prepared from each cold rolled foil. One of the foils from each batch will be sacrificed for characterization. Foils will nominally be $3 \mathrm{in}$. wide representing the median HPRR foil width.

Radiographic measurements will be performed on each foil (24 foils total). Radiograph thickness measurements shall be acquired as near as possible to locations of physical thickness measurements for comparison to metallographic and bulk thickness measurements. A visual inspection of the foils will be conducted and each foil will be weighed after cold rolling and trimming. If there is edge cracking, the foil may be trimmed to remove the cracks (there is no specified trimming dimension). However, if there are no significant edge cracks, the foil will be suitable for the HIP bonding study described in Section 5.1.1. Uniformity of the $\mathrm{Zr}$ thickness will be performed non-destructively using an XRF technique before cutting samples for destructive analysis.

Samples for metallography and microhardness will be sectioned from the sacrificial foil at a minimum of three locations (i.e., both ends of the foil and the center) in both the transverse and longitudinal direction. Optical microscopy will be utilized for performing a "feature survey" of each foil sample. Namely, identification of atypical foil features such as voids, inclusions, etc. Optical microscopy will also be used for evaluating the thickness uniformity of the $\mathrm{Zr}$ layer and for performing an average grain size analysis of the DU-10Mo alloy (note any rolling-induced banded microstructure may make measurements of grain size challenging). Optical metallography $\mathrm{Zr}$ thickness measurements will be compared to XRF measurements performed in the same region as the met sample to validate the nondestructive technique. Variations in composition and/or decomposition should be determined via optical microscopy, SEM, and EDS. A minimum of three tensile test specimens both in the transverse and longitudinal direction will be prepared from the sacrificial foil in the same locations as the metallographic 
samples. The scrap generated from the shearing process will be weighed and labeled accordingly (for each sample) and will be retained throughout the duration of the study. The scrap may be needed for additional characterization later in the R\&D program, depending on the results of subsequent studies.

\subsubsection{Rolling of Separately-alloyed and Downblended Foils (1.2.4.4)}

Using the coupons produced in the separate alloying and downblending study described in Section 3.1.6, two foil rolling processes will be studied. One coupon will be machined, canned, co-rolled, then decanned and cold rolled. Another coupon will be homogenized after casting, bare rolled, machined, canned, co-rolled, then decanned and cold rolled. The resulting foils will be inspected for defects and radiographed for low density defects. Results obtained from these activities will be compared with results obtained as part of the studies described in Sections 3.1.4, 4.1.1, and 4.1.2 to evaluate the effect of the separate alloying and downblending steps on downstream foil processing.

\subsubsection{Effect of Annealing Parameters on Foil Flatness (1.2.4.6)}

Experience with the AFIP-7 and RERTR-FE foils has demonstrated a tendency for foils to curve after cold co-rolling. Furthermore, coiling foils for subsequent shipment resulted in unexpected cracking. One contributing factor to these experiences and observations may have been the amount of cold work imparted into the foils, which currently is not specified. The rolling schedule for those experiments produced roughly $65 \%$ cold work in the foils as compared to $25 \%$ cold work produced by the "reference" rolling schedule originally developed by FD. The main driver for this deviation was the limitation of production-scale processing equipment. Whether or not the eventual product specification allows this range of cold work for a given final foil thickness, some flexibility will be needed to obtain the full range of prototypic foil thicknesses from a "standard" rolling coupon size. Further, final foil trimming to the tight tolerances proposed to date will be much more successful for fully flat foils than those with curvature. A connection between foil flatness before HIP bonding and difficulty in machining the cladding to achieve dimensional tolerances without violating minimum cladding thickness requirements has also been hypothesized.

Annealing in vacuum has been suggested as one way to help reduce curvature and flatness issues in cold co-rolled foil. It has also been suggested as a way to increase process yield for rolling the foil to the $0.007 \mathrm{in}$. fuel meat thickness being considered for some of the U.S. HPRRs. Annealing is also commonly used in metals processing to help remove non-uniform plastic deformation such as kinks, bends and twists, sometimes in combination with mild stress from a metal weight placed on the foil. Optimum annealing temperature (in vacuum) has not been established to date.

This study will look at the effect of five different annealing conditions ( $1 \mathrm{hr}$ at 600,650,700, 750, and $800^{\circ} \mathrm{C}$ ) on the flatness of co-rolled foils having five different levels of cold work (nominally 5, 25, 50,65 , and $75 \%$ reduction in thickness). The shape of the foils will be qualitatively assessed before and after annealing. The effect of coiling after annealing will be evaluated by examining the foils for cracks or other macroscopic damage. The U-Zr interfaces will be characterized by optical and scanning electron microscopy to determine the effect of annealing on the interface structure. Foils produced by this effort that are not dedicated to destructive analysis may be utilized in other optimization and demonstration activities. 


\subsubsection{Effect of Warm Rolling on Foil Flatness (1.2.4.6)}

As a complement to the cold co-rolling and annealing study described in Section 4.1.4, the effect of warm co-rolling at $250^{\circ} \mathrm{C}$ on foil flatness will be evaluated and compared to cold co-rolling. The U-Zr interfaces will be characterized by optical and scanning electron microscopy to determine the effect of warm rolling on the interface structure. In addition, the foils will be evaluated for surface finish, thickness, and residual stress.

\subsubsection{Optimized Co-rolling Parameters (1.2.4.7)}

This study seeks to optimize the existing $\mathrm{Zr}$ co-roll bonding process parameters to improve fabrication performance and guide manufacturing of test articles for upcoming irradiation experiments. Alloy coupons for this study will be prepared via surface machining of vacuum annealed alloy plate material; $\sim 0.130$ in. thick plate will be sectioned into coupons for the rolling study. Four DU-10Mo coupons (3.5 in. $\mathrm{x} 5 \mathrm{in}$.) will be used for the study. For the initial "first round" component of the study, two of the large coupons will be sectioned into four samples each. Remaining large coupons will be used in second round scale-up experiments; additional coupons may become available via other FFC R\&D studies described in Section 3.0.

The first round of experiments will focus on hot rolling reduction factor $(2.5 \mathrm{x}, 4 \mathrm{x}, 7.5 \mathrm{x})$, time at elevated temperature $\left(650^{\circ} \mathrm{C}\right)$, and typical vs. aggressive rolling. The cold rolling component of the first round study will involve typical, skin, and aggressive per-pass cold rolling schedules. Cold rolled foils will not be annealed after cold rolling. Characterization of the cold rolled foils will include x-radiography to evaluate fuel meat homogeneity, dimensional measurements to evaluate foil thickness uniformity and flatness, optical microscopy to investigate $\mathrm{Zr}$ thickness uniformity, U-Mo and $\mathrm{Zr}$ grain size and orientation, and defects (second-phase inclusions, cracks, etc.), SEM to observe the condition of the U-Zr interaction layer, microhardness to characterize localized mechanical properties of the U-Mo and $\mathrm{Zr}$, and tensile testing to characterize bulk mechanical properties of foils.

Based on results of the first round, and using input from the rolling model developed by the study described in Section 3.1.9, a second round test matrix will be formulated after identifying the most promising process parameters explored during the first round. The focus of the second round of experiments will be to fine-tune these process parameters to yield flat foils of uniform thickness (including Zr barrier thickness), minimization or elimination of macroscopic foil defects (e.g., edge cracking, Zr barrier layer debonding), and maximized yield/minimized processing cost.

Other parameters that will be computationally investigated using the model developed in the study described in Section 3.1.9 include evaluation of alternative rolling can (i.e., picture frame) materials to better match the mechanical properties of the foil materials, alternative rolling can end configurations, and alternative rolling can designs. As part of these efforts, better mechanical properties data (e.g., compression data to yield flow stresses and hot XRD to understand time-temperature-transformation relationships in the U-10Mo alloy) will be generated to provide input into process parameter selection and mechanical modeling studies. Finally, computational evaluation of rolling mill parameters such as roll size and rolling speed will be conducted in an effort to better match the mill to the materials being reduced. 


\subsubsection{Foil Trimming by Laser (1.2.4.8)}

The baseline process of trimming foils to shape via mechanical shearing is known to produce undesirable mechanical deformation and a shear lip along the cut edge that causes a poor fit with the pocket machined in the Al clad. This study will compare dimensional accuracy, cut quality and reactivity of sheared edges of Zr-clad stainless steel foil surrogates with those produced by laser processing. The objective of this study is to identify improvements in dimensional control of foil edges, and reduced damage and reactivity of the U-Mo fuel meat with the $\mathrm{Zr}$ barrier and Al 6061 cladding. The study will also consider how to address $U$ accountability with regard to process losses in a manufacturing setting. Laser cutting can be accomplished in at least two modes: ablation and melting with liquid expulsion. In this study, laser ablation will be optimized with the surrogate materials and then down-selected for subsequent development. Specific experimental goals include optimizing the laser cutting parameters to achieve dimensional and mass tolerances while minimizing kerf and heat damage to surrounding material, adapting the parameters for use with a range of foil thicknesses, and identifying methods for dealing with $\mathrm{U}$ vapor produced during cutting. Surrogate foils will also be sheared in this part of the study, and dimensional accuracy and cut quality will be compared to the laser cut surrogate foils. The process will then be demonstrated on Zr-clad U-Mo foils for subsequent use in evaluating plate manufacturing via can-less HIP (see Section 5.1.4) and subsequent laser cutting of plates (see Section 5.1.5).

\subsubsection{Foil Trimming by Water Jet}

A possible alternative to the shearing process currently used to trim foils to shape is water jet cutting. This process is used commercially in a variety of industries for cutting materials including food, leather, polymers, metals/alloys, and engineered and natural (e.g., granite) ceramics. Commercially-available water jet cutting systems range in size from a few square feet to hundreds of square feet, so the process is amenable to full-size foil (or plate) trimming. The process produces no heat-affected zone in the workpiece. There are a number of process parameters that require investigation including working pressure, desirability of using abrasives or pure water, nozzle size and design, cutting speed, distance from nozzle to workpiece (affects kerf), and positioning accuracy and precision (i.e., repeatability). The study would also need to consider how to address $U$ accountability with regard to process losses in a manufacturing setting.

\subsubsection{Foil Slitting}

Foil slitting is a modest variation of the foil shearing that has been employed at the bench scale to fabricate experimental test foils to date. Slitting offers an advantage over raw shearing in that a higher productivity can be achieved and foils can be sized to width simultaneously, as opposed to sequential shearing each side of the foil separately. Slitting is especially attractive for the processing of longer fuel foils (24 - 48 in.) where the foil may have a tendency to walk during a pure mechanical shearing operation, resulting in non-uniform widths. A foil slitter has been procured and is awaiting installation in the pilot-production line being established at Babcock \& Wilcox. Preliminary studies have been completed by FD on a similar piece of equipment located at INL. It is not anticipated that a significant amount of R\&D will be required to prove-in a foil slitting method, but to date, the process has not been demonstrated. 


\subsubsection{X-Ray Fluorescence Measurements of Zr Thickness (1.2.4.10)}

After $\mathrm{Zr}$ co-rolling, the thickness of the foil must be measured and the foil must be inspected for gross material density variations, voids, and inclusions. The most appropriate method for the thickness and density measurements over large areas is moderate-energy $(160 \mathrm{kV})$ digital radiography. However, the thickness of the $\mathrm{Zr}$ barrier must be known to within $\pm 0.0002 \mathrm{in}$. because the $\mathrm{Zr}$ affects the $\mathrm{x}$-ray attenuation. An XRF method has been demonstrated to measure the $\mathrm{Zr}$ thickness between $0.0005 \mathrm{in}$. and $0.002 \mathrm{in}$. with resolution of $0.0001 \mathrm{in}$. This technique is fast (10s), accurate, portable (can be handheld) and measures the coating thickness with a $0.2 \mathrm{in}$. diameter spot size. The goal of this study is to develop and validate measurement techniques that can be used in foil manufacturing to determine $\mathrm{Zr}$ thickness. The feasibility of the technique has already been demonstrated, and the present study is focused on calibration and demonstration in a foil manufacturing context. The system will also be used in conjunction with plate manufacturing (see Section 5.1.6).

\subsubsection{U-Mo/Zr Scrap Recycle Process Development}

A study is currently underway to support U-Mo coupon scrap recycle process optimization (see Section 3.1.11), and an initial feasibility study has been done to evaluate foil scrap recycle. While feasibility was demonstrated, there are outstanding issues with regard to product purity and process details associated that require further investigation. Recycling of foils is complicated relative to coupons by the addition of $\mathrm{Zr}$ to the U-Mo coupons. Scrap produced during trimming or by rejected foils must be separated into the U-Mo and $\mathrm{Zr}$ constituents (or U, Mo, and $\mathrm{Zr}$ constituents) before it can be recycled. A further complication is that the $\mathrm{U}-\mathrm{Mo}$ (or $\mathrm{U}$ and $\mathrm{Mo}$ ) separated from the $\mathrm{Zr}$ must be recycled into coupon manufacturing, which is performed by a different organization than foil manufacturing. Therefore, the two organizations must work together to ensure the recycle products meet the necessary feed material requirements. Many of the foil process alternatives discussed in the following section address this very issue by attempting to minimize the process steps after the $\mathrm{Zr}$ is applied to the U-Mo coupon (e.g., by applying the $\mathrm{Zr}$ coating after the U-Mo coupon is rolled to the final fuel meat thickness) to improve yield and reduce scrap. If the $\mathrm{Zr}$ deposition process alternatives discussed in Section 4.2.1 are unsuccessful and co-rolling is the method selected in the final fuel fabrication downselection, then a better defined method for separating and recycling the enriched $U$ will be required to minimize waste to the extent possible.

\subsection{Foil Process Alternatives}

The principal foil manufacturing process alternatives are focused on improved methods for depositing the $\mathrm{Zr}$ diffusion barrier on the U-Mo fuel meat. This is perhaps the most problematic aspect of the baseline HPRR fuel manufacturing process. This process is time-consuming and expensive, but it also has proved problematic in terms of ensuring consistent product quality. There are many issues associated with the foils that are addressed by the optimization studies described in Section 4.1, and it is possible that optimization of the process can improve product quality and consistency. However, one aspect of the co-roll bonding process that cannot be optimized in this fashion is material utilization (i.e., yield). When the co-rolled foils are trimmed, the excess material consists of $\mathrm{Zr}$ diffusion bonded to the U-Mo fuel meat. Thus, the $\mathrm{Zr}$ and U-Mo cannot be easily separated and recycled. The current baseline process is estimated to produce over $750 \mathrm{~kg} / \mathrm{yr}$ of $\mathrm{U}-\mathrm{Mo} / \mathrm{Zr}$ scrap in full production. As discussed in Section 4.1.11, currently there is no scrap recycle process to remove the $\mathrm{Zr}$ from the U-Mo, and development of such a process is complicated by the very nature of the diffusion bond between the $\mathrm{Zr}$ and the U-Mo. Therefore, it is likely 
that the co-roll bonding process will result in significant waste, which is problematic both in terms of low yield on finished foils, but also poor utilization of scarce resources (i.e., LEU-Mo).

\subsubsection{Alternative Zr Application Methods}

The goal of the studies described in the following subsections is development of a process to apply the $\mathrm{Zr}$ to a U-Mo coupon of final (or near-final) dimensions (i.e., 0.006 in. to 0.020 in.). Replacing coroll bonding of $\mathrm{Zr}$ to U-Mo with an alternative method will simplify the rolling process (no canned rolling), possibly resulting in higher yield, better control of foil dimensions and mass, and reduced waste (no rolling cans). This could potentially address not only the scrap and material utilization issues, but also provide a process better suited to producing high quality, repeatable $\mathrm{Zr}$ dimensions and microstructure. A further advantage of some of the alternative processes is that they could potentially be applied to contoured fuel shapes such as those required for HFIR. A challenging requirement for any alternative process is to produce a strong bond between the $\mathrm{Zr}$ and U-Mo fuel meat while minimizing formation of intermetallic phases that may trap fission gases and lead to clad debonding (i.e., blisters or pillowing).

\subsubsection{Plasma Spray (1.2.4.18)}

Plasma spraying is being considered as a means of applying diffusion barrier materials ( $\mathrm{Zr}$ and $\mathrm{Mo}$ ) to the U-Mo fuel meat. In addition, plasma spraying can be used to deposit Mo as a diffusion barrier that has the added advantage of lower cost fuel recycle than fuel with the $\mathrm{Zr}$ diffusion barrier. Zirconium and molybdenum plasma sprayed diffusion barriers were previously demonstrated on "mini-plates" of 1 in. $x$ 4 in. $x 0.15$ in. size but need to be demonstrated on a larger scale to evaluate the feasibility of the process for production.

This work scope will utilize as-cast plates from the studies described in Sections 3.1.5 and 3.1.7 that are not selected for other purposes. At least one as-cast plate will be used to produce processing a minimum of three DU-10Mo foils (i.e., no Zr interlayer). Spraying of Zr on surrogate material will precede the coating of the DU-10Mo foils. Characterization of the plasma sprayed foils will include microscopy and surface condition, including thickness and roughness of the applied barrier.

Measurement of bond strength via existing techniques is of interest. The plasma spray coating process will then be scaled up to produce 24 in. long foils for subsequent application of Al 6061 cladding via HIP (see Sections 5.1.3 and 5.1.4).

The study will evaluate applying the diffusion barrier to the foil edges via plasma spray. The study will also evaluate plasma spray coatings on contoured foils (using surrogate materials), including methods to use flat rolls in conjunction with contoured $\mathrm{Zr}$ coatings to produce the desired finished foil geometry. Another aspect of complex fuel to be considered in this study is deposition of burnable poisons (e.g., Hf, $\mathrm{B}, \mathrm{B}_{4} \mathrm{C}, \mathrm{Gd}_{2} \mathrm{O}_{3}$ ) onto the foil in conjunction with $\mathrm{Zr}$ deposition by plasma spray. Specifically, the study will evaluate the concentration of poison deposited with the $\mathrm{Zr}$ and retained in the final coating, and spatial variations in poison concentration. Finally, the study will consider using $\mathrm{Zr}$ wire as a feed material for plasma spraying instead of powder. The advantages are higher purity, safer handling, and possibly more accurate feed rate control. 


\subsubsection{Electromagnetic Pulse Joining (1.2.4.7)}

A feasibility study will be performed to evaluate the applicability of the electromagnetic pulse joining (EPJ) method for depositing $\mathrm{Zr}$ on U-Mo coupons. The EPJ process utilizes a rapid discharge of a capacitor bank to produce a locally intense magnetic field that is directed via careful tooling design into a workpiece to create high velocity motion over very short time periods $(<1 \mathrm{~ms})$. The workpiece (in this case, $\mathrm{Zr}$ foil) is directed toward a substrate material with which it mechanically or metallurgically bonds due to the high velocity imparted (up to $300 \mathrm{~m} / \mathrm{s}$ ). Ideally, the workpiece is highly conductive so that it responds strongly to the electromagnetic pulse; however, poor conductors can also be accelerated via the use of a conducting driver plate. The EPJ method is used commercially for forming high-conductivity materials such as $\mathrm{Al}$ and $\mathrm{Cu}$ (e.g., expanding or shrinking cylindrical tubing to size), and it is used to join dissimilar materials that cannot be welded.

Initial feasibility of the EPJ process will be evaluated by depositing $\mathrm{Zr}$ foil on a stainless steel surrogate substrate. At least two methods will be considered, including displacement of the $\mathrm{Zr}$ foil via electromagnetic force using a driver plate, and direct displacement of the $\mathrm{Zr}$ foil via electrohydraulic force. The $\mathrm{Zr}$ foil motion will be characterized using high-speed cameras, and process parameters will be varied to investigate their effect on bond integrity and uniformity. The resulting coatings will be characterized using optical microscopy and SEM/EDS/EBSD, as necessary, to evaluate bond integrity and microstructure.

\subsubsection{Electroplating (1.2.4.7)}

A feasibility study will be performed to evaluate the applicability of electrochemical methods for depositing $\mathrm{Zr}$ on U-Mo coupons. Because of the reactivity of $\mathrm{Zr}$, a traditional aqueous electrolyte cannot be used. The electrolytes used to deposit $\mathrm{Zr}$ are mixtures of $\mathrm{ZrF}_{4}$ and alkali flourides (in the case of this study, $\mathrm{LiF}-\mathrm{NaF}-\mathrm{ZrF}_{4}$ ). The workpiece is used as the cathode, and a carbon electrode is inserted into the molten salt to serve as the anode. By controlling temperature and current density, the $\mathrm{ZrF}_{4}$ is disassociated, resulting in the $\mathrm{Zr}^{4+}$ ions traveling to the workpiece where they are deposited in a coating layer. If properly controlled, the coatings can be very dense and uniform in thickness. Atmosphere control is very important to the quality of the deposited $\mathrm{Zr}$ coating, with oxygen and water contents as low as possible. The electroplating process results in a mechanical bond, so it avoids formation of intermetallic layers between the $\mathrm{Zr}$ and U-Mo.

Initial feasibility of the electroplating process will be evaluated by depositing $\mathrm{Zr}$ on a stainless steel surrogate substrate. Process characteristics such as temperature, current density, and time will be evaluated for their effect on coating microstructure. As with most electroplating process, surface preparation is key to ensuring good adhesion and uniform coatings. Accordingly, a variety of surface preparation techniques will be evaluated. The resulting coatings will be characterized using optical microscopy and SEM/EDS/EBSD, as necessary, to evaluate bond integrity and microstructure. Simple adhesion tests will also be performed to ensure an adequate mechanical bond.

\subsubsection{Co-Extrusion (1.2.4.7)}

A feasibility study will be performed to evaluate the applicability of co-extrusion to produce $\mathrm{Zr}$ coated U-Mo coupons. Zirconium-clad U metal fuels have a significant high-volume manufacturing history (e.g., for Pu production reactor fuel at the Hanford Site). However, the addition of $10 \mathrm{wt} \% \mathrm{Mo}$ 
results in a significantly higher strength alloy than $\alpha-U$, requiring higher forces for extrusion. The mechanical properties testing effort described in Section 4.1.6 will provide input to the co-extrusion study to enable proper selection of equipment and process parameters.

Initial feasibility will be evaluated by co-extruding $\mathrm{Zr}$ on a stainless steel surrogate substrate in a cylindrical geometry. The extrusions will then be reduced in size via hot and cold rolling to thickness dimensions representative of finished foils. The study will consider a number of process parameters including extrusion temperature, force, speed, choice of lubricants (e.g., glass or polymer-based), hot and cold rolling reductions, and intermediate anneals. The resulting coatings will be characterized using optical microscopy, SEM/EDS/EBSD, and XRD to evaluate bond integrity, coating thickness uniformity, and microstructure of the coating and substrate.

\subsubsection{Electro-spark Deposition (1.2.4.18)}

There is some concern within FD that diffusion bonding of the U-Mo fuel meat to the $\mathrm{Al} 6061$ cladding along the foil edges could be problematic with respect to fission gas accumulation, swelling, and cracking during irradiation. Some of the alternative $\mathrm{Zr}$ deposition techniques are amenable to coating edges to final dimensions while others are not. Further, if the current baseline process of Zr co-roll bonding can be optimized sufficiently the edges will still have no barrier coating. The electro-spark deposition (ESD) process is being considered for applying a diffusion barrier material (e.g., Zr) to finished foil edges in conjunction with either co-rolled $\mathrm{Zr}$ or one of the alternative deposition methods. The ESD process is akin to welding in which a consumable electrode is used to deposit the electrode material with very precise position control, which makes it attractive for the thin edges of fuel foils. Like welding, ESD creates a metallurgical bond that must be evaluated for its potential impact on fuel performance. The thickness, density, roughness and diffusion layers with surrogate fuel foils will be characterized.

\subsubsection{Physical Vapor Deposition (1.2.4.17)}

Physical vapor deposition (PVD) offers another option for depositing $\mathrm{Zr}$ on U-Mo coupons in their final dimensions (i.e., 0.006-0.020 in. thick). There are two approaches for producing PVD coatings, evaporation and sputtering. In evaporation, a solid or molten coating material is sublimed or evaporated by application of localized heating (via electrical resistance, laser, electron beam, etc.) and deposited on an appropriately positioned substrate. In sputtering, a solid target composed of the coating material is bombarded with ions to eject atoms that are then deposited on the substrate. Because of the high vapor pressure and reactivity of $\mathrm{Zr}$, sputtering may be more suitable for diffusion coatings on U-Mo fuel. Both methods are typically conducted under high vacuum, requiring large coating chambers for full-size (48 in. long) foils. Deposition rates are relatively slow and line-of-sight, but advantages of PVD methods include high coating density, fine grain structure, and good thickness uniformity (given proper control in the orientation of source and substrate). Another advantage for the HPRR fuel application is that these methods are typically conducted at or near room temperature, resulting in little diffusion between coating and substrate materials. As with most coating methods, proper attention to substrate surface preparation is required to ensure adequate adhesion.

This study would conduct a feasibility investigation into PVD (both evaporation and sputtering) as a means of applying $\mathrm{Zr}$ diffusion barriers to U-10Mo fuel foils. The study would also include an evaluation of appropriate coating systems for both development work and, if proven feasible, production-scale manufacturing. 


\subsubsection{Zr Deposition on Powder Metallurgy Coupons}

If a suitable process can be developed for producing PM coupons, particularly if it produces near-netshape coupons, some of the alternate $\mathrm{Zr}$ deposition techniques discussed in the previous sections should be evaluated for applicability. However, another possibility is the use of PM methods to deposit the $\mathrm{Zr}$ also, either simultaneous with coupon forming, or in a subsequent operation. Such an approach offers potential benefits not only to coupon and foil fabrication, but also to plate fabrication as described in Section 3.2.3.

\subsubsection{Chemical Analysis Method Improvement (1.2.4.23)}

The femtosecond laser ablation inductively-coupled plasma mass spectrometry (FLA-ICP-MS) method for characterizing chemical composition offers some advantages over existing baseline techniques (e.g., ICP-MS or ICP-OES). The advantages for nuclear fuel characterization include 1) elemental characterization of both bulk and trace composition, 2) isotopics of major elements, 3) rapid analysis, 4) little to no sample preparation, 5) depth profiling, 6) homogeneity of sample, and 7) high accuracy and precision analyses. Conventional methods of analysis require significant sample preparation involving dissolution of the specimen and eventual measurement for composition and isotopics. FLA-ICP-MS avoids time-consuming sample preparation by directly sampling the specimen and rapidly providing elemental composition and isotopics. The utilization of femtosecond laser ablation offers reduced matrix dependence, quantitative sampling and highly accurate analysis of the sample.

This study will demonstrate the feasibility of using FLA-ICP-MS to characterize DU-10Mo and LEU10Mo foils for elemental composition and $\mathrm{U}$ isotopics. These foil samples will include the $\mathrm{Zr}$ barrier coating and will offer a good test of the depth profiling and quantitative capabilities of the instrument. The primary focus of this effort will be demonstrating accuracy and precision of the technique using both a known cast alloy reference material as well as exploring low volume deposition technology for calibration. In addition, conventional laser ablation ICP-MS and high resolution ICP-MS with sample dissolution will be conducted to compare with the performance of the FLA-ICP-MS instrument. 


\subsection{Plate Manufacturing Research and Development}

Plate manufacturing encompasses all activities from the finished $\mathrm{Zr}$-coated U-10Mo foil described in Section 4.0 through to the final Al 6061-clad fuel plate in its final dimensions. This portion of the baseline manufacturing process is shown in Figure 5.1 (HIP can assembly) and Figure 5.2 (plate manufacturing), and the $R \& D$ activities described in this section are shown in Figure 5.3. The following sections describe R\&D efforts that are needed to optimize the baseline process as well as process alternatives that may offer improvements in quality, repeatability or cost. As described in Sections 3.0 and 4.0, numbers in parentheses following some of the subsection headings indicate the Convert Program WBS under which the work is planned. If a subsection does not have a WBS associated with it, it is because this work is not currently included in the Convert Program planning basis. In these cases, inclusion in this document forms the basis for a recommendation to include the work in future FFC scope planning for the reasons described in the subsections below.

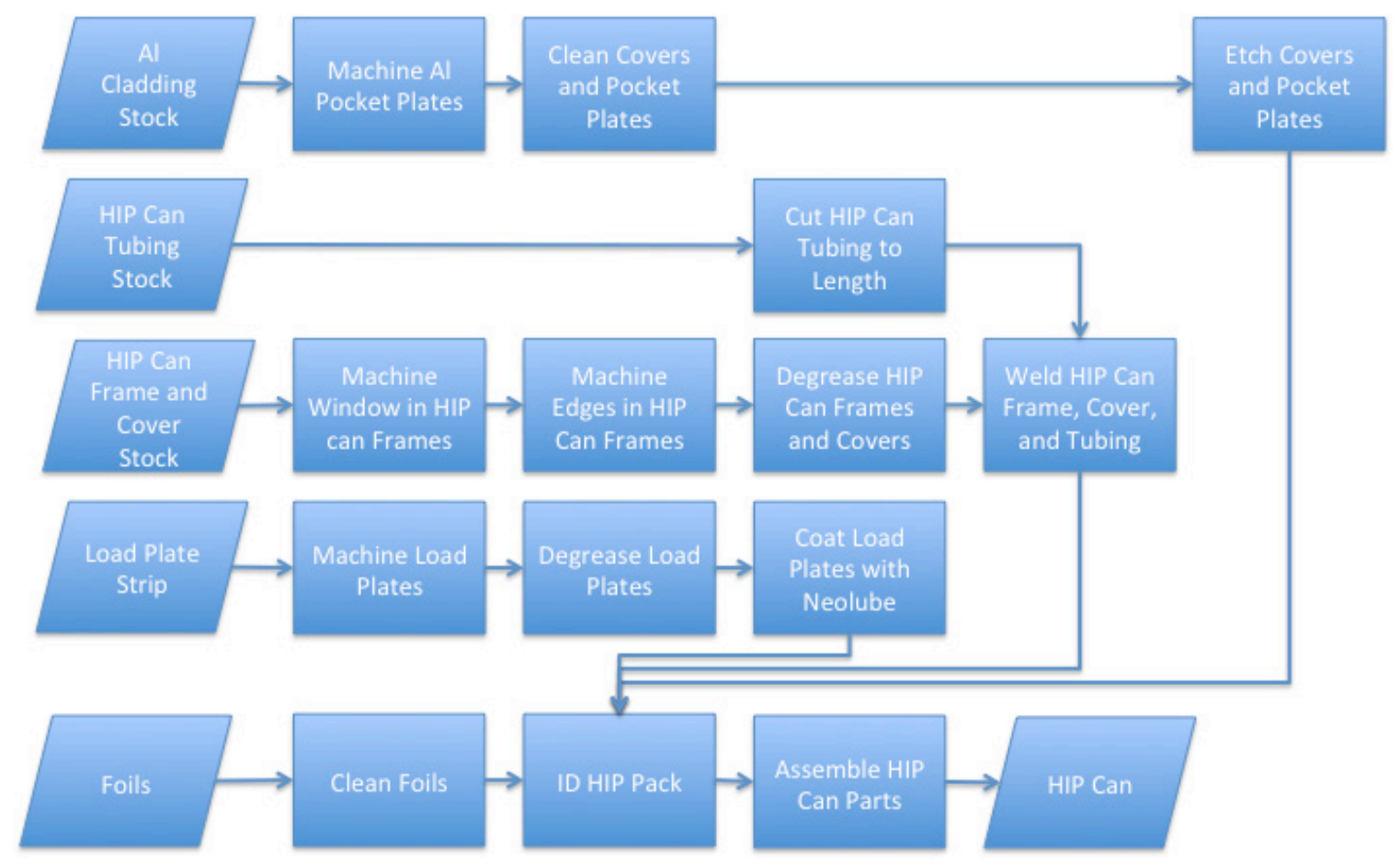

Figure 5.1. Simplified Flow Sheet for Baseline HIP Can Assembly Process 


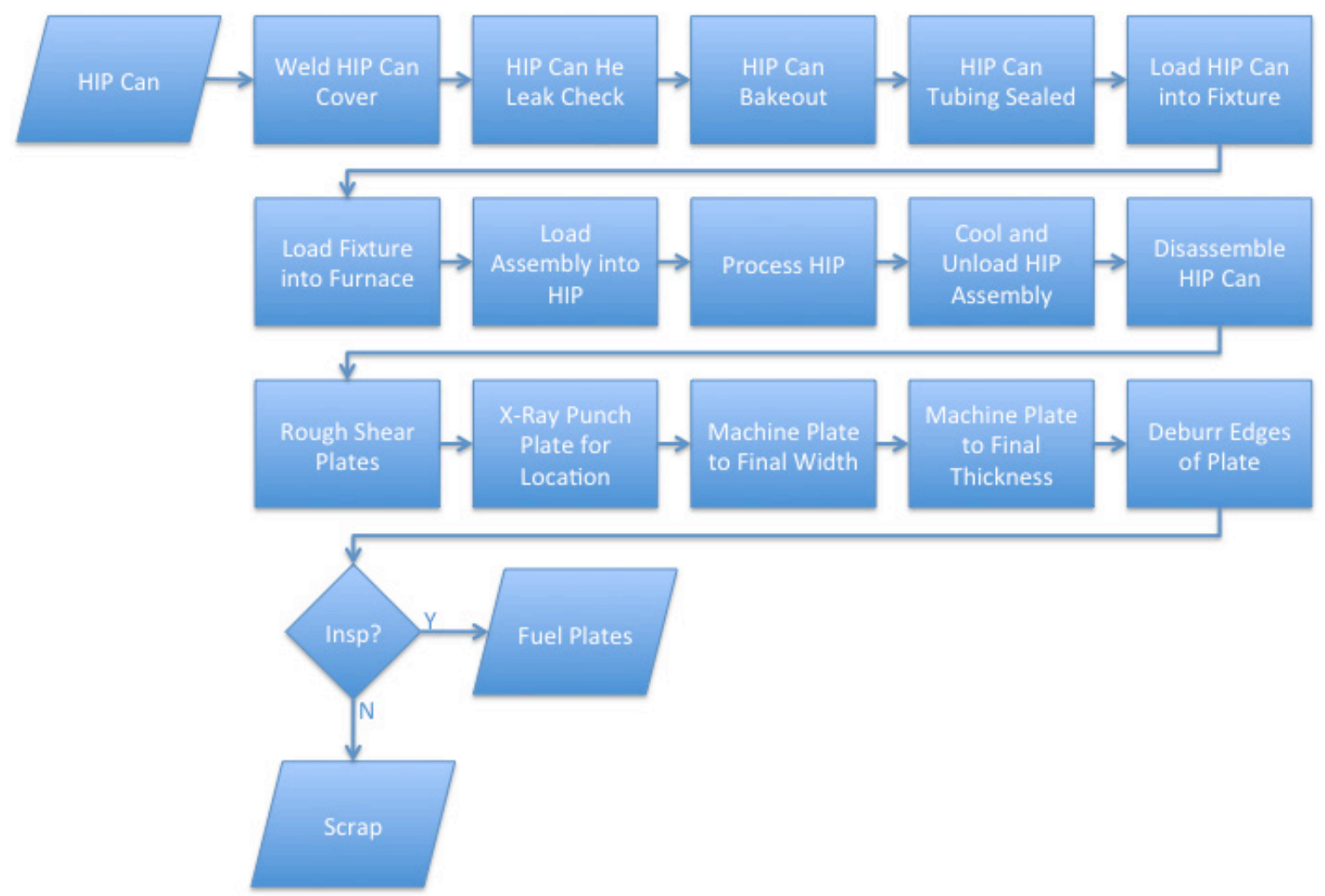

Figure 5.2. Simplified Flow Sheet for Baseline Plate Manufacturing Process

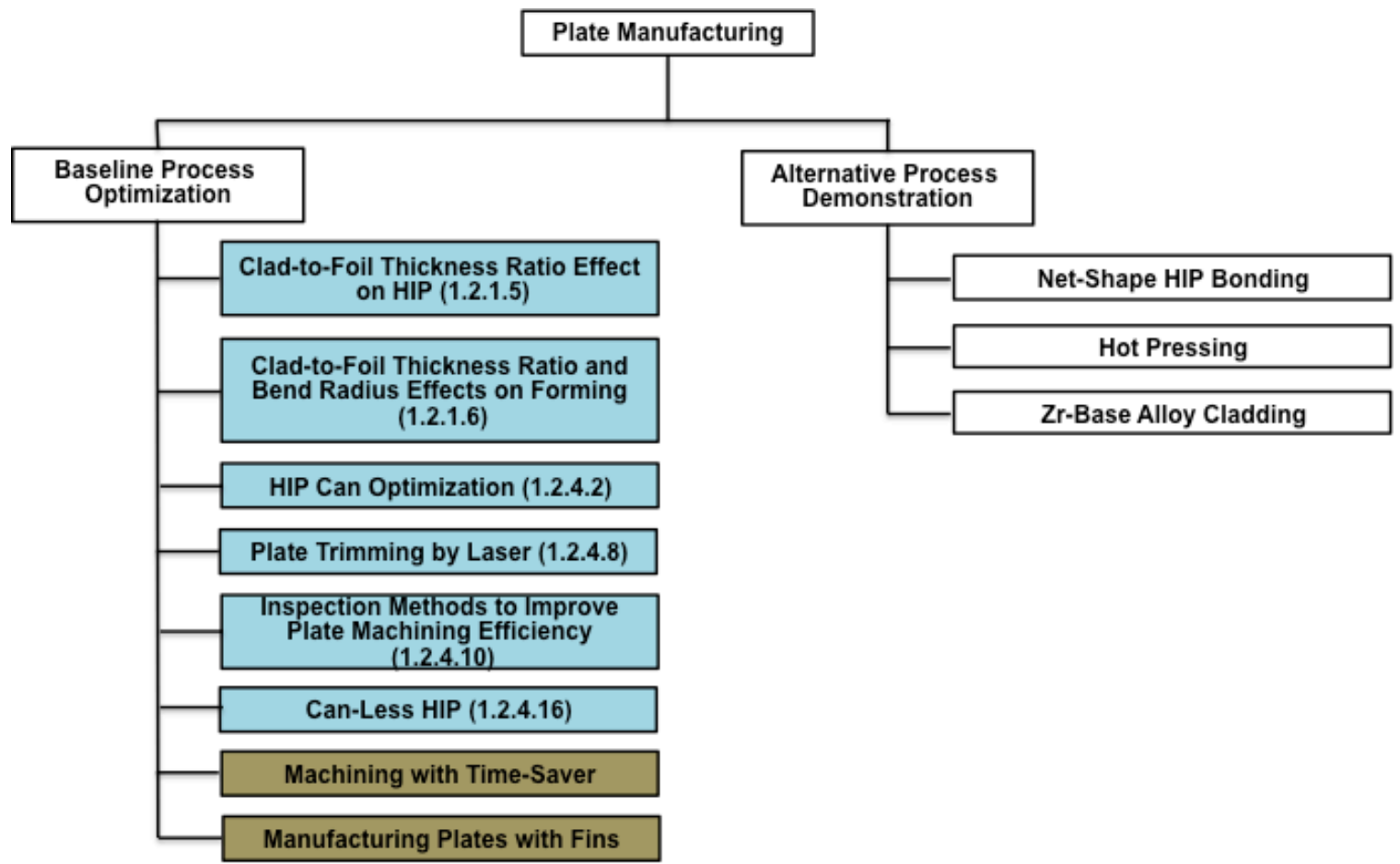

Figure 5.3. FFC Plate Manufacturing R\&D Activities Described in Section 5.0. The colors denote the responsible organization(s) for each activity and correspond to the colors in Figure 1.1. The white boxes denote activities that are recommended but not currently funded. 


\subsection{Plate Baseline Process Optimization}

The principal process development needs for plate manufacturing are related to improving the efficiency of HIP processing and optimizing plate machining and trimming operations. Much of the cost associated with plate manufacturing is bound up in these process steps. Specifically, anything that can improve dimensional control (with acceptable throughput) such that plates can be HIPed and machined to final thickness with high confidence they will meet minimum cladding thickness requirements will result in time and material utilization savings that ultimately lower the production cost.

\subsubsection{Clad-to-Foil Thickness Ratio Effect on HIP (1.2.1.5)}

This activity investigates the HIP process utilized to bond the Al alloy 6061 cladding to the $\mathrm{Zr}$-coated U-10Mo monolithic foils prepared in the cold rolling study (Section 3.1.6). Previous work by FD has demonstrated that clad surface cleanliness, applied pressure, and applied temperature affect bond strength. The previous work suggests that successful Al-to-Al bonding does not depend strongly on the characteristics of the U-10Mo foil. Therefore, this study will use a single foil type produced in the cold rolling study described in Section 3.1.6, and will not vary foil characteristics as an experimental parameter. Wide applicability of HIP bonding to relevant fuel dimensions will be evaluated by cladding two different U-10Mo foil thicknesses (0.009 in. and 0.022 in.) with two different Al 6061 cladding thicknesses ( 0.38 in. top and 0.32 in. bottom) for a total plate thickness of $0.70 \mathrm{in}$.

The surface finish and flatness of the HIPed plates will be evaluated after bonding. These characteristics largely dictate the cost of downstream processing steps. There is a balance to be struck between minimizing costs of downstream processing such as machining, and preserving the minimum cladding thickness. While net shape HIPed plates may be practical after further process optimization, there are not sufficient data at the present time to address this issue (see Section 5.2.1).

Forty-eight foils will be dedicated to this study after cold rolling in the study described in Section 4.1.2. Twenty-four foils will be 0.009 in. thick, and 24 foils will be 0.022 in. thick. Foil width will be 3.00 inches that represents the median U.S. HPRR foil width. The stainless steel HIP can will be designed using lessons learned from previous work. Each HIP can will be filled with an assembly consisting of DU-10Mo foils, strongbacks (Grade 01 tool steel) and a parting agent down-selected from previous experiments. Because a standard set of upper and lower cladding pieces will be used, thinner foils will have a greater cladding thickness in the HIP can assembly than thicker foils. Graphite foil will be used as needed to fill any gaps between the assembly and can walls. The interior of the HIP can and all metallic components will be cleaned using a standard procedure qualified by surface science measurements. After welding, the HIP can will be degassed at $350^{\circ} \mathrm{C}$ for 90 minutes. The plates will be HIPed at $560^{\circ} \mathrm{C}$ and 15,000 psi for 120 minutes. Afterwards, the HIP can external dimensions will be measured at the ends of the can and three equally spaced intermediate positions for comparison to finite element models of the HIP process. After cutting off one end of the HIP can, the assembly will be removed from the remainder of the can. Plates will be manually separated from strongbacks and any difficulties will be noted. Plates will be photographed from the face and edge to document any curvature. Curvature will be assessed using white light interferometry. Plate surfaces will be manually inspected for adhesion of parting agent. Any residual parting agent will be manually removed. The post-HIP data will be used in the computational models being developed for process definition and optimization. 
Starting at a reference corner, thickness measurements will be taken at $0.25 \mathrm{in}$. intervals along the length in rows spaced $0.5 \mathrm{in}$. apart along the width of each plate. Surface finish and plate thickness will be assessed, with application of confocal microscopy as needed. The as-HIPed surface finish will be compared to the surface finish of typical HEU dispersion fuel plates. This will lead to the identification of methods to improve surface finish, and identify the degree to which methods need to be employed. At least one plate from each batch will be allocated towards demonstration of surface finish techniques.

Ultrasonic testing will be conducted to evaluate potential unbonded areas and determine minimum cladding thickness (min-clad) values on each plate. The centering of the plate in the thickness dimension will be determined from these data. Flash thermography may be conducted to evaluate potential unbonded areas and to determine thermal diffusivity of the plate. These methods may be evaluated as potential quality control techniques.

At least one plate from each batch will be sacrificed for metallography and microhardness measurements to evaluate the integrity of the Al-Al bond and Al-Zr bond, and evaluate any variations/deviations as a result of the HIP process. Samples for metallography and microhardness will be sectioned from the sacrificial plates at a minimum of five locations (including both ends of the plate and the center). Metallography will be used to note any microstructural anomalies in the plate, foil, and along the fuel-clad interface, while microhardness will be used to determine and structural changes/variations of the foil as a result of the HIP process step. A minimum of two nanocantilever test specimens and two controlled bulge test specimens will be prepared from the sacrificial plate in the same locations as the metallographic samples (one nanocantilever and one controlled bulge test specimen on either side).

The remainder of the as-HIPed plates will be prepared as necessary for machining to one of two final dimensions for use in subsequent studies (Sections 5.1.2 and 5.1.3). Eight plates will have 0.009 in. foils with 0.020 in. plate thickness ( 0.006 in. cladding on each side of foil), eight plates will have 0.009 in. foil with 0.038 in. plate thickness ( 0.015 in. cladding on each side of foil), eight plates will have 0.022 in. foil with 0.042 in. plate thickness ( 0.006 in. cladding on each side of foil), eight plates will have 0.022 in. foil with 0.062 in. plate thickness ( 0.020 inch cladding on each side of foil). Finishing will be by gang milling and utilize in-situ measurements of minimum cladding thickness from a handheld ultrasonic testing unit and a handheld X-ray fluorescence unit. It should be noted that there is a cross over in relative accuracy of the two techniques at about $0.030 \mathrm{in}$. aluminum cladding thickness. UT is more accurate above $0.030 \mathrm{in}$. and XRF is more accurate below. Surface finish and thickness measurements will be performed on all 32 plates.

\subsubsection{Clad-to-Foil Thickness Ratio and Bend Radius Effects on Forming (1.2.1.6)}

Many fuel element designs for HPRRs require plates to be curved with radii of curvature from approximately 2.5 in. (e.g., inner fuel plate in MURR) to approximately 5.5 in. (e.g., outer fuel plate in MURR). This activity investigates the plate forming process utilized to form the aluminum alloy 6061 clad, Zr-coated U-10Mo monolithic foil to a specified radius of curvature. Thirty-two (32) plates prepared in the study described in Section 5.1.1 are utilized for this activity. Two plates from each set will be formed to $2.5 \mathrm{in}$. radius of curvature. Two plates from each set will be formed to $5.5 \mathrm{in}$. radius of curvature. Two plates from each set will be formed to the median radius of curvature for the U.S. HPRRs 
(4.197 in.). This will provide three sets of data for each of the clad-to-foil thickness ratios that will be used to improve a non-linear forming computational model.

Two plates from each set will be progressively formed in roughly 1 in. increments from $5.5 \mathrm{in}$. radius of curvature to $2.5 \mathrm{in}$. Fabricated plates will be successively formed to smaller radii of curvature with interim visual and non-destructive evaluation. All formed plates will be photographed and have curvature quantified. One of each two-formed plates with 2.5 in. radius of curvature will have three metallographic samples taken (end, center, end). The samples will be examined by optical metallography and/or SEM for cracks and/or delamination at the $\mathrm{Al} / \mathrm{Al}$ and $\mathrm{Al} / \mathrm{Zr}$ interfaces.

One plate from a set formed to $2.5 \mathrm{in}$. radius of curvature will be sliced into eight pieces. A heat treatment will be done to simulate in-service temperature at eight different hold times. Formed samples will be measured for changes in curvature for various times at temperature. This is to evaluate the hypothesis that there may be thermally-activated reduction in residual stress at in-service temperatures which may result in shape change with some potential for channel blockage. Curvature before and after will be measured. Samples that show greater than $5 \%$ change in curvature will be sampled for metallographic specimens, nanocantilever bond strength tests and controlled bulge tests.

If available, UT will be utilized to identify any delaminations or weaknesses that develop as a result of the forming operations. Thermography may also be used as an alternative technique to identify any delaminations or weaknesses (when compared to baseline measurements taken in the study described in Section 5.1.1) that develop as a result of the forming operation.

\subsubsection{HIP Can Optimization (1.2.4.2)}

This activity will focus on optimization of the HIP process for Al 6061 cladding of Zr co-rolled LEU10Mo fuel foils, using stainless steel, Zr co-rolled DU-10Mo surrogate fuel, and/or Al-only plates without fuel surrogate. Variables to examine include improving efficiency of fabrication/welding of the HIP cans, decreasing/eliminating the need for machining HIP can parts, evaluating alternate HIP can designs (formed/tubular cans and cans with increased fuel plate capacity), and, in parallel, further parting agent studies (refinement of Neolube or $\mathrm{Mo}_{2} \mathrm{~S}$ application techniques). In addition, the use of alternate materials (i.e., carbon steel versus stainless steel, or thinner materials) for HIP can materials, effects of shorter bake-out periods, and the effects of multiple HIP cycles (i.e., if a HIP cycle is prematurely halted, is it viable to re-HIP a can) will also be examined. Finite element analysis will be utilized in conjunction with the experimental work to model HIP can parts to inform the design work and support down-selection from suggested designs.

The primary purpose of this study is to identify minor changes to the HIP can design that can be implemented before full-scale commercial demonstration of fuel fabrication. A secondary benefit of performing this study is identifying areas to reduce the significant costs and inefficiencies associated with the current baseline HIP can production process. Previous studies (Katz et al. 2011) have shown that strongbacks can be recycled, but no other parts of the HIP can are reused. The primary costs in HIP can fabrication are associated with machining and welding that are the focus of this development study. Any significant reduction in machining or welding time can provide a significant cost savings. Two HIP cans will be processed to determine the viability of significantly increasing the number of fuel plates per can, either by increasing the number of plates in the stack or making a wider can to accommodate two plates per stack layer, depending on the results of the finite element analysis. Three additional HIP can designs 
will be evaluated: a block design, a clamshell design, and a foil bag design. Each has the potential to decrease manufacturing costs. A degassing tube design and procedure will be developed for the formed cans to allow the flexibility in choosing either e-beam welding or TIG welding. A study will be done to determine the difference, if any, in bond strength and interface impurities of TIG welding a HIP can closed in a glovebox versus TIG welding a HIP can closed outside of a glovebox. A few trials will be done to determine the upper limit on the number of foils that can be clad in a single HIP can. Three HIP cans will be made: one with 8 foils, one with 12 foils and one with 20 foils. There has been discussion about the real impact of cleaning and the effectiveness of various cleaning processes on the bonding during HIP. The hydrocarbon contamination samples from a recent HIP can will be analyzed. In addition, a HIP experiment will look at the effect of zirconium oxide thickness on bonding during HIP. Fuel plates from each of the cans will be characterized by dimensional measurement, metallographic examination and basic mechanical testing (bend test).

\subsubsection{Can-Less HIP (1.2.4.16)}

As described in Section 5.1.3, there are many aspects to HIP can design, fabrication, and use that impact the quality and cost of fuel plates. An alternative to optimizing the HIP can design is elimination of the HIP can entirely. The purpose of this study is to evaluate the feasibility of HIP processing fuel plates directly, without the use of the stainless steel HIP can. Previous studies (Montalvo et al. 2013) have shown promise that properly prepared Al 6061 cladding surfaces can bond successfully (i.e., with observable grain growth across the bond line). Initial analyses have shown the potential for significant labor reductions, while also potentially increasing throughput.

The initial task for this study will involve scale-up to larger specimens than previously used and evaluation of a fixture for hanging full-scale plates during HIP processing. Four fuel plates comprised of $\mathrm{Al} 6061$ cladding and stainless steel fuel foil surrogate will be electron beam welded in vacuum. Use of electron beam welded allows sealing and evacuation of the assemblies in a single step. The plates will be hanged from an appropriately designed fixture during HIP. The flatness and thickness of all four HIPed plates will be measured, and UT imaging will be performed to evaluate bonding across the various interfaces. Two of the plates will be bend-tested to assess bonding and the remaining two plates will be examined via optical and scanning electron microscopy. Grain growth across the bond line will be evaluated with polarized optical microscopy and with EBSD in the SEM.

The second task for this study will use results developed in the initial task to produce two full-scale plates with DU-Mo foils. The foils produced in the study described in Section 4.1 .7 will be used to assemble these plates. These plates will be evaluated after HIP processing via dimensional measurements, UT, and bend testing.

\subsubsection{Plate Trimming by Laser (1.2.4.8)}

The baseline process of trimming plates to shape via machining is a time-consuming and laborintensive process. This study will compare dimensional accuracy of laser trimmed plates with those produced by machining. The objective of this study is to identify improvements in the plate trimming process that could reduce the overall cost of plate manufacturing. Plates produced during the can-less HIP demonstration study described in Section 5.1.4 will be used for this study. Laser ablation will be used in this study for a demonstration of plate trimming. Specific experimental goals include optimizing 
the laser cutting parameters to achieve dimensional tolerances while minimizing heat damage to surrounding material and adapting the parameters for use with a range of plate and foil thicknesses.

\subsubsection{Inspection Methods to Improve Plate Machining Efficiency (1.2.4.10)}

After HIP processing, there is significant time and cost associated with inspecting and machining the fuel plate to final dimensions. For cladding thicker than 0.025 in., conventional pulse-echo UT instruments provide reliable measurements, but for thinner cladding XRF and/or through-thickness UT methods may offer improved resolution, efficiency, and insensitivity to surface condition. Determining the thickness of the cladding over the fuel meat is a time-consuming but critical process during machining. If the minimum cladding thickness is violated, the plate must be scrapped. Thus, accurate and rapid measurement of the cladding thickness is critical to ensuring an efficient plate machining process that maximizes yield. Depending on the plate thickness, either XRF or through-thickness UT methods could provide the necessary data.

The fuel meat may not be properly centered in the Al clad after HIPing since the Al is close to the plastic limit and will flow. Thus, it is imperative to know the location of the edges of the fuel meat after HIP processing so the Al may be trimmed in the proper location. This can be done most accurately and easily with through-transmission ultrasonic transducers or single-sided dual transducers. While the UT pulse echo technique can be problematic if the Al is not sufficiently smooth, there should be little difficulty with the transmission UT techniques because the signal will dramatically drop during transmission through the fuel meat. Depending on the resolution required for edge sensing, a custom transducer array or focused transducer may be designed and fabricated.

The goal of this study is to develop and validate measurement techniques that can be used in plate manufacturing to 1) locate fuel edges in a plate, and 2) determine Al cladding thickness before and during machining to verify the location of the fuel foil. To this end, automated XRF and UT systems that measure the parameters described above for implementation on a machine tool so operators have rapid feedback to guide machining is being investigated.

The feasibility of the techniques has already been shown and the present study is focused on calibration, demonstration, and implementation on fabrication machines. Specifically, the study will optimize XRF and UT methods for specific foil dimensions and specific machine tools. This will start with an assessment of specific fuel foil geometries and other relevant parameters potentially impacting cladding measurement, modeling as appropriate to assess impact of aforementioned parameters, and surveying of machining stations associated with fabrication of specific foils. Experimental work will progress to fine-tune measurement parameters for specific foil types. The study will evaluate the impact of residual stress after HIPing on XRF and UT measurement accuracy and resolution. After demonstration on small samples, the techniques will be scaled up to accommodate 24 and 48 in. long plates. Use of the inspection methods on the $\mathrm{Zr}$ coatings produced by the studies described in Section 4.2.1 will be investigated to evaluate applicability. Consideration will be given via modeling studies to applying the methods to curved plates and contoured foils. 


\subsubsection{Machining with Time-saver}

The baseline plate machining process after HIP processing is to remove material with a mill on one side of the plate at a time, while determining cladding thickness between machining passes via UT to ensure that the minimum cladding thickness specification is not violated. Any waviness in the foil will complicate this process because the thickness of Al 6061 cladding will vary with position. To simplify and speed up the thickness machining process, a possible optimization would be the use of a belt sander, referred to as a time-saver. A similar process is being considered for coupon machining (see Section 3.1.8). A requirement of the time-saver is that it produce a surface finish at least comparable to that produced by milling. The advantage is that it could be applied to both sides of the fuel plate simultaneously, which increases throughput but also could improve product quality by allowing better stress management. A study on this topic would evaluate processing time, surface finish, and dimensional control.

\subsubsection{Manufacturing Plates with Fins}

The MITR utilizes a unique plate design that incorporates grooves (referred to as "fins") to improve heat transfer into the reactor coolant during operation. The fins are nominally $0.010 \mathrm{in}$. wide and 0.010 in. deep with about 0.008 in. between each fin. There are 110 fins on each face of the fuel plate that run the full 23 in. length of the plate. Fin machining must be demonstrated at typical throughput on full-scale plates in the commercial fuel manufacturing environment. Process parameters that need to be studied include tool selection, tool wear, cutting speed, choice of lubricants, dimensional fidelity, and surface finish. Techniques for cleaning the machined fins and performing visual and dimensional inspections must also be demonstrated and validated.

\subsection{Plate Process Alternatives}

The principal plate manufacturing process alternatives are focused on more efficient methods for bonding the Al 6061 cladding around the foil. In addition to the time and cost associated with preparing the HIP cans themselves, there is significant time and cost associated with machining the plates to final dimensions after HIP processing. Another possible alternative to the baseline manufacturing process is replacing the Al 6061 cladding with a Zr-base alloy for increased strength and potentially improved burnup capacity and accident tolerance. This would entail significant changes to the manufacturing process, but could also potentially eliminate the need for a diffusion barrier between the fuel meat and the cladding.

\subsubsection{Net-shape HIP Bonding}

Net-shape HIP bonding could be an attractive alternative plate processing method. If process modifications employed in foil manufacturing result in a consistently flat, well-characterized fuel foil, then the feasibility of net-shape HIP bonding increases dramatically. At present, thick Al sheets are used for bonding the clad to the fuel foil. This step requires significant machining and significant nondestructive evaluation to ensure that the fuel plate meets final dimensional requirements. Due to the complex stress state of the fuel plate, final machining can be quite challenging. Use of net-shape HIP bonding would promote use of Al sheets that are closer to the final dimensions of the fuel plate, which would eliminate a significant portion of the final machining. Such a change would also likely result in 
increased throughput and reduced processing costs. This alternative has not been investigated in great detail to date as a result of the challenges associated with fabricating a repeatable, flat fuel foil. However, if progress is made in the studies described in Section 4.0, then net-shape HIP bonding deserves closer investigation.

\subsubsection{Hot Pressing}

In its current form, the HIP process used for cladding the fuel foils with Al 6061 cladding applies essentially a uniaxial load to bond the cladding to the fuel foil and itself. There might be advantages to finding a more straightforward method for applying this axial load at appropriate elevated temperatures. Hot pressing might offer an alternative approach that would utilize simpler equipment with a smaller footprint. This alternative also offers an opportunity to eliminate the use of an external steel can to accomplish bonding, i.e., the Al clad would essentially become the can (similar in concept to can-less HIP, Section 5.1.4).

\subsubsection{Zr-Base Alloy Cladding}

There is currently an effort underway within the Convert Program, but outside FFC, to evaluate the advantages and disadvantages of replacing Al 6061 cladding with a Zr-base alloy (Marra 2012). Zr-base alloy cladding was briefly considered during development of U-Mo dispersion fuel, but significant fuel development and manufacturing development work would be required to bring it to the necessary level of technological maturity. Depending on the outcome of the assessment currently underway (results expected in late fiscal year (FY) 2013), a number of fuel fabrication processes would need to be evaluated including the method of bonding the cladding to the U-Mo fuel meat and to itself, surface preparation before bonding, trimming to shape, machining to final thickness (or producing net-shape fuel plates), inspecting cladding thickness, etc. Using a Zr-base alloy would require a number of other metallurgical factors to be considered in conjunction with evaluating process parameters including residual stress in the bonded plates, effect of alloy texture on fabrication processes, and oxidation /hydrogen uptake during processing. 



\subsection{Element Manufacturing Research and Development}

The intent of the Convert Program is to develop and qualify fuel plates for the six U.S. HPRRs that, externally, are as similar to existing dispersion fuel plates as possible. Thus, the monolithic U-Mo fuel plates should be amenable to existing fuel element manufacturing processes. A possible exception to this that would require investment in research and development activities is the use of borated side plates in the fuel element in the event that burnable absorbers cannot be incorporated into the fuel meat, diffusion barrier coating, or fuel plate cladding (e.g., for MURR transition core, ATR, and HFIR). While borated Al-base alloys are commercially available, some effort would be required to demonstrate the applicability of existing fuel element manufacturing processes with the boarated side plates. The presence of boron in the side plates will affect their mechanical properties, which could have an effect on their swaging behavior, and it will affect their chemical composition, which could have an effect on their welding behavior. Similarly, if Zr-base alloys are adopted for fuel cladding as described in Section 5.2.3, then modifications to existing fuel assembly manufacturing processes will be required (Figure 6.1).

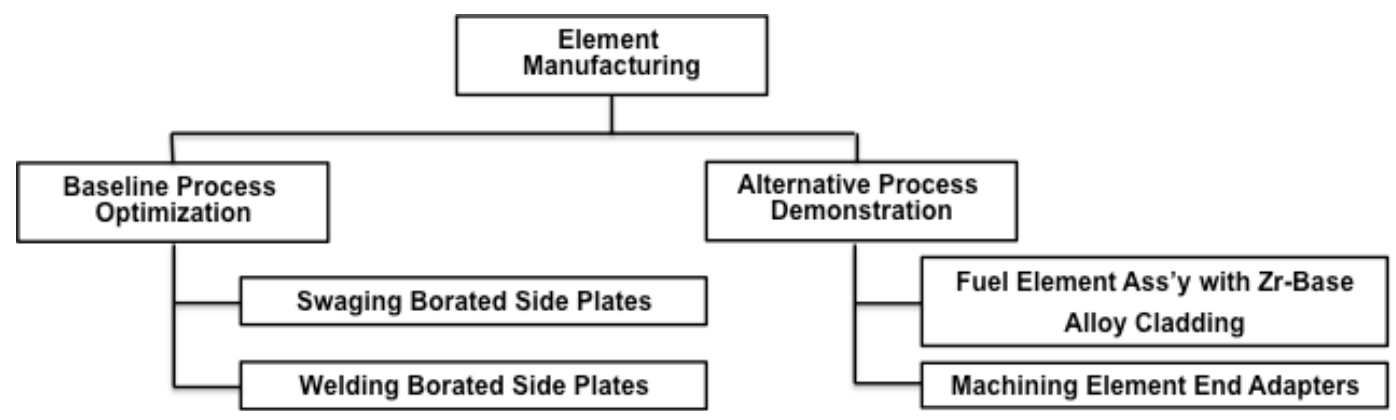

Figure 6.1. FFC Element Manufacturing R\&D Activities Described in Section 6.0. The colors denote the responsible organization(s) for each activity and correspond to the colors in Figure 1.1. The white boxes denote activities that are recommended but not currently funded.

\subsection{Swaging Borated Side Plates}

Two of the U.S. HPRRs (MURR and ATR) utilize swaging for attaching the fuel plates to the side plates. Both of these reactors are considering the use of borated side plates to achieve neutronics performance objectives with LEU fuel (in the case of MURR only for the initial transition from HEU to LEU). Estimates of the required boron concentration in the side plates range from 2000 to $3000 \mathrm{ppm}$ for both reactors, and it is likely that the side plate designs could be similar for both. Because MURR will not require a large quantity of these borated side plates, commonality of design with ATR is highly desirable to minimize manufacturing costs. Boron concentrations in this range will impact the mechanical properties of the Al-base alloy side plates, and development will be needed not only in the manufacture and inspection of the new side plates, but also with regard to assembling fuel elements. Thus, development activities will be needed to evaluate swaging methods and determine the best technique for attaching the fuel elements to the borated side plates.

\subsection{Welding Borated Side Plates}

The other U.S. HPRR that may require borated side plates for optimum neutronics performance with LEU fuel is HFIR. It is likely that the HFIR side plate design will differ significantly from the eventual 
designs for MURR and ATR, and the HFIR fuel elements are welded to the side plates, rather than swaged as for the other four U.S. HPRRs. The presence of boron (and other alloying addition changes that might be required) will have an impact on the welding behavior of the side plates. Thus a separate development effort will be required for the HFIR design to address side plate manufacturing and attachment of fuel elements to the side plates.

\subsection{Fuel Element Assembly with Zr-Base Alloy Cladding}

In the event that Zr-base alloy fuel plates is a viable alternative, development efforts will be required to address both swaging and welding behavior into the side plates for each HPRR. It is possible that a significant departure from current swaging/welding capability would be required to fabricate fuel elements containing a Zr-base alloy clad. In addition, materials compatibility studies would need to be investigated to ensure that any assembly process employed would not introduce an undesired performance consequence.

\subsection{Machining Element End Adapters}

Element end adapters are currently produced by casting. Modern computer-controlled machining systems allow the possibility of efficiently producing these complex parts. Besides eliminating the casting operation, savings potentially could be realized by eliminating the need for certain inspections that are required to address defects specific to the casting process (e.g., voids). 


\subsection{Cross-Cutting Research and Development Efforts}

There are research and development efforts that have an impact across multiple aspects of fuel fabrication and therefore cannot be categorized as coupon, foil, plate, or element processes. Currently, there are two areas that need to be addressed to support many of the individual processes described in Sections 3.0 through 6.0: 1) source material availability, and 2) manufacturing process modeling. These two areas are described in detail in the following subsections and shown in Figure 7.1.

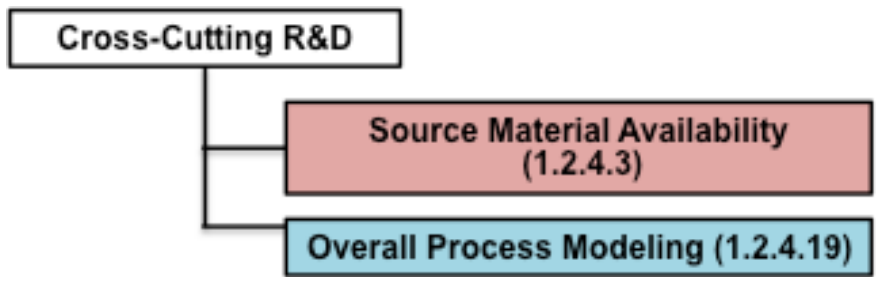

Figure 7.1. Cross-cutting FFC R\&D Activities Described in Section 7.0. The colors denote the responsible organization(s) for each activity and correspond to the colors in Figure 1.1.

\subsection{Source Material Availability (1.2.4.3)}

In addition to the technical work scope described in this plan, there is an activity underway to identify the availability of DU and EU to support the significant number of coupons that will be needed to support the R\&D efforts as well as production runs for irradiation experiments and eventual reactor conversion. For the available materials, an assessment of their material properties, chemistry, dimensions, etc. will be conducted to understand the amount of work involved in preparing these feed materials for use in various aspects of the Convert Program. Like the R\&D Plan itself, this material assessment will be updated on an as-needed basis (e.g., annually) to stay current with anticipated programmatic requirements.

\subsection{Process Modeling (1.2.4.19)}

There is an effort underway to develop discrete-event process models of the full range of fuel manufacturing processes with the intent of enabling cost-benefit trade studies for various fabrication options. To date, this effort has produced a detailed simulation model of most of the baseline manufacturing operations. The primary development goal is to provide a flexible data-driven system that could be readily altered to provide "what-if" analyses. Ideally, the model provides a tool to evaluate costs and benefits of manufacturing choices such as those described above in Sections 3.0 through 6.0. For example:

- Implications of implementing a separately-alloyed and downblended feedstock material

- Insertion of a foil annealing process to address foil quality and manufacturing yields

- Impacts of a can-less HIP procedure and alternate Zr barrier application techniques

- Implications of adopting alternatives to HIP processing for plate manufacturing

- Comparisons of alternative fuel cladding materials and fabrication techniques 
Further development of the models will include incorporating new or modified baseline processes, evaluating process alternatives as data becomes available for input, adding manufacturing data required to enable production risk assessments, and exploring synergies between dispersion fuel and monolithic fuel manufacturing. Adding models or improving the fidelity of existing models will require close cooperation with, and input from Y-12 and B\&W Nuclear Operations Group. 


\subsection{Other Considerations}

Besides the technical and economic considerations described in Sections 3.0 through 6.0 for the various manufacturing processes, there are a number of other considerations that must be taken into account when planning the FFC R\&D program. Among these are a determination of commercial viability, quality assurance (QA) requirements, and the overall Convert Program schedule. As the optimized or alternative manufacturing processes are evaluated, after establishing their technical and economic validity, their suitability for implementation in a prototypic-scale, production-throughput manufacturing environment will dictate whether further development is warranted. In addition, any optimized or alternative process must be amenable to implementation under full QA and safety rigor in a commercial production environment. If a process is not suited to full-scale implementation with appropriate process control, calibration standards, and qualified inspection methods, it will not offer an improvement to the baseline process regardless of its technical merit. Finally, there are numerous programmatic drivers that dictate when decisions must be made. If a process cannot be developed on the time scale needed to support the final fuel down-selection in 2020, then further expenditure may not be justified despite potential advantages.

\subsection{Commercial Viability}

There are numerous considerations when deciding whether or not to continue development of a particular optimized or alternative manufacturing process. Qualitatively, these considerations include the following:

- Technical Merit - Does the process produce parts that meet product specification requirements?

- Reproducibility - Does the process consistently produce high-quality parts?

- Economics - Does the process offer life-cycle (not just capital) cost savings over the baseline process, including considerations of efficient use of uranium feedstock and scrap recycle?

- Scaling - Does the process scale to full prototypic part dimensions?

- Throughput - Does the process lend itself to high-volume throughput without sacrificing its advantages?

- Quality Assurance - Does the process lend itself to implementation in an NQA-1 manufacturing environment?

- Environment, Safety, and Health - Can the process be implemented effectively in a uranium production facility regulated by DOE and/or NRC?

- Schedule - Can the process be developed and implemented in time to meet the Convert Program schedule for fuel down-selection?

These criteria will be applied to each of the optimized and alternative processes described in this R\&D Plan when making decisions regarding further development. Each of the R\&D activities described in this plan culminates in one or more decision points that will determine the course of future development work. The relationships between the activities and their interdependent decision points are described in Section 9.1. 


\subsection{Quality Assurance}

The QA requirements for the Convert Program are documented in the "GTRI Convert Program Quality Assurance Program Document," that is currently in draft form (NNSA 2013a). Overall, each program participant is expected to have a DOE- or NNSA-approved QA program that complies with the requirements of DOE Order 414.1, or its equivalent, as well as the requirements specified in $10 \mathrm{CFR}$ 830.120, as applicable for radiological work. The draft QA Program Document describes a graded approach that is applied using assigned quality rigor levels (QRLs) for specific activities at national laboratories. In general, QRL-2 or -3 is consistent with the high-level QA requirements described by DOE Order 414.1 and 10 CFR 830.120. For QRL-1 activities, a QA program compliant with the requirements of NQA-1 (2000 or later) will be required. Each participating national laboratory will be required under the QA Program Document to develop a cross-reference matrix demonstrating compliance with the appropriate requirements. These matrices will be coordinated by each of the three pillar leads for R\&D work within their scope of responsibilities.

According to the guidance in the QA Program Document, activities directly related to NRC licensing actions including facility safety analyses, experiments, tests, reactor-specific design and analyses, and design code verification and validation are all designated QRL-1. Activities that inform policy and key programmatic decisions, reports to Congress and other stakeholders, analyses to support NEPA compliance documents, and cost estimates that support Critical Decisions are designated QRL-2. Routine research and development activities such as feasibility studies, preconceptual and conceptual designs, exploratory trade studies, and conceptual modeling are designated QRL-3. In addition to the requirements described above, QRL-2 activities shall undergo peer review per the requirements in Appendix C of the QA Program Document, and QRL-3 activities shall undergo a technical review per the requirements in Appendix B of the QA Program Document. Contracts with universities or other subcontractors shall flow the requisite QA requirements for the appropriate QRL level as described above. The QA Program Document notes that the specified requirements are minimums, and additional QA requirements can be imposed on individual activities at the discretion of the FD, FFC, and RC pillar managers. In general, the majority of the activities described in this R\&D Plan will fall into QRL-2 or -3 , but the determination of QRL will be documented in the Work Package for each activity, and the QRL will be communicated to the performing organization via the individual Task Work Plans.

\subsection{Schedule}

There is a limited window of opportunity to make manufacturing process changes (either optimization of the existing process or alternative processes) for the HPRR conversion fuel, as illustrated by the Convert Program schedule shown in Figure 8.1. Down-selection of candidate manufacturing processes based on the R\&D described by this plan must occur by 2016, after which candidate fuel plates for the MP-1, MP-2, and FSP-1 experiments must be fabricated. It is envisioned that several manufacturing options may be included in these experiments, but the overall Convert Program schedule dictates that the final prototypic fuel form and manufacturing process be down-selected after PIE is completed on the second insertion of the MP-1 experiment in 2020. This means that all of the down-selected candidate manufacturing processes must be carried in parallel until that time. Because there is insufficient time to manufacture fuel for the third insertion of MP-1 as well as the MP-2 and FSP-1 experiments using the down-selected prototypic process, all candidate plates for these experiments must be produced at the same time as the plates for the first two insertions of MP-1. As a result, the work described by this R\&D plan 
is very important, because it will form the basis for the ultimate prototypic production process (except possibly for very minor tweaks to certain process parameters). The only opportunity to explore parameter space and alternative processing is between now and 2016 when the candidate processes are downselected in preparation for the MP-1, MP-2, and FSP-1 plate manufacturing campaigns.

Modified USHPRR Base Fuel Road Map*

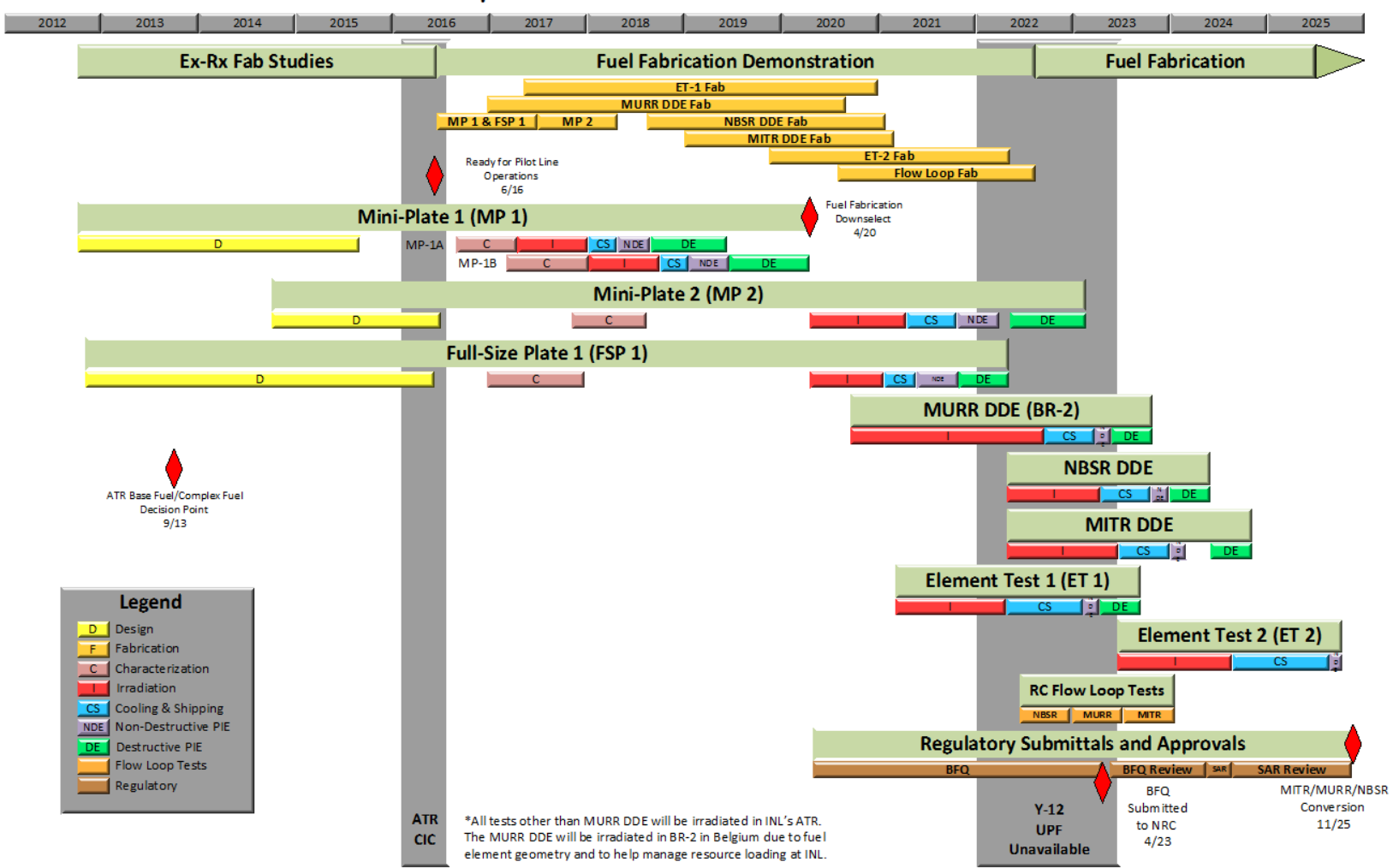

Figure 8.1. Convert Program Schedule Showing Key Fuel Down-selection Decision Points That Drive Manufacturing Process Research and Development Needs 



\subsection{Summary and Recommendations}

This plan provides an integrated overview of research and development needs that have been identified as necessary for ensuring that FFC is positioned to provide high-quality, cost-effective manufacturing processes consistent with the overall needs of the Convert Program. Section 9.1 describes decision points for each of the research topics such that they support the ability of FFC to produce candidate down-selection fuels for the MP-1, MP-2, and FSP-1 irradiation campaigns so that a final fuel down-selection decision can be made following the second insertion of the MP-1 experiment (MP-1B). In addition to describing work currently planned and funded, the R\&D Plan identifies a number of areas that require attention to meet this objective. Recommendations for additional work, schedule drivers for the additional work, and recommended decision points for initiating the additional work are discussed in Section 9.2. Finally, a number of risks are considered in Section 9.3 that have the potential to impact the $\mathrm{R} \& \mathrm{D}$ program as defined in this plan, and therefore have the potential to impact the ability of FFC to meet Convert Program objectives on the specified schedule. Recommendations are provided for actions to mitigate the likelihood of realizing these risks.

\subsection{Decision Points}

Figure 9.1 shows the schedule for the activities described in the FFC R\&D Plan along with the logic for making fuel fabrication technology downselection decisions in advance of the MP-1 experiment. The R\&D activities are listed down the left-hand side of the figure, along with the WBS number associated with it. The activities are divided into coupon, foil, and plate fabrication technologies, and they correspond to the activities described in the text in Sections 3.0, 4.0, and 5.0, respectively. Activities in black text represent baseline process optimization studies, while those in blue text represent alternative manufacturing technologies. Solid lines indicate activities that are currently funded within the Convert Program, while dashed lines indicate activities that are not currently funded. Within the categories of coupon, foil, and plate fabrication technologies, there are groupings of activities that feed into particular decision points, indicated by blue diamonds. The activities feeding into each of the decision points has earlier decision gates associated with it indicated by the solid circles. In these cases, work leading up to each initial decision gate is currently scoped and funded, but progress beyond these decision gates will require assessment against the criteria described in Section 8.1. Those judged to show promise toward meeting these criteria will proceed to a subsequent decision gate. Any technology that has not demonstrated satisfactory progress toward addressing the criteria in Section 8.1 may be terminated at the initial decision gate. 


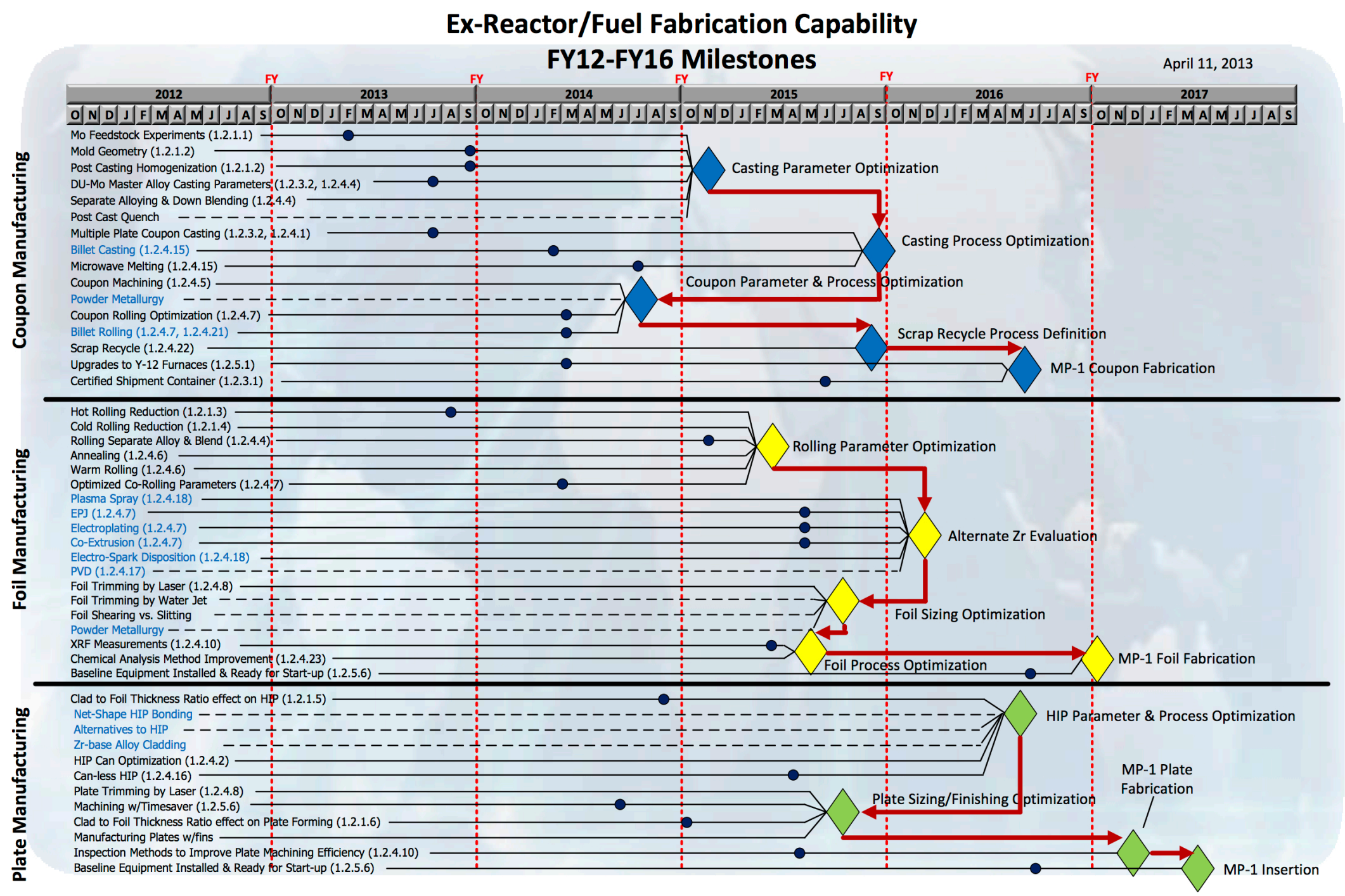

Figure 9.1. FFC Research and Development Down-selection Milestones Supporting the Overall Convert Program Schedule 
While Figure 9.1 only shows the initial decision gates, technologies may be required to pass several gates before reaching the ultimate decision point for each grouping of activities. The goal of the FFC R\&D effort is to generate the information necessary to make informed downselection decisions by the time the decision points are reached. The timing of the decision points themselves is contingent on the schedule for the MP-1 experiment, and the relevant MP-1 fabrication milestones are indicated in Figure 9.1. It is evident from Figure 9.1 that some technology areas have more schedule "float" than others, primarily due to higher technical maturity in these areas. It is also evident that the timing of the decision points can be adjusted as needed to support the MP-1 experiment. However, pulling the decision points forward in time may reduce the number of viable alternative technologies or the degree of optimization in the baseline process. Note that the outcome of the decision points is not necessarily the selection of one set of optimized fabrication parameters or a single alternate technology, but rather the identification of all baseline process optimization and alternate manufacturing technologies that meet the downselection criteria. Thus, all of the candidate parameters and technologies that successfully pass the decision points will, in principle, be available for fabrication of test specimens for the MP-1 irradiation experiment.

Given the time available, not all of the alternate technologies may be able to be implemented at the commercial fuel fabrication facility in time to support MP-1 specimen production, but the intention is to ensure that the specimens would be fabricated using commercially-relevant methods if they are processed elsewhere (e.g., an alternative $\mathrm{Zr}$ coating is applied somewhere other than $\mathrm{B} \& \mathrm{~W}$ ). Because of the short turnaround between MP-1 and the follow-on MP-2 and FSP-1 experiments as shown in Figure 8.1 and discussed in Section 8.3, the suite of specimen types that will be available for MP-1 will be the same as those available for MP-2 and FSP-1. In fact, the parent plates for all three tests might be fabricated during the same fabrication campaign or separated by only a short period of time in separate fabrication campaigns.

\subsection{Knowledge Gaps}

As described in Sections 3.0 through 6.0, there are a number of recommended studies that are not currently funded to support baseline process optimization or alternative manufacturing technologies associated with coupon, foil, plate, and element fabrication. These R\&D topics are referred to here as "knowledge gaps" that need to be addressed to ensure all relevant options are considered when optimizing the existing manufacturing processes or evaluating alternate technologies. In this way, confidence will be high that the final downselected fuel form represents the best value for money and the lowest technological risk. The knowledge gaps identified in the R\&D Plan include the following:

- Coupon Manufacturing

- Post-casting quench (Section 3.1.4)

- Powder metallurgy coupon fabrication (Section 3.2.3)

- Foil Manufacturing

- Foil trimming by water jet (Section 4.1.8)

- Foil slitting (Section 4.1.9)

- U-Mo/Zr scrap recycle process development (Section 4.1.11)

- $\quad$ Electro-spark deposition for coating foil edges (Section 4.2.1.5) 
- Physical vapor deposition (Section 4.2.1.6)

- $\quad$ Zr deposition on powder metallurgy coupons (Section 4.2.1.7)

- Plate Manufacturing

- Plate machining with timesaver (Section 5.1.6)

- Manufacturing plates with fins (Section 5.1.7)

- Net-shape HIP bonding (Section 5.2.1)

- Hot pressing (Section 5.2.2)

- Zr-base alloy cladding (Section 5.2.3)

- Element Manufacturing

- Swaging borated side plates (Section 6.1)

- Welding borated side plates (Section 6.2)

- Fuel element assembly with Zr-base alloy cladding (Section 6.3)

- Machining element end adapters (Section 6.4)

From the list above, it is clear that most of the existing knowledge gaps are associated with foil, plate, and element manufacturing. There has been significant emphasis on coupon manufacturing because its product is the source material for all later manufacturing operations, and consequently, it has the earliest decision points as shown in Figure 9.1. However, the two areas listed above must be addressed soon or the possible opportunity to improve coupon manufacturing via these two topics will be lost due to schedule pressure as indicated in Figure 9.1. While there is slightly more time to address the foil and plate manufacturing topics in the list above, these R\&D topics (with a couple of exceptions, e.g., foil slitting) also tend to be less mature and will require significant development if initial feasibility studies show promise. Therefore, work on these topics also should start soon (e.g., FY 2014) in order to give them the time necessary to mature and offer a meaningful assessment of their potential.

Two of the element manufacturing topics (swaging borated side plates and welding borated side plates) and one of the plate manufacturing topics (manufacturing plates with fins) specifically address complex fuel issues. There are other manufacturing knowledge gaps associated with complex fuel that are not included in the list above, such as production (e.g., rolling) of contoured fuel meat and application of diffusion barriers to contoured fuel meat. While the first two insertions of MP-1 are specifically geared to evaluating base fuel irradiation performance, the third insertion of MP-1 and potentially MP-2 and FSP-1 will need to include complex fuel specimens. As discussed in Sections 8.3 and 9.1, the schedule shown in Figure 8.1 does not allow time to incorporate feedback from MP-1 before the MP-2 and FSP-1 fuel specimens must be fabricated. Therefore, $\mathrm{R} \& \mathrm{D}$ on complex-specific topics must be conducted in parallel with the remainder of the work necessary to enable fabrication of the MP-1 test specimens.

Another potential knowledge gap not included in the list above, and currently receiving little attention is deposition of diffusion barrier materials other than Zr. There is some evidence to suggest that Mo might serve as an adequate diffusion barrier between the U-Mo fuel meat and the Al-base alloy cladding. An attractive feature of Mo as a diffusion barrier is that recycle issues associated with separating the fuel meat from the diffusion barrier are eliminated because Mo is already present in the fuel composition. Several of the alternative 
Zr deposition methods may be amenable to depositing Mo (e.g., thermal spray, physical vapor deposition, powder metallurgy methods). Therefore, opportunities to evaluate Mo as an alternative to $\mathrm{Zr}$ should be considered while pursuing the R\&D activities described in Section 4.2.

Two of the topics in the list above (Zr-base alloy cladding and fuel element assembly with Zr-base alloy cladding) are dependent on decisions that have not yet been made by the Convert Program. If the ongoing consideration of $\mathrm{Zr}$-base alloy cladding provides a recommendation to evaluate this fuel form, then these studies will be necessary. Alternatively, if a decision is made not to pursue Zr-base alloy cladding, then these studies will not be needed. Therefore, the timing on decision whether or not to pursue these recommended studies is tied to the outcome of the Zr cladding study (Marra 2012).

\subsection{Risks}

Specific risks that have been identified within individual FFC WBS categories are listed in Table 9.1 along with mitigating actions that are within direct control of FFC to implement. Some of the risks cross pillar boundaries and thus will require higher-level coordination of mitigating actions (e.g., delays in producing the fuel specification). The FFC will continue evaluating risks and the list in Table 9.1 will be updated at least annually in concert with annual revisions to this R\&D Plan.

Table 9.1. Risks Related to FFC Work Scope

\begin{tabular}{|c|c|c|}
\hline WBS & Risk Description & FFC Mitigation Options \\
\hline 01.02 .01 & $\begin{array}{l}\text { Delay in completing development of a } \\
\text { comprehensive fuel product specification } \\
\text { increases fuel fabrication costs and/or delays } \\
\text { development and implementation of FFC. }\end{array}$ & \\
\hline 01.02 .01 & $\begin{array}{l}\text { Inadequate integration of multiple DOE } \\
\text { laboratories/sites and associated } \\
\text { facilities/equipment delays development of the } \\
\text { fabrication process baseline. }\end{array}$ & $\begin{array}{l}\text { - Include performance incentives in contracts. } \\
\text { - Engage laboratory senior management on importance } \\
\text { of meeting schedule. } \\
\text { - Move scope to another laboratory. } \\
\text { - Delay scope and include it in B\&W contract } \\
\text { (equipment available in April 2014). }\end{array}$ \\
\hline 01.02 .02 & $\begin{array}{l}\text { Lack of a feedback loop between experiment } \\
\text { products fabrication and fuel development } \\
\text { increases fuel fabrication costs and/or results in } \\
\text { reduced fuel performance. }\end{array}$ & $\begin{array}{l}\text { Incorporate an additional MP-1 experiment into the } \\
\text { schedule (up to } 3 \text { year and } \$ 5 \mathrm{M} \text { ). } \\
\text { - Procure equipment (HIP, etc.) to fabricate full-scale } \\
\text { fuel, which then may never be used. }\end{array}$ \\
\hline 01.02 .03 & $\begin{array}{l}\text { Change in the fuel fabrication process requires } \\
\text { installing additional equipment and facility } \\
\text { modifications at Y-12 and B\&W that delays } \\
\text { completion of fuel and fabrication process } \\
\text { qualification. }\end{array}$ & $\begin{array}{l}\text { - Add scope to conduct facility modifications that would } \\
\text { include a decision point to proceed with facility mods } \\
\text { only after it is determined that the fuel fabrication } \\
\text { process will require additional equipment. }\end{array}$ \\
\hline 01.02 .03 & $\begin{array}{l}\text { A planned extended outage of the Uranium } \\
\text { Processing Facility (UPF) scheduled for about } \\
\text { the year } 2020 \text { delays completion of fuel } \\
\text { fabrication and qualification. }\end{array}$ & $\begin{array}{l}\text { - Negotiate a level-loaded, pre-fabrication agreement } \\
\text { with UPF. }\end{array}$ \\
\hline
\end{tabular}


Table 9.1. (contd)

\begin{tabular}{|c|c|c|}
\hline WBS & Risk Description & FFC Mitigation Options \\
\hline 01.02 .03 & $\begin{array}{l}\text { The planned use of new melting/casting } \\
\text { technology at UPF delays completion of fuel } \\
\text { and fabrication process qualification. }\end{array}$ & $\begin{array}{l}\text { - Engage Y-12 management to influence technology } \\
\text { choices for UPF. } \\
\text { - Perform alloy process in a different Y-12 facility. } \\
\text { - Utilize a different uranium processing facility } \\
\text { (e.g., NFS, Manufacturing Sciences Corporation, } \\
\text { Aerojet, etc.). }\end{array}$ \\
\hline 01.02 .04 & $\begin{array}{l}\text { Process optimization identifies improved } \\
\text { fabrication technology resulting in a schedule } \\
\text { delay to deploy the new technology. }\end{array}$ & $\begin{array}{l}\text { - Include sufficient time in the baseline schedule to } \\
\text { support scale-up testing of the new technology. } \\
\text { - Engage B\&W early on requirements for the new full- } \\
\text { scale equipment. } \\
\text { - Engage NRC early on potential new technologies. }\end{array}$ \\
\hline 01.02 .04 & $\begin{array}{l}\text { Delay in completing development of a } \\
\text { comprehensive fuel product specification delays } \\
\text { performing optimization experiments and } \\
\text { testing. }\end{array}$ & \\
\hline 01.02 .04 & $\begin{array}{l}\text { "Optimized" processes may not be acceptable to } \\
\text { the NRC and/or B\&W that increases fuel } \\
\text { fabrication costs and/or delays development and } \\
\text { implementation of FFC. }\end{array}$ & $\begin{array}{l}\text { - Engage NRC and B\&W early on potential new } \\
\text { technologies. }\end{array}$ \\
\hline 01.02 .05 & $\begin{array}{l}\text { "Dated" fabrication technology utilized at Y-12 } \\
\text { increases fuel fabrication costs. }\end{array}$ & \\
\hline
\end{tabular}

A significant higher-level risk that is not included in Table 9.1 is the overall risk to the program resulting from the ultimate fuel product fabrication method downselection decision that must be made after PIE is completed on the second insertion of the MP-1 irradiation experiment. Because there is not enough time in the schedule to implement changes to fabrication processes after this downselection decision is made before the fuel for the MP-2 and FSP-1 experiments must be produced, there is a risk that unexpected performance issues discovered during MP-2 or FSP-1 could challenge the downselection decision. If this risk is realized, it would not be possible to continue fuel qualification on the schedule shown in Figure 8.1 if it resulted in significant changes to the downselected fuel fabrication process. A corollary to this risk is that all the fuel for the MP-1, MP-2, and FSP-1 irradiation experiments must be fabricated at the same time as the MP-1 fabrication campaign to ensure that all possible candidates for downselection are available on a schedule that supports the MP-2 and FSP-1 experiments. Thus, the definition of the MP-1 test matrix is of considerable importance to the program, not only to ensure that fuel is available for the MP-2 and FSP-1 tests rapidly following the MP-1 experiment, but also to include in the MP-1 first and second insertions the appropriate fuel configurations and test parameters to minimize the risk of unexpected performance issues during MP-2 or FSP-1. In particular, the first two insertions of MP-1 should consider including ATR- and HFIR-relevant operating conditions (originally not planned until the third insertion of MP-1), off-normal operating conditions (originally not planned until MP-2), and size effects (originally not planned until FSP-1). 


\subsection{References}

Cadden, JL, NC Jessen and PS Lewis. 1974. "Melting and Casting of Uranium Alloys," in Proceedings of the $3^{\text {rd }}$ Army Materials Technology Conference, JJ Burke et al. (Eds.), 12-14 February 1974, Vail, CO.

Cook, JA, E Ripley and D Schechter. 2012. "Enhanced Alloy Processing in Microwave Castings: FY12 Report for PD110738," Y/DV-2271. Oak Ridge, TN: Y-12 National Security Complex.

Fox, JB, DM Cheney, AA Bauer and RF Dickerson. 1958. "Studies for the Preparation of ZirconiumClad Uranium-10 wt\% Molybdenum Fuel Pins," BMI-APDA-644. Columbus, OH: Battelle Memorial Institute.

Foyto, L, K Kutikkad, JC McKibben, N Peters, E Feldman, J Stevens and J Stillman. 2012. "The University of Missouri Research Reactor HEU to LEU Fuel Conversion Project Status," presented at the $5^{\text {th }}$ International Symposium on Material Testing Reactors, 22-25 October 2012, Columbia, MO.

Gerstner, D, A McCartin, D Reeder and P Roth. 2010. "Safety Analysis Challenges with Irradiation of Reduced Enrichment for Research and Test Reactors (RERTR) Program Test Fuel Elements in the Advanced Test Reactor," presented at the EFCOG 2010 Safety Analysis Workshop, April 2010, Knoxville, TN.

Hanson, AL and DJ Diamond. 2011. "Calculation of Design Parameters for an Equilibrium LEU Core in the NBSR,” BNL-96386-2011-IR. Upton, NY: Brookhaven National Laboratory.

INL. 2011. "Specification for U-Mo Monolithic Foils", SPC-1167, Rev. 3. Idaho Falls, ID: Idaho National Laboratory.

Katz, J, K Clarke, B Mihaila, J Crapps, B Aikin, V Vargas, R Weinberg, A Duffield and D Dombrowski. 2011. "Scale-Up of the HIP Bonding Process for Aluminum Clad LEU Reactor Fuel," presented at the $33^{\text {rd }}$ International Meeting on Reduced Enrichment for Research and Test Reactors, 23-27 October 2011, Santiago, Chile.

Moore, GA and MC Marshall. 2010. "Co-Rolled U10Mo/Zirconium-Barrier-Layer Monolithic Fuel Foil Fabrication Process," INL/EXT-10-17774. Idaho Falls, ID: Idaho National Laboratory.

Newton, TH. 2011. "Challenges with the Conversion of the MITR," presented at the Russian-American Symposium on the Conversion of Research Reactors to Low Enriched Uranium Fuel, 6-10 June 2011, Moscow, Russia.

Marra, J. 2012. "Assessment of Zirconium Clad Fuel Alternative for U.S. High Performance Research Reactors," Draft. Aiken, SC: Savannah River National Laboratory.

Meyer, MK, et al. 2012. "Investigation of the Cause of Low Blister Threshold Temperatures in the RERTR-12 and AFIP-4 Experiments," INL/EXT-12-26500. Idaho Falls, ID: Idaho National Laboratory. 
Montalvo, JD, PA Papin, B Aikin, VD Vargas, RL Edwards, DE Dombrowski, TJ Lienert, DA Summa, DW Bucholz, PW Hochanadel, P Burgardt, MJ Dvornak and CE Cross. 2013. "Canless HIP Development for Aluminum Cladding of LEU Fuel Foils Using Electron Beam Welding," LA-UR-1322779. Los Alamos, NM: Los Alamos National Laboratory.

NNSA. 2013a. “GTRI Reactor Conversion Program Quality Assurance Program Document," Revision 0. Washington, DC: U.S. Department of Energy.

NNSA. 2013b. "U.S. High Performance Research Reactor Conversion Program: Program Execution Plan," Draft. Washington, DC: U.S. Department of Energy.

Park, BH, CR Clark and JF Jue. 2010. "INL HIP Plate Fabrication,” INL/EXT-10-17792. Idaho Falls, ID: Idaho National Laboratory.

Primm, RT, RJ Ellis, C Gehin and DL Moses. 2006. "Design Study for a Low Enriched Uranium Core of the High Flux Isotope Reactor," presented at the $28^{\text {th }}$ International Meeting on Reduced Enrichment for Research and Test Reactors (RERTR), 29 October - 2 November 2006, Cape Town, South Africa.

Robinson, AB, GS Chang, DD Keiser, DM Wachs and DL Porter. 2009. "Irradiation Performance of UMo Alloy Based 'Monolithic' Plate-Type Fuel - Design Selection,” INL/EXT-09-16807. Idaho Falls, ID: Idaho National Laboratory.

Shoudy, AA, WE McHugh and MA Silliman. 1963. "The Effect of Irradiation Temperature and Fission Rate on the Radiation Stability of the Uranium-10wt\% Molybdenum Alloy," in Radiation Damage in Reactor Materials. Vienna, Austria: International Atomic Energy Agency.

Wachs, DM, CR Clark, and RJ Dunavant. 2008. "Conceptual Process Description for the Manufacture of Low-Enriched Uranium-Molybdenum Fuel," INL/EXT-08-13840. Idaho Falls, ID: Idaho National Laboratory. 



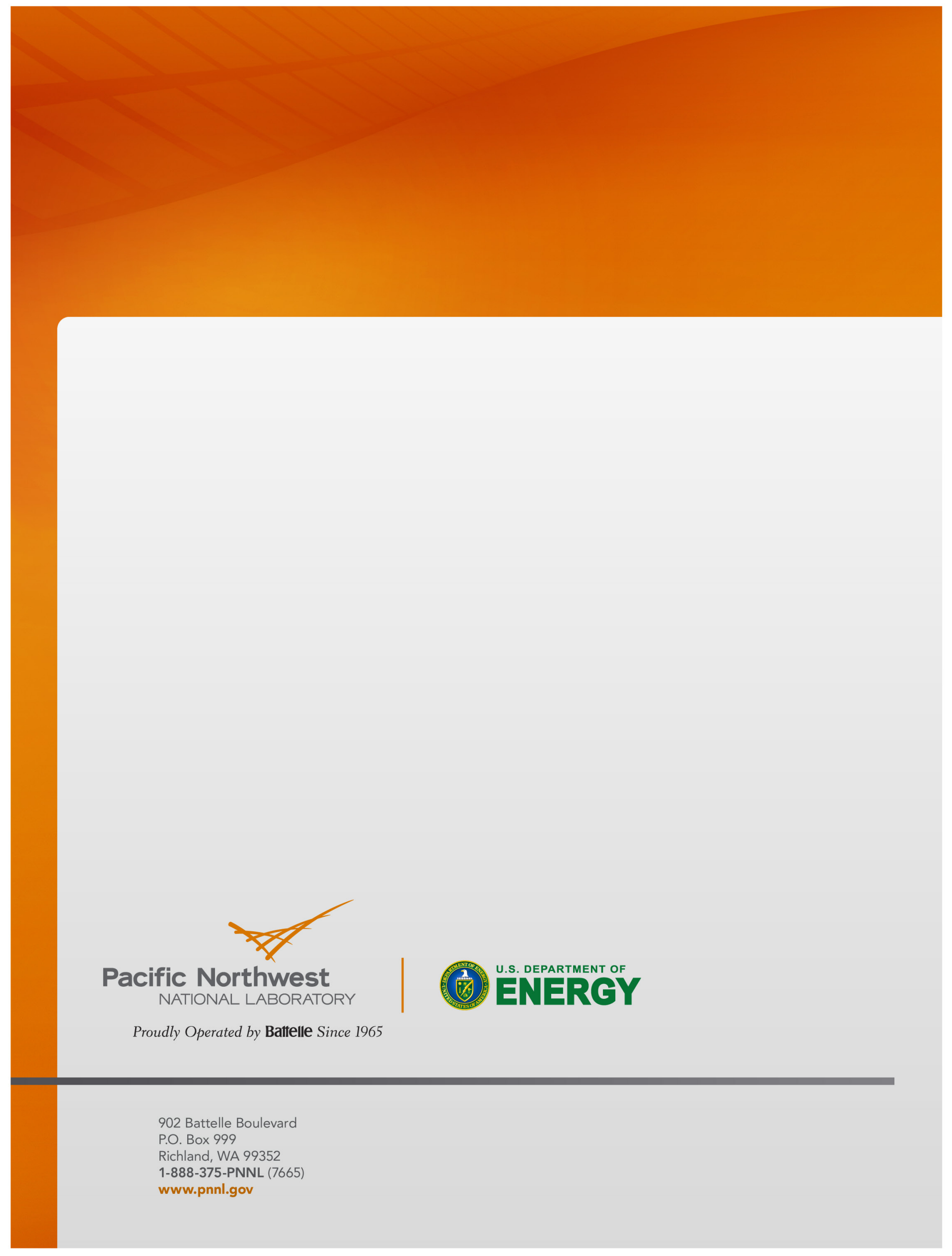

